\title{
La primera cerca medieval de Granada. Análisis historiográfico.
}

\author{
Juan A. García Granados
}

El estudio de las murallas nos interesa en cuanto serían el hecho más significativo en la verificación de las distintas fases del proceso de configuración de la ciudad medieval. La historia de la ciudad vendría marcada por una serie de fortificaciones desde época romana. En dichos elementos, constituidos en permanencias arquitectónicas, estaría, si aceptamos las propuestas historiográficas vigentes, la clave tanto de la estructura del poblamiento correspondiente a los diversos períodos históricos cuanto del modo en que se produce la configuración de la ciudad islámica del siglo XI. Este trabajo se centra en el análisis de los argumentos dados por la historiografía sobre el significado de los distintos complejos castrales identificados en el área urbana de Granada.

Cuando existe una larga tradición historiográfica, como sucede con Granada, se produce un estado de inercia donde los nuevos datos positivos a veces se interpretan en base a teorías válidas sólo en contextos historiográficos ya obsoletos. La ausencia de análisis sobre el grado de certeza que dichas teorías tienen en el momento actual y sobre los distintos problemas que plantean en ámbitos históricos o espaciales, ha tenido graves consecuencias a la hora de interpretar los hallazgos, siempre fragmentarios, de las excavaciones arqueológicas. La proyección mecánica de dicha tradición sobre los restos materiales ha hecho que éstos aparezcan como datos positivos demostrativos de la teoría tradicional, cuando en realidad sucede todo lo contrario: que cuestionan la validez de dicha teoría. Un caso paradigmático de esta situación nos parece todo lo referido al primitivo recinto de murallas levantado en Granada.

La pregunta a responder es cómo se han llegado a configurar las teorías vigentes. Además de saber qué se dice queremos saber por qué se dice, si es que los textos lo permiten. Los textos citados son pocos. Una recopilación exhaustiva y sistemática convertiría este trabajo en un catálogo crítico' que escapa a los límites de una revista, y las conclusiones no serían distintas. En todo caso ya otros se encargarán de mostrar nuestros errores.

Queremos insistir en que no se trata de explicar el proceso histórico de la ciudad, sino valorar los distintos discursos interpretativos que se han venido produciendo.

Las ideas básicas que articulan el discurso historiográfico son tres;

I. Existió una ciudad antigua, lliberri, que pudo permanecer hasta el siglo VII.

2. Con la invasión musulmana la ciudad desaparece. Se funda una nueva capital (Ilbīra) y en el solar de la antigua se levantan fortificaciones para controlar la población autóctona.

3. A partir del año 1010 se procede al traslado de la capital hasta el solar de la ciudad antigua.

I Existen repertorios bibliográficos a los que remitimos 
Estos tres hechos se apoyan en una serie de argumentos que agrupamos en sendos apartados, precedidos de una síntesis historiográfica. En el primero exponemos todo lo referido a la determinación de un conjunto de núcleos de población asentados en el área de la actual ciudad de Granada y sus inmediacio- nes. En el segundo analizamos los criterios usados para identificar una serie de fortificaciones que se irían levantando desde época visigoda hasta el siglo XI como epígonos o sustitutos de la ciudad antigua. En tercer lugar analizamos las teorías sobre el proceso de organización de la nueva ciudad generada en el siglo Xl.
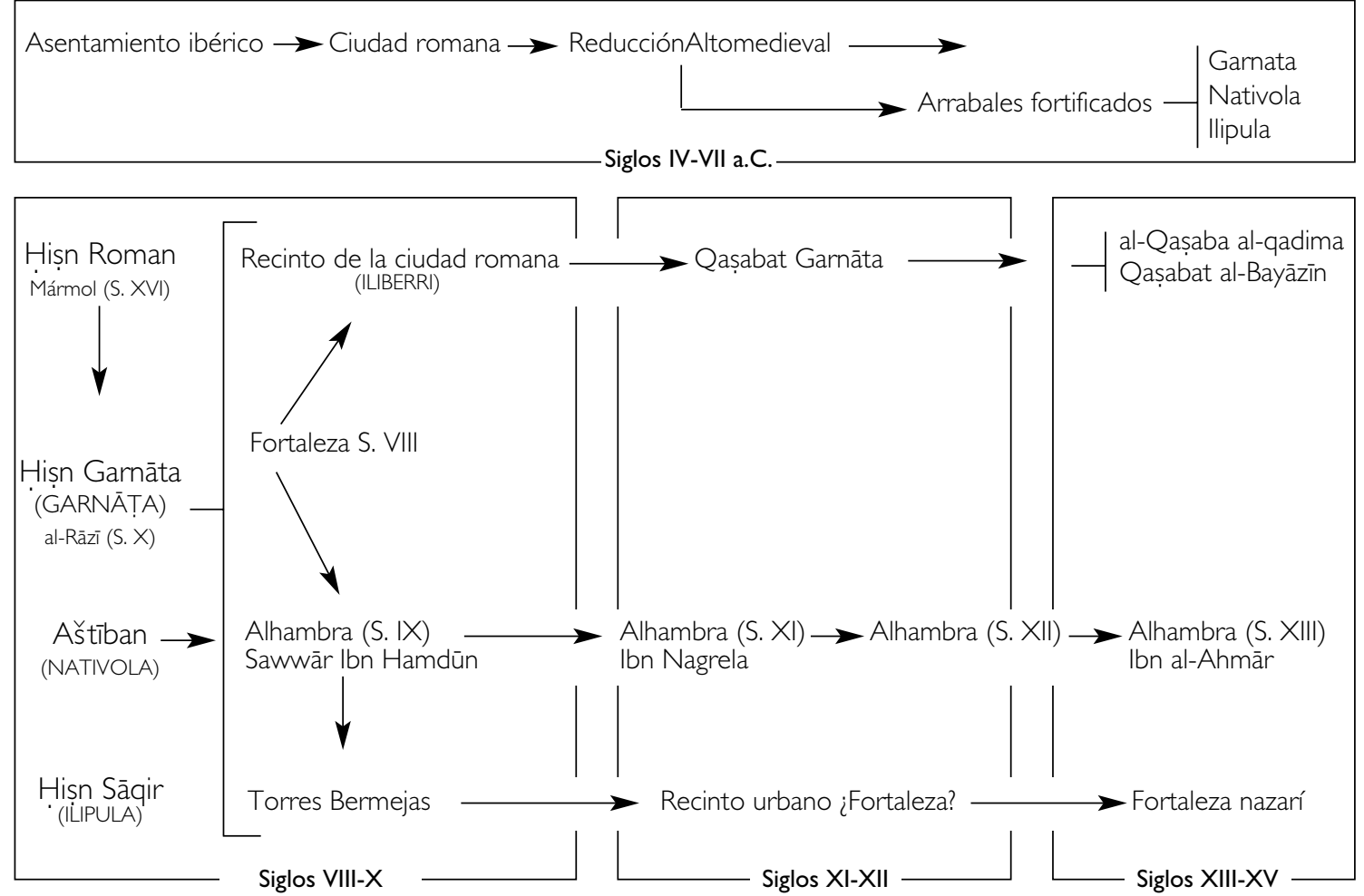

Procesos espaciales y funcionales propuestos en la historiografía sobre Granada

\section{EL PROCESO HISTORIOGRÁFICO}

El punto de partida lo constituye el texto de Luis de Mármol (1600) que no tuvo en su momento el reconocimiento que hoy se le otorga. Se basa en la Crónica del moro Rasis para justificar los origenes de Granada, que no sería lliberri, identificada con llurco, sino un asentamiento fundado por los judíos con una fortaleza aneja "el castillo de Gazela, que ninguno asemeja tanto a la ciudad de Damasco en riquezas como él". ${ }^{2} .$. de donde se colige haberse llamado Gacela en algún tiempo las alcazabas antiguas de la ciudad de Granada... la cual hallamos haberse también Ilamado Hizna Roman".

La interpretación que Mármol efectúa de al Rāzī condiciona todas las que vendrán después: "Conforme a lo que Raxid dice, la villa de los judíos fue en aquella parte de la ciudad de Granada que está en lo llano entre los dos

\footnotetext{
2 En la reconstrucción de Lévi-Provençal el texto de al-Rāzī sería el siguiente, en su version francesa: "Dans ce district [Ilbīira], il y a des villes qui sont sous la dépendence du chef-lieu: ainsi Qastiiliya, qui es le chief-lieu du district d'Elvira, et dont le territoire n'a pas son pareil au monde pour la fertilité et l'excellence, sauf celui de la Gūtțta de Damas... Un autre château est celui de Grenade, que l'on apelle la "Ville des Juifs" parce que des Juifs la peuplèrent; c'est la ville la plus antique que l'on trouve dans le district d'Elvira. Au milieu de la ville de Grenade, passe un cours d'eau qui s'appelait Falum (Flumen) et qui s'apelle aujourd'hui le Genil."
} 
ríos referidos [Darro y Genil]... desde la parroquia de la iglesia Mayor hasta la de Santo Matía... y la fortaleza debió ser donde ahora están las Torres Bermejas, porque según fuimos informados de los naturales de la tierra, el muro que baja destas torres, roto y aportillado en muchas partes, es el edificio más antiguo desta ciudad. Ésta sería la población antigua." Además "en los altos que caen sobre Granada parece que pudo estar fundada la antigua ciudad de Illipa, que refiere Tito Livio...". Los musulmanes "edificaron cerca de ella [la ciudad judía] un castillo fuerte sobre un cerro que agora cae dentro de la ciudad, llamado el cerro de la Alcazaba Antigua. A este castillo llamaron Hizna Roman...y los moriscos le llaman Alcazaba Cadima, que quiere decir castillo o fortaleza antigua." Por último "en el año del señor 1006 había ya otra nueva alcazaba .lla cual llamaron Alcazaba Gidid que quiere decir Alcazaba Nueva. Esta segunda población dicen que hizo un africano... Ilamado Bendici Aben Habuz, y que la llamó Gazela".

La propuesta de Mármol era inaceptable para la mentalidad contrarreformista, empeñada en demostrar las raíces cristianas de la ciudad. Luis de la Cueva (1603) rechaza la teoría de Mármol y establece el escenario adecuado para el acontecimiento determinante de la historiografía granadina de la Contrarreforma. Su intención ya la declara en la nota preliminar al lector: "A la grandeza de Granada conviene provar que siempre ha sido la Metrópolis de esta provincia, y ser lo mismo que lliberris titulo de yglesia Catedral, en los Concilios antiguos muchas vezes repetido". Cueva identifica la ciudad de Granada con llíberis: "Granada que antiguamente se llamaba lliberis,..." y pasa de inmediato a comentar los hallazgos romanos efectuados desde 1540, asociados a los cristianos que se producen después de 1570: una lápida conmemorativa en la colina de la Alhambra, en 1585; las primeras láminas de plomo con motivo del derribo del alminar de la mezquita mayor de Granada, la Torre Turpiana supuesta "fenicia", en 1588, prolegómenos de las que aparecen en 1595 en el Sacromonte. Sobre el hallazgo de la Torre Turpiana Mármol había emitido un informe (CABANELAS 1965, pp.185-188) donde identificaba la torre como indudable alminar musulmán y la comparaba con los otros dos alminares granadinos, S. José y S. Juan de los Reyes: "todos tres tenían sus torres altas para llamar a la çala, de la misma fabrica y según que las acostumbran tener los moros en sus mezquitas, y después los cristianos las hicieron servir de campanarios, subiéndolas más altas, como se puede ver el día de hoy en las dos que están en pie". Unido a la localización de lliberis en Pinos Puente, Luis de Mármol descontextualizaba por completo el hallazgo de los supuestos restos de $\mathrm{S}$. Cecilio y sus compañeros.

Tras el estudio de los restos romanos Luis de la Cueva comenta las fortificaciones de la ciudad en el que constituye primer análisis de las diferencias constructivas entre las estructuras existentes, que le permiten distinguir obras de distintos momentos. Inicia la identificación de la muralla antigua en "un castillo que los arábigos llaman Hizna Roman, que el solo es suficiente prueba de la Antigüedad y preeminencia de Granada; su fábrica muestra ser más antigua que Romanos...". Los límites del recinto a que pertenecen coinciden con la Alcazaba Cadima. Un segundo recinto añadido sería igualmente anterior a los árabes y viene a ser la muralla general de la ciudad. Como muestra de la potencia de la ciudad antigua señala la configuración de la muralla en el "postigo de S. Nicolás": "demás de la muralla de trece pies hecha de hormigón tiene otra más adentro con torres muy altas, cosa extraordinaria aver dos muros el uno tan alto como el otro."

De la Cueva utiliza dos criterios para asegurar la antigüedad de los recintos, uno es la presencia de numerosas reparaciones, ${ }^{3}$ otro,

3 "..muchas torres reparadas por lo alto más de dos varas, y el muro calçado de arriba abaxo, por dentro de la ciudad, vese que es calçamiento, por que es por unas partes más delgado que otras según se hallava gastado el muro, esto es clara señal de su antiguedad, porque si fuera de moros no le dexara tanto gastar, teniendo mortales guerras unos con otros, y todos contra cristianos.."

".las torres que hay entre estas puertas estan reparadas casi la mitad, clara señal de que no son de tiempos de moros, porque ellos no las dexaran gastar tanto, estando siempre con las armas en la mano.." 
las características constructivas, que le permiten reunir en un mismo grupo obras como el segundo arco de la Puerta de Elvira, el alminar de la mezquita mayor (Torre Turpiana), la iglesia del Sagrario -que no identifica como mezquita sino como templo de la Antigüedad- la torre de la iglesia de S. José y el Puente sobre el río Genil, junto con una torre no conservada "en frente de Santa Anna". Los edificios de este grupo "con mucha evidencia muestran ser más antiguos que los Romanos, porque ellos nunca usaron tal fábrica, ni de moros; como se ve en sus edificios, que son casa Real, la de moneda y de cabildo".

En esquema, los elementos del grupo y sus características son:

Sagrario (mezquita mayor): los cimientos.. son de argamasa y las paredes de tapias sin rafas ni cintas. Se ven pedazos de piedra y yeso en las dos puertas de la nave quinta al modo de la torre.

Torre del Sagrario. (Alminar de la mezquita mayor).

Alminar de S. José. Es de piedra y yeso, las piedras puestas a modo de tabiques.

Puente del Genil. Hecho al modo de la torre de S. José.

Puerta de Elvira. En el segundo arco es de la misma fábrica que la antiquísima Torre Turpiana.

Hizna Roman. Paredes de argamasa con trece pies de grueso. Las puertas de piedra y yeso.

Bermúdez de Pedraza culmina el proceso iniciado por De la Cueva con un cuidadoso plan. Entre la Antigüedad y Excelencias de Granada de 1608 y la Historia Eclesiástica de
Granada de 1638 existe una línea común. La primera obra sienta las bases "objetivas" de la existencia de la ciudad romana, el escenario sin el cual carece de sentido el segundo libro: una historia de la tradición cristiana de Granada desde la Antigüedad. ${ }^{4}$ Una tercera obra, la Historia Eclesiástica de Antolínez, quedará inédita; para ella realiza Heylan una serie de grabados donde se fijan de forma gráfica los monumentos primigenios de la ciudad según la nómina de Luis de la Cueva (MORENO GARRIDO 1976).(ff.4,5)

De la primera cerca Pedraza (1638, fol.31) dice que abarcaba cuatro parroquias: S. Nicolás, S. José, S. Juan y S. Miguel "y para tiempo que no había artillería, era inexpugnable, porque era de piedra, y yeso, fabrica anterior a los Romanos".

Las crónicas contrarreformistas tienen su epígono en los Paseos por Granada y sus contornos de Juan de Echevarría, ya en el siglo XVIII. Echevarría se limita a copiar los textos del siglo anterior, en especial de Luis de la Cueva.

La ruptura viene propiciada por el episodio de las excavaciones en la Alcazaba Vieja protagonizado por Flores que D. Manuel Sotomayor (1988) ha reconstruido con precisión. La mezcla de elementos históricos y religiosos, con el problema de la autenticidad de los hallazgos sacromontanos como fondo y el recurso a la falsificación como extremo, permite una polémica entre la propuesta contrarreformista y la revisión de los ilustrados representada por la Academia de S. Fernando. La opción iluminista, que en lo local se inicia con la inacabada obra de Simón de Argote, volverá la mirada hacia Luis de Mármol, cuya obra se reedita en 1797, situándolo en la posición destacada que va a mantener hasta hoy, y hacia las posiciones humanistas del siglo XVI. En el "prólogo de los editores" a los Nuevos

\footnotetext{
4 ".. dejamos reconocido el asiento donde fue lliberia y el sitio de llipula, ciudades antiquisimas. Tambien se ha hecho demostracion del puesto donde fue Granada la vieja y de la fundacion de judios que dice Rasis, dejando a la ciudad de lliberia libre del combate que le hacian todas estas fundaciones, o la ignorancia de sus sitios, originada de su antiguedad. Estos celajes escuros, y lejos deste pais, en esta primera parte serviran de aparato para entrar en la segunda de la religion Catolica, y doctrina Evangelica, que se predicó en la primitiva iglesia en esta ciudad; en que se reconoceran las huellas hermosas de los primeros predicadores apostolicos, que vinieron a manifestar la ley de Gracia en los últimos fines de la tierra en que estamos: porque en que sabiendo, que lliberia fue en Granada, se sabe quien predicó en ella, quien fueron sus Prelados, que martires tuvo, y el discurso de sus vidas y sucesos: los hechos admirables de los sucesores, los Concilios catolicos en ella celebrados, que son los materiales con que se llena el fuste desta historia, y el blanco de este marco sagrado"(fols. 27v-28).
} 
paseos.. Argote declara la intención de depurar la obra de Echevarría. Desde ahora se distingue entre la identificación de la ciudad antigua, que pierde sus componentes religiosos $-y$ por tanto es posible negar su localización en la colina del Albaicín-, y la posible cronología de las distintas cercas defensivas medievales.

La difícil tarea acometida a lo largo del siglo XIX será reconciliar el proceso de configuración urbana propuesta por Luis de Mármol con la existencia de una ciudad romana defendida por la historiografía contrarreformista, la cuestión iliberitana. En esencia se trata de reconstruir todo lo afirmado en el siglo XVII con argumentos nuevos. La crítica irá sustituyendo las referencias a textos clásicos por fuentes árabes sin que por ello se modifique de manera significativa ni el sistema espacial ni el proceso de configuración propuesto desde comienzos del siglo XVII.

Es posible distinguir dos períodos. En el primero dominan las preocupaciones filológicas. Favorecida la investigación por los estudios de R. Dozy, cuyos escritos son referencia obligada, genera las primeras historias generales, como los cuatro volúmenes de la Historia de Granada de Lafuente Alcántara (I8431846), y tiene dos hitos: la Descripción del reino de Granada de Simonet (1860) y Del lugar donde fue lliberis de Eguílaz (I88I). El segundo período se inicia con los Monumentos Romanos... de Gómez Moreno (I 890) y tiene espléndida continuidad en las investigaciones de Torres Balbás. Se caracteriza por su positivismo que vuelve la mirada hacia los restos materiales conservados frente a las discusiones "lógicas" del período anterior.

El texto más paradigmático de la primera tendencia es la amplia recapitulación en base a los textos árabes que Leopoldo Eguilaz efectúa en 1881. Eguilaz busca definir la estructura de la primera población islámica y probar su correspondencia con elementos de origen antiguo. El amplio uso de textos árabes no oculta una lectura de reminiscencias clásicas que desvirtúan su auténtico significado. Eguilaz latiniza los términos árabes y dado que lo que discute es un origen romano, establece una equivalen- cia de contenidos que falsea su significado histórico. Las crónicas del siglo XVII pesarán de forma decisiva en la interpretación de los datos y el interés por lo islámico queda supeditado a la gran polémica que domina el panorama granadino: la localización de la ciudad romana.

No es de extrañar que la otra tendencia se inaugure con una obra esencial sobre el tema: los Monumentos romanos y visigodos de Granada (1890), la obra de juventud de Gómez Moreno, donde la revisión de las teorías sobre los recintos medievales se encuentra en una amplia nota a pie de página. No es posible entender el significado de esta obra en el proceso historiográfico granadino sin asociarla de forma indisoluble a la Medina Elvira de su padre. Ambos textos configuran una propuesta global sobre el tema de la cuestión iliberitana. Probablemente se escribieron de forma simultánea y aparecerán casi seguidos en el Boletín del Centro Artístico y Literario de Granada, aunque se hicieron tiradas aparte, que son las ediciones reimpresas recientemente. En ambos casos se recurre a la argumentación arqueológica frente a los artificiales juegos lingüísticos al uso, se redactan sendos catálogos de materiales al tiempo que efectúan una relectura de los textos medievales. La polémica a resolver viene establecida en Medina Elvira: "..los unos, al afirmar que lliberri estuvo en la Alcazaba Cadima, tienen de su lado datos arqueológicos incontestables, que prueban, hasta la evidencia, que su opinión en este punto, está en pleno dominio de la verdad; los otros tienen de su parte datos irrecusables en los textos de autores musulmanes, por los que consta de una manera positiva que Medina Elvira fue una ciudad distinta de Granada y situada a larga distancia de ella. Los primeros, al esforzarse por demostrar que la capitalidad no salió del recinto actual de Granada se encuentran en contradicción con autorizados textos, en tanto que los sostenedores de que lliberri estuvo en la Sierra de Elvira, se ven obligados a confesar que si no se encuentran en aquel paraje inscripciones del Municipio lliberritano se debe a haber sido llevados en su totalidad por los habitantes de Elvira al trasladarse a Granada, lo cual de todo punto es inverosímil" (GÓMEZ MORENO 1888, pp.4-5). 
Hasta ese momento las opciones eran dos: a) Granada e lliberri son la misma población. Constituyen la Elvira islámica; b) Iliberri se encontraba en Sierra Elvira mientras que Granada era un núcleo judío que se convierte en la capital de los musulmanes. En ambos casos existiría una continuidad de poblamiento en el área de la ciudad refundada en el siglo Xl; lo que ahora se introduce es la solución de continuidad del nucleo urbano antiguo. La ciudad romana cede su hegemonía a otro centro reorganizado como capital islámica. En el área de la ciudad antigua se levantan defensas al servicio de los nuevos grupos sociales dominantes. Gómez Moreno sistematiza los datos observables para establecer distintas fases constructivas en dichas fortificaciones, rechaza la propuesta de Mármol y niega origen romano a cualquier resto de muralla conservado; acaba así con el mito de su origen fenicio, mantenido como argumento apriorístico en todos los estudios del siglo $\mathrm{XIX}$ e incluso algunos del $\mathrm{XX}$.

La Guía de 1892 mantiene la línea de los Monumentos romanos.. que se rompe en 1905 con su trabajo del Boletín de la Real Academia de la Historia De lliberri a Garnata, donde expone su tesis última que Torres Balbás recoge y sintetiza de la siguiente manera: "Además del tradicional romano arabizado de Qasțilña, los autores islámicos la llaman haḍra Ilbirra, es decir, capital de la küra de Ilbīra, mientras a la actual Granada conocíanla por madinat (ciudad principal, cercada y con mezquita mayor) Ilbirra" (TORRES BALBAS 1957a, p.207). Los escritos posteriores son obras poco accesibles, como los pliegos no publicados de los Monumentos arquitectónicos de España. Granada y provincia, de $1907^{5}$-que nos han llegado a través de pruebas de imprenta- u obras generales como el volumen III de Ars Hispaniae (|95|), junto a las anotaciones y rectificaciones a la Guía de Granada dadas a conocer como volumen anexo en la edición de 1982. Dichas obras corrigen lo publicado en los años finales del siglo XIX y establecen teoría distinta, pese a lo cual siguen apareciendo en nuestros días trabajos basados en lo afirmado en 1890.

Los trabajos de Gómez Moreno establecen dos conclusiones:

a) El ḥișn Garnāța sería el único elemento a tener en cuenta en contraposición dialéctica con la fortaleza del siglo VIII, que en un primer momento identifica con el recinto de la Alcazaba Cadima y más tarde con la primitiva Alhambra. No es una fortaleza asociada espacialmente al posible arrabal judío. La ciudad permanece.

b) Destruye la teoría del ḥișn Roman como vestigio preexistente reutilizado en tiempos islámicos.

Torres Balbás profundizó en la línea abierta por Gómez Moreno. Descartados los argumentos decimonónicos, trata de establecer sobre bases positivas la posible secuencia cronológica de las murallas. El abandono del siglo VIII para el recinto más antiguo, unido a los grupos diferenciados mediante análisis técnico-formales hace que Torres Balbás apunte una última fase en época almorávide. ${ }^{6}$

De las controversias y polémicas que se originan en la historiografía local a comienzos del siglo XX sólo una entre las distintas líneas que difieren de Gómez Moreno logra asentarse, e incluso predomina desde hace dos décadas. Es la representada por Luis Seco de Lucena Escalada y su hijo Luis Seco de Lucena Paredes. El Plano de Granada árabe de 1910 ha tenido una influencia decisiva en la histo-

\footnotetext{
5 La fecha corresponde al momento de interrupción de la publicación, tal como se indica en nota a la parte correspondiente al siglo XIII, publicada en los Cuadernos de la Alhambra, n², 1966. La correspondiente a la Antigüedad fue incluida en el volúmen Misceláneas, Primera Serie. La Antigüedad de 1949.

6 El trozo de muralla granadina que centraba a norte su Alcazaba Qadima sería "del siglo Xl, si lo identificamos con las fortificaciones levantadas por los monarcas ziries, a los que aluden los testimonios históricos; de la primera mitad del siglo siguiente, juzgando por su disposición de ingreso en recodo en el interior de una torre, por la bóveda vaida de su Puerta Nueva y por los torreones cilíndricos, disposiciones y formas arquitectónicas frecuentes en fortificaciones almorávides" (TORRES BALBÁS, I95 I, p.424). No obstante en los escritos posteriores nunca alude a dicha posibilidad.
} 
riografia sobre la ciudad. La obra se estructura en tres partes: una breve narración del proceso histórico bajo dominio árabe, un listado de elementos y toponímia ordenados por tipologías funcionales y un glosario etimológico donde explica el significado de los topónimos, incluye lecturas de distintos autores y anota las discrepancias existentes.

En la segunda mitad de siglo hasta mediados los setenta el vacío en lo que respecta al tema que nos ocupa es casi absoluto. Aparte de las aportaciones de Torres Balbás en su Arte hispanomusulmán hasta la caída del califato de Córdoba (1957), sólo destacan algunos trabajos filológicos como el de Gonzalo Maeso sobre la Granada judía (1963) o los de Seco de Lucena con la revisión de la teoría de las alcazabas (1966), que hace desaparecer la alcazaba gidida, o sobre la coracha (1968). La obra de Seco de Lucena culmina con La Granada nazari del siglo XV, de 1975, entendida como un compendio de sus distintas investigaciones. La Granada nazarí viene a ser una revisión del Plano de Granada árabe de 1910, con dos importantes novedades, la organización no es por tipologías funcionales sino por barrios, y se refiere a un período concreto, el siglo XV. No obstante la dependencia de la obra de su padre es casi absoluta. Podríamos decir que es el resultado del vaciado de los libros de habices en el esquema urbano propuesto en 19l0. Al respetar en su integridad casi todos los datos de comienzos de siglo, viene a sancionar la validez de la primera obra con un amplio aparato documental. El modelo establecido constituye un sistema abierto donde en adelante sólo cabría rellenar huecos en el gran puzzle o corregir datos puntuales en un proceso acumulativo. Es lo que podríamos denominar la "trampa positivista". La opción positivista enmascara las fuertes contradicciones existentes en la historiografía granadina al presentar una imagen de línealidad acumulativa donde las aportaciones decimonónicas pueden ser incorporadas si no se ha producido una corrección posterior. Esto da lugar a que las obras de síntesis posteriores se limiten a yuxtaponer datos procedentes de diversos autores al objeto de ofrecer la imagen más completa posible del puzzle. ${ }^{7}$ Se olvida con esto que en su mayor parte se trata de datos cuyo sentido histórico sólo lo adquieren en virtud de la propuesta teórica o metodológica vigente en su momento.

Buena prueba de las consecuencias de dicha opción es la producción bibliográfica de los años 80. La configuración del Estado de las autonomías da lugar a una fiebre editorial de historias regionales y locales y las obras de encargo se multiplican. A su vez se recupera la historiografía decimonónica, mediante la reedición de sus principales obras, lo que actualiza una tradición, mal conocida en su problemática intrínseca, que se toma como estado de la cuestión sobre el que desarrollar nuevas investigaciones.

Es importante la recuperación de los estudios sobre la ciudad romana en este período. En 1983 J.M. Roldán retoma la historiografía del siglo XIX para presentar una síntesis de los períodos romano y altomedieval argumentada en lo referente a lo urbano con criterios tipológicos generalizadores. Se atreve incluso a establecer diferencias entre la estructura urbana de Granada de los momentos ibérico, imperial y visigodo. ${ }^{8}$

\footnotetext{
7 La yuxtaposición produce textos como el siguiente: "Garnata según los textos era una fortaleza cercana a llbira y así se deduce de los relatos que cuentan los enfrentamientos de las poblaciones en los siglos VIII y IX, la Alhambra y Torres Bermejas estaban unidas por un lienzo de muralla. Eguílaz, Gómez Moreno y Seco de Lucena defienden que Garnata estaba en la orilla izquierda del Darro en el Albaicín con centro en San Nicolás. Excavaciones realizadas por el padre [falta texto, quizá: ..Sotomayor parecen.. ] darles la razón, un torreón excavado se fecha en el siglo VIII y se piensa que el recinto árabe coincidía con otros anteriores. Seco de Lucena siguió a Mármol, Argote, Lafuente...[falta texto] y el recinto alrededor de San Nicolás y calles contiguas llamándola Alcazaba Cadima. El recinto con varias puertas como Bab Qastar donde está la ermita de S. Cecilio, Bab al Bunud y otras que no han dejado vestigio ni recuerdo. Seco de Lucena dice que el aprovisionamiento de agua se hacía mediante una qawraya que a modo de espolón llegaba a un torreón a la calle del Bañuelo donde está el Puente del Cadí. Granada en el siglo X designaba una población a ambos lados del Darro". (ESPINAR MORENO, 1991, pp.215-216)

8 "... cabe suponer una evolución que, desde el primitivo y elemental urbanismo de la ciudad ibérica, lleva, a través del despliegue máximo de la ciudad romana en época altoimperial, a las contracciones de los siglos III y IV, con las que lliberri alcanza la época árabe.
} 
En 1984 se inicia un nuevo período en las investigaciones granadinas con las excavaciones arqueológicas anejas al proyecto de restauración de la muralla del siglo Xl, luego continuadas en el proyecto de investigación La ciudad iberromana de Granada, dirigido por Mercedes Roca Roumens, que pusieron al descubierto un importante tramo de una muralla. Su existencia modificaba de forma substancial las premisas que sustentaban el proceso de configuración de los distintos recintos urbanos, por tanto los análisis posteriores debían reinterpretar las relaciones espaciales y cronológicas entre las estructuras reconocidas, sin embargo esto no ha sucedido y las discusiones de tipo filológico seguirán dominando. Se une a ello que la interpretación dada al recinto descubierto no se ha hecho desde el conocimiento del estado de la cuestión tal como lo dejaran Torres Balbás y Gómez Moreno en sus últimos escritos, sino desde las interpretaciones del Gómez Moreno de 1890 y de Seco de Lucena.
En los últimos años destaca la amplia aportación de A. Malpica. En 1992 publica el único trabajo de conjunto sobre las murallas de Granada realizado desde el estudio de Seco de Lucena de 1974, un importante trabajo donde por primera vez se aborda una lectura global del proceso histórico de la ciudad desde una relectura de los textos medievales y los datos arqueológicos.9 La opción elegida, hace que sólo de manera secundaria se recojan conclusiones historiográficas, casi en exclusiva Gómez Moreno, Torres Balbás y Seco de Lucena, aunque hay mucho implícito de las mismas cuando se interpretan espacialmente los textos medievales. Es por esto que el trabajo no debe ser considerado un estado de la cuestión sobre las fortificaciones granadinas, sino una propuesta nueva llena de novedades. La naturaleza de la publicación donde se incluye, una obra colectiva de divulgación, hace que no se ofrezcan los argumentos y el aparato crítico que muchas afirmaciones requerirían, ${ }^{10} \sin$ que hasta el momento haya habido

El recinto de la ciudad iberromana de época republicana viene subrayado por la propia topografía del asiento y por la necesidad de adaptación al terreno, que ha de cumplir los requisitos estratégicos y defensivos idóneos para poder levantar sobre él el conjunto urbano. Su centro geográfico se encuentra en los alrededores de la plaza de S. Nicolás.

El recinto se extiende, pues, en un perímetro de algo más de 1.500 metros, entre el callejón del Gallo, al oeste; la plaza de San Salvador, al este; el callejón de las Minas, al norte, y el Aljibe de Trillo, al sur... Ofrece confirmación de esta ubicación la presencia de restos de dos cementerios ibéricos equidistantes en sus flancos septentrional y meridional..

Más difícil es trazar el territorio de la ciudad imperial, cuyo desarrollo habría de desbordar los límites del recinto ibérico en una extensión desgraciadamente, sin posibilidad de precisión. La existencia de cementerios o enterramientos romanos en los alrededores no es, en este caso, un punto de referencia fiable, puesto que, si se trata de necrópolis tardías, como parece ser alguno de los casos, podrían haber estado asentadas sobre anteriores cimientos urbanos, perdidos con la regresión que experimenta la ciudad a partir de la crisis del siglo III.

...Quizá lliberri... buscara en la contracción de su población, tras la seguridad de un recinto amurallado, la protección necesaria para continuar su existencia, como consecuencia, no sólo de la crisis militar, sino también de otra más profunda, social y económica, que afecta a toda la Bética desde mediados del siglo III...

...Es sin duda en esta coyuntura cuando lliberri contrae su recinto municipal con el que alcanzará la Edad Media, que Gómez Moreno identifica con el perímetro de la Alcazaba Qadima, el primer circuito cercado de la Granada musulmana.. La descripción del recinto se debe a Seco de Lucena [Plano de Granada árabe, 1910]..

... Posiblemente el llamado Hizn Roman no sea otra cosa que los restos de la fortificación tardorromana, si nos atenemos a la significación de Hizn "castillo" y Román, rumí, "cristiano" que le dieron los ziritas al instalarse sobre la propia fortaleza" (ROLDAN I983, pp.24I-252)

9 Según el principio claramente expuesto (MALPICA, 1994) de que la necesidad de una reflexión intelectual de mayor alcance "... pasa por una valoración de lo hecho hasta aquí, claro está que desde el punto de vista de un arqueólogo dedicado a la época medieval. Queremos mostrar que la arqueología genera una práctica historiográfica que le es propia. Sin ella es imposible el conocimiento científico y sólo quedaría reducida a una mera técnica." (p.199) "la Arqueología produce conocimiento histórico y... genera una práctica historiográfica que le es propia"(p.199-200). "No se debe olvidar que la Arqueología parte del análisis de los restos, tanto del subsuelo como los que hay encima de la tierra. En otras palabras, los datos extraidos de las fuentes escritas y del análisis espacial no pueden quedarse limitados, sino que deben de buscar su integración con los que se obtienen de la excavación estratigráfica. El rigor en ésta no queda, pues, subsumido en una serie de generalidades y de hipótesis por muy brillantes que sean. Además, hay que romper de una vez por todas con la visión en mosáico que tenemos como fruto de intervenciones concretas".

10 Ponemos un solo ejemplo: "Problema consiguiente es cómo esta nueva dinastía [zirí] se implanta en el territorio y, en particular, en el medio urbano que crea, pero que tiene que ir conformando. No se ha trabajado apenas sobre este tema. Sólo cabe destacar que algunos edificios y restos aislados se pueden adcribir al siglo Xl. No es facil hacer más precisiones cronológicas"(p.74). "Los cálculos realizados por Torres Balbás suponen que la ciudad zirí abarcaba unas 75 hectáreas, incluyendo, lógicamente, la qasaba y una serie de barrios intra y extramuros"(p.75). La referencia a barrios, e incluso arrabales extramuros, no procede de Torres Balbás. Antes se afirma que "... hay referencias indudables a barrios en la madīna Garnāța del siglo XI. Aparte del denominado Rabaḍ Bādīs, junto al alcázar del rey zirí, y del de Sanad situado debajo de éste, llamado así por estar situado en cuesta, hay numerosas citas de barrios que se encontraban en una u otra parte de la ladera que coronaba la Alcazaba Vieja o Qadima" (p.75). Dichos barrios tampoco nos constan en ningún trabajo sobre el siglo XI por lo que la novedad de la afirmación es indudable. 
ocasión de precisar numerosas cuestiones. Problema añadido es que si, como parece, el desarrollo de la investigación arqueológica en Granada dista bastante de ser satisfactorio," las conclusiones en base a los datos obtenidos debieran ser puestas en cuarentena.

A. Malpica mantiene que no existe ciudad antes del siglo Xl.12 Según las teorías vigentes, en las murallas granadinas se reutilizarían estructuras anteriores, y aunque existen textos que han dado lugar a una amplia gama de opciones que podrían haberse replanteado, no hay en este trabajo una sola referencia al conjunto de fortificaciones granadinas atribuidas a algún momento anterior al siglo Xl.13 Buena prueba de la opción elegida es que no aparece el término ḥiṣn Garnāța .

Fuera del ámbito local las investigaciones son escasas, aparte de lo contenido en obras generales. Inciden en el problema filológico, tendencia justificada por un conocimiento mucho más riguroso de los textos árabes, volviendo una y otra vez sobre temas imposibles de solucionar, pues sea cual sea la opción elegida no constituye más que una hipótesis a demostrar. Entre los trabajos aparecidos en los últimos años hay tres que inciden de manera especial sobre el tema, debidos a $\mathrm{R}$. Pocklington (1988), Pavón Maldonado (1994) y Fernando Valdés (1995). Los trabajos de
Pocklington y Valdés recuperan la tradición filológica del siglo XIX. El primero reitera las conclusiones de Seco de Lucena, que glosa apoyado en los recursos de la moderna lingüística; mientras que el segundo recurre a las nuevas ediciones de textos árabes para reiterar los presupuestos contrarreformistas enlazando con las teorías de J.M. Roldán.

\section{LOS NÚCLEOS INICIALES DE ASENTAMIENTO}

El análisis de los núcleos de poblamiento anteriores al dominio islámico en el área de la posterior ciudad nunca se ha planteado de forma sistemática en sus procesos sincrónico y diacrónico. Las sucesivas aportaciones de los investigadores se han limitado a episodios puntuales.

\section{I ILIBERRI}

El problema de la ciudad romana es posiblemente el más debatido en la historiografía local. El catálogo de Gómez Moreno (1890) junto con el estudio de las excavaciones del siglo XVIII de D. Manuel Sotomayor constituyen las dos obras esenciales para el estudio del tema. El trabajo de Delfín Rodriguez (1992) identificando un núcleo documental no utilizado por Sotomayor, permite intentar una

I I "Las intervenciones de urgencia no han superado el nivel más elemental desde el momento en que no se formulaban desde una concepción propia de la Arqueología urbana, sino a partir de un planteamiento en el que la ocupación pluriestratigráfica no quedaba contemplada"... "En primer plano resalta la realidad de la investigación arqueológica y el problema, en consecuencia, de la Arqueología urbana. Con claridad se percibe hasta el presente la absoluta carencia de un proyecto, tendente a un mejor conocimiento de la ciudad en su integridad, que haya intentado vertebrar los datos de todo tipo. El desconcierto, en el mejor de los casos, ha sido la nota dominante. Una arqueología anclada en unos principios en desuso en toda Europa desde hace décadas, que enarbolaba la superioridad de la técnica, vacía de todo contenido y magnificando unos presupuestos y unos medios, ignoraba el valor científico del trabajo arqueológico. Sólo ha conducido a una acumulación de datos, en el mejor de los casos, difíciles de organizar y presentar, con la vana esperanza de que alguien los pueda interpretar" (MALPICA, 1994, p. 199), lo mismo con alguna ligera variante de redacción en MALPICA I995a.

12 Recordemos los datos que al respecto ofrece Vallve ( 1986 pp.270-27I): "Durante las guerras civiles de finales del siglo IX, las fuentes árabes citan ḥișn Garnāța "Castillo de Granada" o Qalat Garnāța "la alcalá de Granada" donde se había sublevado en el año 277 (25 abril 890-I4 abril 892) Sawwār, jefe de los árabes de la cora de Ilbīra, menciona también Qasțiliyo, Qasțilla o Qasațillo, capital de la cora (hāẹirat llbīra) y Madīnat llbīra "la ciudad de llbira".."

"En el primer año del reinado de Abd al-Rahmān III la crónica de lbn Hayyān narra que el emir de Córdoba recorre la zona rebelde de Guadix y las Alpujarras Umar ibn Hafșun aprovecha la ocasión y se dirige a hadrat llbīra "la capital o sede del gobernador de llbīra". El general omeya al-Qurašī se acerca con un destacamento de caballeriza a Madīnat Garnāța, la ciudad de Granada, mientras Umar ibn Hafsūn se dirige a llbīra, próxima a aquella.."

".. en rabī II el año 318 (3-3I mayo 939) Mūsa ibn Saīd ibn Hudayr fue nombrado gobernador de las dos capitales Ilbīra y Granada (hāẹiratay Ilbīra wa-Garnāța)". Ver también JIMENEZ MATA, (i 990) pp. I 0 I - 102.

13 "El poder político necesitaba formar una madina que lo justificara, esto no quiere decir que lo sea de forma literal, ex nihilo. Así se explica que en los textos aparezcan referencias a un poblamiento anterior y toda una política edilicia posterior. En base a estos mismos textos cabe afirmar, por tanto que Garnāta no era una ciudad (madīna) antes del establecimiento zirí. Sin embargo los indicios arqueologicos de esta antigua fase son prácticamente inexistentes"(MALPICA,A. 1994, p.200). 
reconstrucción del proceso de los trabajos y un conocimiento detallado del corpus de hallazgos. Aparte, los trabajos del equipo de investigacion de la ciudad romana durante los años 80 , que culminan en un ensayo de estructuración del núcleo romano.

El énfasis en el repertorio mueble como probatorio de la ubicación de la ciudad romana ${ }^{14}$ ha hecho que sólo en las últimas décadas se haya intentado definir el área de la ciudad. Mercedes Roca ha efectuado una propuesta, incluida en la información histórica del Plan Especial del Albaicín, y argumentada en una monografía (ROCA, MORENO, LIZCANO, 1988). Es seguida por Sotomayor (1992).

Los criterios usados son tres: a) La distribución espacial de los hallazgos según el catálogo de Gómez Moreno; b) La posibilidad de identificar un viario correspondiente a la ciudad antigua; c) La ubicación de las necrópolis, que establecerían los límites del área urbana. El primer argumento depende de la consideración de resto in situ que se le de a los distintos hallazgos y del uso que se haga de las referencias espaciales para su ubicación; el segundo pretende que en la trama urbana actual existen vestigios del viario de la ciudad romana, ${ }^{15}$ hipótesis que articulaba las previsio- nes arqueológicas iniciales del Plan Urbanístico para el Albaicín. El tercer criterio se basa en la ubicación de necrópolis en las parroquias de S. Juan de los Reyes y S. José. ${ }^{16}$

Carecemos en los escritos del siglo XIX de cualquier precisión sobre la naturaleza de la ciudad en el contexto altomedieval. J.M. Roldán (1983) es el único que ofrece una propuesta sobre la ciudad entre los siglos $\mathrm{V}$ al VII. Un reforzamiento militar de la ciudad tendría incluso dos fases, la primera en el siglo VI en el contexto de un limes frente a los bizantinos; ${ }^{17}$ la segunda en el siglo VII, en un contexto que considera más de "mutación" que de decadencia: "continuó el proceso de amurallamiento, que ya vimos se había iniciado en el Bajo Imperio, con la consiguiente reducción en el perímetro urbano y la concentración de la población intramuros. Pero el hábitat urbano no quedó restringido al perímetro murado. En los extramuros, surgieron barrios suburbanos, generalmente en torno a una iglesia o basilica, de la que toman el nombre". Esta última afirmación establece todo un sistema urbano en base a una lectura generalizadora de la inscripción de Nativola, caracterizado por la reducción del núcleo urbano princi$\mathrm{pal}$, que se fortifica, y un complejo de núcleos periféricos de nueva formación. Dichos núcle-

\footnotetext{
14 Existen dos posiciones al respecto. Una deriva de la cuestión iliberitana y tiende a valorar los monumentos epigráficos como prueba del nombre de la ciudad; la otra opción incide en la naturaleza de resto in situ no monumental. Gómez Moreno ya resaltó (I 897), que el peso de la prueba no recae en las piezas monumentales sino en aquellas otras cuya reutilización estaría escasamente justificada: "Cuando estos autores [Oliver Hurtado] recogían datos para su citada obra en los altos de la Alcazaba, explicaban la presencia frecuente de restos arquitectónicos con el obligado argumento de la traslación de estos objetos desde la falda de Sierra Elvira; pero no pudieron apelar a él cuando llamamos su atención sobre el gran número de tejas planas que se encuentran esparcidas por toda la Alcazaba...hay que convenir en que ese cascajo perteneció a un pueblo muy anterior a la invasión musulmana; pues no es de creer se trajeran de otro lado, al par de las columnas, pedestales y epígrafes latinos".

15 Es defendida también por D.Manuel Sotomayor (1992, p.62): "La actual calle o cuesta de María la Miel, continuación de la Placeta de las Minas hacia el S. es muy posible que conserve, más o menos, el trazado de uno de los principales ejes viarios de la antigua Granada romana."

16 Esta última nunca ha sido probada. La propuesta procede de Sotomayor (1992, p.6I): "La zona de la actual iglesia de S.José sí hay que considerarla como ciertamente extraurbana, ya que en ella, en I888, aparecieron varias sepulturas, quedando así manifiesta la presencia en ese lugar de una necrópolis romana". Se basa en los Monumentos romanos..(p.29) de Gómez Moreno donde se dice: ".. en abril de $\mid 888$, al abrir una zanja en la Placeta de S. José .. se sacaron pedazos de tejas planas en gran cantidad, como acontece siempre en este barrio, y al mismo tiempo haciendo el desagüe de la fuente, entre pedazos de aquellas se halló un fragmento de losa con parte de inscripción sepulcral..". Los restos pertenecían a un edificio monumental localizado en dos momentos, descrito por Gómez Moreno: "El edificio a que estos vestigios pertenecieron, debió ocupar, a lo que se colige por lo que de él se descubrió, la extensión de la actual placeta del Almirante, dirigiéndose hacia la casa asilo, iglesia de S.José y la inmediata casa de D. José Ortega en cuyo jardín, según manifestacion de este señor, se hicieron algunas excavaciones hace 18 años, descubriéndose restos arquitectónicos, discos de piedra, grandes ladrillos, cimientos y entre los escombros una lucerna de barro... lo descubierto últimamente debió ser el límite de la parte edificada por el lado de Septentrión... pues al continuar el desmonte en este sentido no se hallaron más cimientos; pero sí muchos sillarejos, restos de tejas... gran cantidad de piedras de río... y dos fragmentos de capiteles corintios de piedra ripia, en que la forma, clase de piedra y factura son idénticas a las de un gran capitel mutiladísimo encontrado... en la calle Muladar de doña Sancha, y que debió pertenecer al mismo edificio".(GÓMEZ MORENO, I897)

17 "si Eliberri fue fortificada entonces o si los visigodos se limitaron a aprovechar, con las reparaciones necesarias, las defensas de que, sin duda, estaba provista la ciudad desde el Bajo Imperio, es algo que no sabemos". (ROLDAN, I993, p.344-345)
} 
os no responden a un proceso de ruralización, pues se mantienen en el área de la ciudad romana, ocupando zonas en altura. Esta propuesta contradice la interpretación de Mercedes Roca, para quien el núcleo romano en su máxima expansión corresponde a la reducción altomedieval de J.M. Roldán.

A. Malpica mantiene una actitud más radical sobre el valor de los datos disponibles: "Poco sabemos aún sobre la Granada romana, al menos que pueda documentarse con fiabilidad. Sólo disponemos de datos aislados y sin organizar. Pero aún suponiendo que no fuera así, ya que cabe una discusión sobre este punto, lo cierto es que hasta el presente nada podemos decir sobre la transición de época tardorromana a altomedieval. Las estratigrafías no muestran una secuencia continuada en ningún punto de los hasta ahora excavados. Por supuesto nada hace suponer que haya una continuidad, tal vez porque el problema esté en que desconocemos, como hemos dicho, la evolución del llamado Municipium Florentinun llibirritanum, ni siquiera su cualificación" (MALPICA 1994, p.200). ${ }^{18}$

\subsection{GARNĀṬ}

La existencia de un asentamiento judío enfrentado a la lliberri romana es el principal referente en la organización urbana altomedieval. Garnāța es entendido de dos formas contrapuestas.

a) El caracter marginal del núcleo judío fue defendido por las crónicas contrarreformistas por la incompatibilidad que establecen con el floreciente núcleo cristiano durante la Antigüedad, a lo que el siglo XIX añadió la propia naturaleza perversa de los judíos, que obligaba a controlarlos estrechamente. Si la presencia judía en la ciudad romana venía argumentada incluso por el contenido de las actas del Concilio de lliberri, en los primeros tiempos islámicos estaría acreditada por el texto de al-Rāzī.

Para Lafuente Alcántara (1844) Garnathad sería "colonia judía, arrabal de la antigua lliberi, oscurecida con el esplendor de este municipio", idea clave que ha llegado hasta nuestros días. Indica (p.5I nota 2) que "Mármol señala como villa de los Judíos lo que hoy se llama barrio de S. Cecilio, en cuya parroquia hay tradición de que duró largo tiempo el culto cristiano" -contradicción evidente. "Las torres Bermejas, cuyos cimientos son antiquísimos, fueron construidas en los primeros años de la conquista para dominar la misma parte de la población. En esta subsisten la antiquísima puerta del Sol y algunos vestigios de la muralla que formaba el recinto de Garnathad al Jahud (Granada la de los judíos)". ${ }^{9}$

En la versión de Simonet (1860) "Cuando los árabes se apoderaron de lliberis... ya existía Granada... Granada era entonces, según dicen los árabes, una alquería, o más bien un arrabal inmediato a Elbira, habitado por judíos, el cual los árabes aseguraron con una fortaleza y alguna guarnición".

b) Frente a dicha interpretación existe otra que establece la asociación entre árabes y judíos para el control del resto de la población autóctona; tiene su origen en el Ajbār Maŷmūca. Ya viene en Eguilaz (I88I, p.45) para quien "la razón de hallarse en la Alcazaba del suburbio de Granada la guarnición goda, y ser aquella fortaleza el asiento y residencia del Conde o Gobernador militar de la plaza, se fundó en la necesidad de vigilar y tener a raya

\footnotetext{
18 Los materiales de las excavaciones del Centro de Salud, Solar de la Comunidad musulmana y calle María la Miel, las únicas realizadas en el área de la ciudad antigua cuando se redacta esa afirmación, no estan estudiados; por tanto ningún dato arqueológico rebate las hipótesis planteadas. La necrópolis de la calle Panaderos, cuya función se mantiene desde epoca romana a medieval, con enterramientos superpuestos de ambos momentos, indica una permanencia funcional que es un primer dato al que en el futuro pueden sumarse otros.

19 La existencia de un recinto de murallas cerrando el barrio sólo ha hemos visto recogida en una obra reciente: "Tenemos constancia al menos de dos núcleos de población en los últimos tiempos del Imperio Romano y la época de las invasiones: la alcazaba del Albaicín o Illiberis, y el Mauror o lo que se llamó más tarde Garnatha al-Yahud. A falta de mayores evidencias sobre la coexistencia de estos núcleos y su extensión, parece lógico suponer que el diferente carácter de estas poblaciones (antigua población ỉbera y después romana lliberis, un posible ghetto judio Garnatha) exigiría la existencia de sendos recintos amurallados, al menos en una etapa tardía de la vida de estos núcleos, durante las invasiones, por ejemplo. En este conjunto de relaciones, en el que aún nos faltan muchas cosas por saber, podemos incluir el recinto de la Alhambra, de cuya ocupación antes de la llegada de la dinastía nazarí tenemos escasos vestigios, pero que cuenta con restos desde época romana".(QUESADA 1994, p. I37)
} 
a la pérfida gente judaica que poblaba el populoso arrabal". Con la conquista musulmana "Establecidos [los árabes] en Granada al abrigo de los judíos, sus naturales aliados, convirtieron los árabes la fortaleza de este arrabal en asiento y residencia de la guarnición mixta de hebreos y musulmanes". La misma idea viene expresada en la Guía de Gómez Moreno aunque no sería arrabal sino la propia ciudad. ${ }^{20}$

Existen por tanto tres opciones en la historiografía del siglo XIX:

A. Garnāța-arrabal. Con dos variantes: I.- Núcleo periférico que es puesto bajo control militar por los conquistadores árabes. 2.- Núcleo periférico controlado militarmente durante época visigoda y que se convierte por su asociación con los árabes en guarnición militar dominante.

B. Garnāta - antigua lliberri. Se mantiene la organización del espacio con orden social diferente. La población judía -sin constituir núcleo diferenciado- pasa a controlar la ciudad tras la conquista musulmana.

Estas discrepancias desaparecen en el siglo $X X$, optándose por el arrabal según lo expuesto por Mármol, la fuente principal de dicha teoría, hasta el punto de que se constituye en postulado apriorístico que condiciona la interpretación de las fuentes. ${ }^{21}$

En 1983 J.M. Roldán (pp. 351-352) desarrolla los argumentos ya conocidos ofreciendo una opción nueva. La dominante judía en la lliberi romana será objeto de fuerte control y represión durante el dominio visigodo. Sería entonces cuando surge la judería tal como la refiere al Rāzĩ: "...habría que sumar a los barrios extramuros de lliberri el hábitat de la populosa colonia judía, que posiblemente extendida por la Antequeruela, fue el núcleo de la Garnatha al-Yahud y matriz, si no de la moderna ciudad, sí de su actual nombre. El antijudaismo visigo- do, segregó en este ghetto, a no dudar extenso y floreciente, a la numerosa población judía, separada de lliberri por el curso del río Darro, población que con la invasión árabe, se instaló, como fuerza suplementaria de ocupación, en el corazón de la ciudad, durante mucho tiempo tan soñada como prohibida para los descendientes de Abraham".

$M^{a} E$. Varela en su estudio introductorio a la obra de Gonzalo Maeso (1990) reune los datos ya vistos para confeccionar el puzzle en un panorama contradictorio: "...se sabe que en tiempos del Califato había una gran comunidad [judía] en esta ciudad. Durante el gobierno omeya el área norte del barrio llamado Granada estaba escasamente poblada, aunque quedaban restos arquitectónicos de épocas anteriores. En la calle donde hoy se encuentra la iglesia de S. Nicolás se levantaban restos de una antigua fortaleza, llamada por los árabes hịșn arrumān (fortaleza de la granada). Los judíos la transformaron en Rimmon Sefarad (Granada de España) y llamaron así a toda la ciudad. Ocupaba esta comunidad los barrios al Sur del río Darro..."

"Hacia el oeste los judíos ocupaban la estrecha zona que hay entre la ladera de la colina y el río Darro, por donde actualmente sube la Cuesta de Gómerez hacia la Puerta de las Granadas, mientras que hacia el Sur de la colina su zona residencial se extendía hacia la llanura del Campo del Príncipe..., y al Norte de esta llanura. Después de la Reconquista, los cristianos construyeron la iglesia de $\mathrm{S}$. Cecilio, donde, según una antigua tradición entre los habitantes de la zona, se habría encontrado antes una sinagoga"(p.XIII-XV). Más adelante (p. XVI) refiriéndose a los acontecimientos del siglo IX dice: "Sawwār persiguió a los muladíes hasta la Puerta de Elvira en una batalla que tuvo lugar en pleno barrio judío", texto que recoge una teoría del siglo XIX que comentamos más adelante.

20 "... en 7II Tarik envió a la cora o provincia de Elvira un cuerpo de ejército, que se apoderó de su capital Garnata, donde vivía a la sazón numerosa colonia de pérfidos judíos, que unidos a los invasores formaron la guarnición destinada a sujetar a los cristianos". (GÓMEZ MORENO, I892, p. I2)

21 En el estudio que Lévi-Provençal dedica a la reconstrucción del texto árabe de al-Rāzī, llega a escribir que el río que pasa "au milieu de la ville de Grenade" es el Genil, algo absolutamente improbable. Por lo mismo, los que optan por considerar que se trata del río Darro -por conveniencia topográfica- debieran considerar que rompen con la idea del arrabal como núcleo delimitado topográficamente con una clara intencionalidad segregacionista para establecer una población en la zona correspondiente a la mādina de época zīīi. 
Esta visión ha sido contestada recientemente por Gonzalbes Cravioto (1992) quien piensa que las interpretaciones anteriores se basan en una interpretación errónea de alRāzī. La "madīna al-yahūd" "no se hallaba en el llano sino sobre el solar de lo que había sido la lliberris romana"... "parece mucho más acertado identificar la "madīna al-yahūd" con el viejo solar de lliberris que con otras extensiones fuera de contexto" (p.17). La ciudad se ampliaría en este momento ocupando la zona baja de las laderas del Albaicín y de la Alhambra, en torno al río Darro. ${ }^{22}$ La propuesta incide en algo evidente: la contradicción que supone una Garnāța como núcleo judío marginal, que procede de la interpretación ideológica del siglo XVI desarrollada por la historiografía contrarreformista, y la población dominante que refieren al-Rāzī y el Ajbār Maŷmūca. El silencio de la historiografía indica al parecer, que se trata de un hecho indiferente respecto al que se considera principal: la existencia de una fortaleza, sin tener en cuenta que la resolución del dilema implica organizaciones del territorio diferentes donde se cuestiona la razón de ser de un barrio judío.

¿Cómo se ha establecido la ubicación del mismo y su extensión?. Si revisamos con atención la bibliografía está claro que todos se han limitado a dar por cierta la afirmación de Luis de Mármol, sin preocuparse por buscar cualquier otra evidencia. El hecho de que Münzer situara la judería del siglo XV en el barrio de S. Matías -donde ya se encontraría en el siglo VII- vendría a corroborar de manera implícita una permanencia de mil años.

\subsection{CASTELLA}

La Cazalla del texto romanceado de al-Rāzī, asociada al $\hat{y}$ und de Damasco, transformada en Qastella, Gazela, Castilia, etc. será interpre- tada en la historiografía del XIX como una fortificación romana que evidenciaría la existencia de un núcleo de población. Para Eguilaz (I88) p.48, nota I) "el nombre céltico Cauracha, sinónimo de los latinos castra y castellum, y de los arábigos alcazaba e hisn con que fue designado en las épocas respectivas túrdula, romana y muslímica, el recinto fortificado de lliberis, demuestra su remota antigüedad."

Simonet lo identifica con el castillo de la Gacela de Mármol, de acuerdo con al-Rāzī, pero rechaza su identificación con el primitivo Hizna Roman "pues todavía, en los tiempos a que nos referimos, la capital de aquel distrito no había pasado a la vecina población de Granada, sino que permanecía en la misma Elbira, o en Casthella, como una fortaleza inmediata", "Casthella o Caxtala, nombre derivado del latino Castellum, o su plural Castella, no era la misma población de Elbira, sino su castillo o fortaleza donde pusieron guarnición los árabes conquistadores, y donde residiría el guali de Elbira" (p.32). En conclusión, "Granada, así como Casthilia, eran unos arrabales y fortalezas dependientes de la ciudad de Elbira" (p.36). ${ }^{23}$

El estudio de Gómez Moreno González sobre Medina Elvira (1888) identificó Qašțiliya en una ubicación que hasta el presente no se ha discutido.

\subsection{NATIVOLA}

El nombre aparece en la inscripción conmemorativa de la erección en el siglo VII de tres iglesias, localizada en la Alhambra el año 1585. Aunque el contexto apunta hacia la comarca de Guadix, (SALVADOR VENTURA 1990, p.225) también se ha considerado que se refiere a un arrabal situado donde más tarde se construirá la Alhambra en base al supuesto de

22 Completamos la argumentación: "Una vez tomada Granada, los musulmanes pusieron a su frente a los judíos. Probablemente atravesaron problemas, lo cual motivaría en el año 7/3 una reocupación musulmana de Granada. Este colaboracionismo hebreo en Granada iba a tener a medio plazo consecuencias importantes para los mismos. El proceso paulatino es mal conocido pero los musulmanes tendieron a establecer sus viviendas al pie de Sierra Elvira. El traslado allí de la capital, producido a los pocos años, ocasionó la emigración de conversos y de cristianos mozárabes. La antigua lliberris fue quedando paulatinamente ocupada de forma casi exclusiva por los judíos" (GONZALBES, 1992, p.24)

23 Lo que viene después hace aún más incomprensible el texto: "..por ampararse mejor de los estragos de la guerra civil, los de Elbira se trasladaron al vecino arrabal de Granada, que reunía juntamente las ventajas de las grandes fortalezas que allí se habían ido construyendo, como el castillo de la Alhambra y el de Hizna Roman, y de la mayor feracidad del suelo, que por esta razón había ido atrayendo hacia aquella parte a la gente de la capital inmediata" (SIMONET, I 860 pp.36-37). 
un hallazgo in situ, algo que la pieza desmiente por sí misma pues una esquina ha sido recortada para una función distinta de la original (GRANADA 1995, n¹21, p.343). En la versión de Simonet (1896, p.6, nota 3) "De la primitiva Granada formó parte el arrabal de Nativola, situado en el collado de la Alhambra, y donde el magnate Gugila o Gudiliulko erigió tres iglesias durante el siglo VII de nuestra Era". Roldán apunta su naturaleza de arrabal fortificado: "sin duda, la colina de la Alhambra, que, posiblemente fortificada, puede considerarse como un barrio extramuros de lliberri" (1983, p.35 I). Teoría ratificada por Fernando Valdés en 1995.

\subsection{ILIPULA}

Aparece asociada a los hallazgos del Sacromonte. Mármol remite a Tito Livio para establecer su origen. Será uno de los mitos transmitidos por la historiografía contrarreformista, que el siglo XIX intentó sustentar en fuentes árabes (ver epígrafe 3.7 dedicado al hișn Sacro).

\section{LOS HUSUNN}

La existencia de fortificaciones islámicas en el contexto granadino responde, según la historiografía, a circunstancias muy diferentes. Se habla desde un reforzamiento urbano visigodo hasta un puesto de control de un ghetto judío, de una fortaleza estatal omeya o del refugio de un señor con pretensiones feudales. La formación de los husūun sería consecuencia de la desurbanización que conlleva el desarrollo paralelo de llbirra, la antigua Qašțiliya, al tiempo que el solar de lliberri y sus contornos adquiere valor militar por la necesidad de controlar la población autóctona.

A cada una de las distintas opciones le dan los investigadores respuesta específica, prescindiendo de intentos sistematizadores que engloben los distintos elementos y justifiquen su simultaneidad.

\section{I. LA FORTALEZA DEL SIGLO VIII}

La principal noticia por su repercusión en la historiografía posterior es la que recoge Conde (1787) de que "hacia la mitad del siglo VIII (765) el wali o gobernador de Elvira Asad ben Abd al-Rahman al-Saybani dispuso en la parte más elevada de la colina, donde esta forma una pequeña planicie, fuese construida una fortaleza que sirviera de acuartelamiento a las fuerzas árabes encargadas de la defensa de los varios núcleos de población existentes tanto en el cerro del Albaicín como en la frontera colina". ${ }^{24} \mathrm{La}$ afirmación identifica con nitidez el lugar de la supuesta fundación en base a su correspondencia con el hișn Roman de Mármol y establece la existencia de varios núcleos de población ("barrios") muy próximos entre sí pero independientes, sin que se hable de ciudad. En realidad la noticia sólo modifica las circunstancias de lo contenido en al-Rāzī que constituye la principal fuente citada por Mármol, pero tendrá una especial incidencia en los análisis de la historiografía más reciente como veremos más adelante. Las precisiones sobre la ubicación de la supuesta fortaleza no proceden de la hipotética fuente medieval.

La construcción en el siglo VIII de una fortaleza por el gobernador de Elvira es interpretada por Eguílaz como una reconstrucción de "las alcazabas o fortaleza primitivas de Elvira", en lugar que identifica con Medina Castilia.

Lafuente Alcántara (1844 p. I08, nota I) vuelve sobre el tema citando el texto de Conde y la referencia de Mármol a la construcción por gente de Damasco de la fortaleza de Hisna Roman; de esta manera yuxtapone el asentamiento de los ŷundíes sirios -con la identificación del "castillo de la gazela"-, la construcción de una fortaleza estatal y el hișn Roman, como si las distintas citas se refirieran a un único conjunto estructural; por último se describen sus restos: "subiendo por la cuesta de la Alacaba, que arranca desde la misma Puerta de Elvira, se divisan los enormes cubos y torreones fabricados en tiempo del wali

\footnotetext{
24 Recogemos aquí el dato tal como viene expuesto en Seco de Lucena (1974) por ser la que mejor expresa la interpretación mayoritariamente aceptada.
} 
Ased". Queda así clara la naturaleza de la supuesta construcción del siglo VIII. Lo mismo viene a concluir Gómez Moreno en 1890 y lo mantiene en la Guía de 1892, aunque en escritos posteriores cambia de opinión y piensa que se trata de la primitiva Alhambra.

En todos los casos el criterio de atribución es simple: como se trataría de la primera obra levantada por los musulmanes, se aplica a los vestigios de murallas más antiguos entre los varios conservados en la colina del Albaicín. Los criterios para distinguirlos son los defendidos en el siglo XVII, en general, y en Gómez Moreno la concordancia con los sucesos del siglo IX.

\subsection{HISTN ROMAN}

Aunque existe un alto grado de identificación de la fortaleza del siglo VIII con el hișn Roman -de hecho la referencia de Mármol es el único dato sobre el que se establece su ubicación- se considera que el topónimo indica una fortaleza anterior al dominio islámico que con la conquista musulmana sería rehabilitada: "el nombre de Hizna Roman, como le llama Mármol, parece con mucha verosimilitud nombre compuesto de árabe y latino, que significa el Castillo del Romano, y a aquella época debió pertenecer, según la traza que presenta todavía la arquitectura de su antiquísima puerta" (SIMONET, 1860 p.40). La tradición contrarreformista ha pesado de manera decisiva en la interpretación de los restos que Mármol identificó como castillo de la Antigüedad hasta el punto de que Simonet (1896 p.58, nota 2) asocia la construcción al culto mozárabe: "Probablemente hubo otro santuario mozárabe en la conocida torre de Hesnaroman, cuya construcción tienen por fenicia arqueólogos competentes, y donde, según escribe D. José Jiménez Serrano, "se cree piadosamente que estuvo preso, antes de su martirio, el apóstol de Granada San Cecilio"'". El topónimo no se encuentra en ningún texto anterior a Mármol y la historiografía ha ido adecuando su grafía en función de sus posibles significados.

La principal crítica a la teoría del hișn Roman se debe a Gómez Moreno (1907 p.41) quien se pregunta por el origen de dicho nombre y sólo lo encuentra en la obra de Luis de Mármol: "Entre el cúmulo de tonterías históricas, al alcance de su época, y de errores geográficos menos disculpables, si bien todo ello juiciosamente expuesto, que afea los primeros capítulos de la obra de Mármol, concluida en 1580, encaja la noticia de haberse llamado la Alcazaba Cadima en algún tiempo Hiznarroman, que significa en árabe castillo del Granado, de donde otros han ido sacando hipótesis tras hipótesis enlazadas con el nombre de la ciudad. Mármol da por testimonio las escrituras antiguas de posesiones que estaban dentro de la Alcazaba, pero lo verosímil es que ellas consignasen el nombre de un cierto Hernando o Hernán Roman, albañil, que vivió en lo alto de aquel barrio hacia 1540, donde poseía una huerta y además varios pedazos de tierra tomados a censo de la ciudad, junto a la puerta referida tocando a las murallas" (cita el apeo de bienes del Ayuntamiento de I547, censos números 61, 137 y 138 de su archivo y los libros sacramentales de S. Miguel).

La denominación hișn Roman tiene dos sentidos, uno castillo de la granada o del granado, con una sospechosísima proximidad al hịṣn Garnātạ, será la opción elegida por Seco de Lucena; otro como castillo del romano. Esta segunda opción implica que sus estructuras una puerta en la muralla- no se reconocían por los musulmanes como propias de su tradición constructiva, cuando son indudable obra islámica; sin embargo, tal atribución es coherente con la idea de la arquitectura islámica que se tenía en la Granada del siglo XVI, que agrupa como "fenicias" un conjunto de estructuras donde se incluye el alminar de la mezquita mayor. Por otro lado, se plantea la identificación hișn Roman-Castella/Qašțiliya, supuesta fortificación romana, que vendría ratificada por la existencia de una Bāb Qaštar, entendida como puerta del castro o del casteIlum, que comentamos más adelante. La fecha que da Gómez Moreno a las estructuras más antiguas (anteriores al dominio islámico) vendría en cierto modo a justificar esta tesis.

Hasta las excavaciones de los años 80 era imposible entender por qué se origina la idea de un castillo en la zona. Los lienzos por 
encima de Plaza Larga, centrada por la Bāb Qaštar, serían el único vestigio conservado; el resto del recinto, arruinado, habría servido de cimentación a las nuevas murallas levantadas en el siglo Xl a todo lo largo de la Alhacaba. La excavación de la primitiva muralla cambia por completo esta imagen pues muestra dos líneas de murallas independientes (f.2I). Este hecho nos permite comprender por qué Luis de la Cueva -que habla de "postigo de San Nicolás"- resalta lo extraordinario de dos murallas paralelas de igual altura, es decir sin considerarse la exterior como barbacana, lo que unido a su distinta fábrica origina la imagen de una fortaleza. El estado de la zona a comienzos del siglo XVII, con los torreones interiores aún en pie, quedó fijado de forma gráfica en la Plataforma de Granada de Ambrosio de Vico, que ahora podemos interpretar correctamente (f.3).

El análisis de las estructuras atribuidas al hișn Roman lo comentamos en el apartado 4.I desde su consideración como recinto urbano.

\subsection{HִISTN GARNĀTA}

El hișn Garnāța es el referente inicial, el más antiguo, en torno al cual giran todas las interpretaciones historiográficas. Su origen es el texto de al Rāzĩ: "otro castillo perteneciente a Illīira es Garnāța, llamada "ciudad de los judíos" porque ellos la poblaban. Es la ciudad más antigua que se encuentra en el distrito de Ilbira". ${ }^{25}$ Citado así, en su versión moderna, que es como se suele encontrar en la historiografía, se altera de forma grave el sentido original de la referencia -una relación de los principales núcleos de población de la kūra- pues la misma denominación tienen Loja, Priego, Pechina, Berja, Juviles, Salobreña y Almuñecar. El texto incluye otra afirmación: por su centro pasa un río, interpretado por unos como el Genil y por otros como el Darro. Ese carácter de núcleo de población fortificado fue advertido ya por algunos investigadores en el siglo
XIX, pero siempre se consideró que existía una fortaleza como elemento dominante.

Identificada Garnāța con un asentamiento judío separado de la ciudad de lliberri, la interpretación del hịșn Garnāța quedaba condicionada de forma inevitable. Por la ubicación dada al núcleo judío Torres Bermejas tenía todas las posibilidades de constituir la fortaleza, y así se mantiene durante el siglo XIX, no obstante las opciones abarcan todas las posibilidades.

Según Eguilaz (|88|, p. I9, nota I) "el maquil de Elvira a que se refiere Ben Aljatib, o sea el hișn Garnāța lo constituían las fortificaciones de la Alcazaba de la Alhambra".

La opción hiṣn/madīna, ha sido tenida parcialmente en cuenta por Gómez Moreno (1907): "De seguro Granata era población murada, Hisn, en el último tercio del siglo IX, cuando los árabes rebeldes de la provincia, a la voz de Sauar, entraron en ella, una vez derrotado el gobernador, haciéndose fuertes allí contra los muladíes.". La fortaleza propiamente dicha sería la primitiva Alhambra.

Como ya hemos indicado, para Seco de Lucena el hișn Garnāța no sería otro que el hiș Roman de Mármol, levantado en los primeros años de dominio islámico. OrihuelaVílchez señalan que se aprovecha el recinto de la ciudad romana. ${ }^{26}$ Supone también la identificación del mismo con la fortaleza estatal del siglo VIII, como las excavaciones arqueológicas probarían (SOTOMAYOR, SOLA, CHOCLAN, 1984). ¿Cómo se ha llegado a esta conclusión?. Para Seco de Lucena la fortaleza del siglo VIII "...es la primera noticia históricamente documentada que poseemos acerca de las primitivas fortificaciones de la ciudad de Granada, que por aquel entonces eran conocidas por Hisn Garnata, es decir castillo de Granada" (SECO, 1974, p. I), eso es todo. Con la misma rotundidad lo reitera en La Granada nazarí..:

\footnotetext{
25 Tomamos la versión incluida en JIMÉNEZ MATA, 1990, p.68.

26 "El hiṣn Garnāța coincidiría exactamente con el perímetro de la ciudad romano-visigoda. En la excavación del Carmen de la Muralla se ha demostrado que los musulmanes lo único que hacen en un primer momento es añadir algunas torres, de hormigón con esquinas de lajas de arenisca y ladrillo, a la muralla anterior, y en distintos momentos embutirlas en otras torres mayores de hormigón" (ORIHUELA, VÍLCHEZ, 1990 p. 16)
} 
"Esta primitiva fortaleza, construida, a lo que parece, hacia la mitad del siglo VIII y conocida entonces por ḥișn Garnāța (Castillo de Granada), tenía su centro en la explanada donde hoy se halla la iglesia de San Nicolás..."(p.37). Con esta afirmación se descartan todas las opciones anteriores. En resumen: habría una fortaleza anterior a los árabes, consolidada en el siglo VIII que recibe el nombre de hișn Garnāța. ${ }^{27}$ Esta teoría invalida los criterios por los que se defendió la existencia de un barrio judío ubicado hacia el Sur de la población antigua.

\subsection{LA PRIMITIVA ALHAMBRA}

La existencia de una Alhambra en el siglo IX proviene de fuentes árabes (Muqtabis). Simonet (1860 pp.30-31) recoge la fundación de la Alhambra por Sawwār, "el famoso caudillo Sawar Ebn Hamdum edificó en Granada el castillo de la Alhambra (Casaba o Alcalá Alhamrá)", y su causa: "La ciudad de Elbira, donde aún no había sido desarraigado el antiguo cristianismo, abundando en ella y su comarca los mozárabes y muladíes, se inclinó a la causa de Omar [lbn Hafsun], y le favoreció en distintas ocasiones... Esta fue la causa por que Sawar edificó en el vecino castillo de Granada la fortaleza de la Alhambra, para tener a raya a los insurgentes de Elbira".

Gómez Moreno desarrolla sus argumentos sobre la primitiva Alhambra en los Monumentos Arquitectónicos... de 1907: "... en dicha ocasión arrojaron los muladíes dentro de la plaza unos versos de su poeta el Abli, que ha conservado transcritos Abenhayan, donde humillaba a los árabes haciéndoles ver la desolación de sus abandonadas casas y pronosticándoles su ruina, allí mismo donde habían sido muertos y aprisionados sus padres. Lo más notable es designarse en ellos la ciudadela que era refugio de los árabes, con el nombre de Alhambra (alcalat alhamrá)... en 889 existía, pues, la Alhambra como refugio y castillo de Granada, (subrayado nuestro) en frente de Eliberri; y era cosa vieja". ${ }^{28}$ Años después (195I) insistirá en el tema haciendo algunas precisiones: "con motivo de las tempranas rebeliones sobrevino lo normal entonces para evitar reincidencias, o sea, imponerle una fortaleza en donde con poca guarnición el gobernador pudiese vivir tranquilo, ésta fue la Alhambra, según lo acredita su actividad militar en el siglo IX y han de referirse a ella las nuevas fortificaciones que hacia 790 erigió el wali de la provincia Ased el Xeibani. Que la fortaleza de la Alhambra era anterior al siglo IX parece acreditarlo que cuando Sawwar al frente de los árabes se refugia en la fortaleza de la Alhambra tienen que reparar sus muros "que estaban a la sazón destruidos".

Torres Balbás comenta el episodio ${ }^{29}$ e identifica Alhambra-Garnāța siguiendo a Gómez Moreno. ${ }^{30}$

\subsection{TORRES BERMEJAS / HISN MAWRŪR}

Torres Bermejas constituye un hecho insólito en la historiografía granadinas. No conocemos ningún otro monumento tan constante a lo largo de la historia de la ciudad desde las

27 Pocklington transforma las conclusiones finales en afirmaciones contenidas en los textos árabes: "ya en el siglo VIII las fuentes árabes hablan de la existencia de un hișn Garnāța (Castillo de Granada), levantado en ese siglo por el gobernador de Ilbīra"(I988, p.380) con referencias a Seco de Lucena y Simonet.

28 En cita a pie de página reproduce su versión del texto de lbn al-Jațīb: "El fue [Sawwār] quien edificó la ciudad de la Alhambra (medina alhamrá) por las noches, y antorchas alumbraban a los árabes del campo" (GÓMEZ MORENO 1907, pp.46-47).

29 "Un día en que Sawwār combatió fuera de las murallas a los indígenas, éstos, volviéndose desde el monte de al-Fajjar en su persecución, se prepararon para dar el asalto decisivo a la Alhambra -o a Garnata- por su parte oriental, y asentaron sus máquinas de guerra en una colina inmediata. Pero, cuando la violencia del combate era mayor, Sawwār salió ocultamente, con una parte escogida de sus tropas, de la fortaleza medio arruinada, y atacando por la espalda, impetuosamente, a los guerreros españoles (sic) que ocupaban una llanura (saria) no lejos del castillo [hișn], los desbarató y puso en fuga".(TORRES BALBAS, 1940, p. I57)

30 La problemática siempre puede ampliarse con un dato nuevo. P. Guichard (1976, p.213-2|4) plantea el problema de los banū-lhamrā, término por el que se designaría a los indígenas, aunque en nota dice lo siguiente: "A primera vista, en los poemas donde se halla la expresión de banū-l-hamrā se podría pensar en otro sentido: se trata, en efecto, de poemas concernientes a la guerra entre los muwallads de la región de Elvira y los árabes de esta misma provincia. Los árabes se refugiaron entonces en la fortaleza establecida sobre el emplazamiento de la futura ciudad de Granada, la Alhambra (Al-Hamrā). Incluso consultando a arabistas más competentes, no hemos podido aclarar el sentido exacto de esta expresión." 
primeras referencias conocidas que haya sido objeto de menos atención por los investigadores. Torres Bermejas carece de planimetría publicada e incluso de una descripción pormenorizada como la de Hernan Roman. Todos los testimonios insisten en su excepcional antigüedad; forma parte de la nómina de edificios supuestos "fenicios" por los cronistas del XVIl; son consideradas la fortaleza de la "villa de los judíos"; su aparejo es descrito como perteneciente al grupo de hipotéticas construcciones del siglo VIII, pero nunca ha sido fotografiado ni dibujado, ${ }^{31}$ ni se le ha dedicado una monografía. Por tanto, Torres Bermejas constituye uno de los más importantes problemas a resolver en la historia urbana de Granada.

Seco de Lucena Escalada (1910) interpreta Hizn Mauror como "castillo de los mauritanos", algo que no tiene sentido. El topónimo Mawrür es, según Seco de Lucena Paredes, "anterior al dominio lingüístico árabe".

Con anterioridad R. Contreras (1898, pp.190191) aplica a las Torres todo lo referente a la Alhambra del siglo IX. Identifica castillo rojo con torres rojas y pone esta segunda denominación como la presente en el texto medieval. Seco de Lucena Paredes (1975, pp. 123-124) mantiene un criterio similar para el siglo XII interpretando un texto de Ibn al-Abbār. ${ }^{32}$

Pocklington (1988) ha desarrollado la idea de Seco de Lucena Paredes. Se argumenta la identidad de nombre con la Alhambra, y el hecho de la existencia de un "barrio de la alcazaba" (haratalcazaba) en su ladera, según
Seco de Lucena. Asociando tres datos: el asentamiento judío, la fortaleza unida a él y la transcripción árabe del nombre, propone la hipótesis de que la Alhambra del siglo IX sea las referidas Torres Bermejas.

\subsection{SAN ESTEBAN (AŠTĪBAN)}

La más reciente aportación, en el contexto de la exposición Arte islámico Granadino. Propuesta para un Museo de la Alhambra (GRANADA, 1995), recupera uno de los mitos de la Granada antigua. Alicia Canto de Gregorio y Fernando Valdés en sendos trabajos inciden en identificar la Natívola de la inscripción conmemorativa de tres iglesias construidas por un noble godo con la colina alhambreña. Ésta opción reproduce una polémica que se remonta al siglo XVII, la novedad reside en que una de las basilicas, San Esteban, se identifica con el topónimo similar del Muqtabis referido a una fortaleza del siglo $X$. En la ficha del catálogo correspondiente a la inscripción conmemorativa (n॰121, pp.343-346,) se afirma que "Nativola debía... encontrarse en el cerro de la Alhambra, donde la Crónica de Rasis menciona, en los principios del siglo $X$, un fuerte de San Esteban (Rasis, 1974, 258)... dominando desde allí la ciudad de lliberri"... La inscripción debió embutirse en la última de las iglesias construidas, y de ahí su aparición... al hacer los cimientos para Santa María de la Alhambra... construida sobre las ruinas de San Esteban". Eso, después de citar a Ibn al Jațïb para deducir que la iglesia construida en el sitio luego ocupado por el principal cementerio islámico de la ciudad sería la obra de Gundiliuva: "Los textos nos describen parcialmente y sitúan

\footnotetext{
31 Tenemos la sospecha de que los supuestos aparejos constituyen un error del siglo XVI. Por los criterios usados en dicho siglo la presencia de lajas de piedra de La Malá sería el dato que lo asociaría al grupo de monumentos fenicios y como han recordado A. Malpica y Jesús Bermúdez (1995, p.299) Torres Bermejas fue forrada con losas procedentes del saqueo de los cementerios musulmanes, lo que pudo dar origen a la teoría de su remota antiguedad. Recordemos que dichas piezas no fueron interpretadas como elementos sepulcrales hasta momento muy reciente, siendo una vez más Gómez Moreno quien aclaró la cuestión. Torres Balbás (I 957. p. 154) ya recogió que "Bermúdez de Pedraza señaló el gran número [de losas] utilizado en los cimientos y muros de casas y los supuso fenicios, no romanos ni moriscos".

32 "Cuenta este historiador, al relatarnos la biografía de CAlī ibn Adhà, rebelde granadino contra los almorávides... que durante la lucha... estos últimos se fortificaron en qașabat Garnāța... Cuando lbn Hūd Sayf al-Dawla... llegó en auxilio de los rebeldes...se instaló en al-Qașaba al-Hamrā'... que bien pudiera ser Torres Bermejas pues por entonces la alcazaba de la Alhambra no existía y si donde hoy se halla, había una fortificación, estaría desmantelada. Por otra parte, cuando en textos árabes se nombra a la alcazaba de la Alhambra se la cita por qașabat al- al-Hamrā' (Alcazaba de la Alhambra) y no por al-Qașaba al-Hamrā' (Alcazaba Roja)" (SECO DE LUCENA, 1975;pp. 123-124). El rechazo de una Alhambra anterior a la nazarí choca con lo expuesto por cAbd Allah en sus "Memorias", donde se comenta una reconstrucción con fines defensivos en el siglo Xl y, por otro lado, debemos recordar que ya no se trata de una fortaleza aislada sino de un complejo enlazado con el recinto urbano, por tanto su ruina implicaría que la ciudad tiene parte de sus defensas desmanteladas. No entendemos por qué en el siglo Xll se habría de mantener en buen estado Torres Bermejas y simultáneamente abandonar una fortificación que tiene las mismas funciones en el cerro frontero.
} 
además, la iglesia de San Esteban "a dos tiros de flecha frente a la puerta de Elvira'"'.

Para Fernando Valdés la fortaleza de Esteban (Aštīban) "que domina la capital de Elvira" no era otra que la primitiva fortaleza de la Alhambra, construcción visigoda del siglo VI reconstruida por Sawwār en el siglo IX. Cita a J.M. Roldán como el primero que efectúa dicha identificación (ROLDAN 1988). Éste investigador efectúa dos afirmaciones: $1^{\circ}$.- "sabemos por el historiador Ibn Hayyān que en el cerro de la Alhambra se encontraba emplazada en el siglo $X$, una poderosa fortaleza, llamada de San Esteban"; $2^{\circ} .-" u n a$ de las tres iglesias, la principal del conjunto levantado por Gudiliuva, fue puesta bajo la advocación de San Esteban, en el lugar que la propia inscripción denomina Nativola, sin duda el nombre cristiano anterior de la Alhambra". La primera afirmación aplica al texto original lo que no es sino la interpretación efectuada desde una posición historiográfica muy determinada. Lo que dice Ibn Hayyān es que la fortaleza de Esteban domina la capital de Elvira que por supuesto no era Granada-, y más adelante: "..emprendió el califa al Nāșir el regreso por Esteban y la fortaleza de Peña Forata, de las del maldito Ibn Hafsun, que hacían daño a las gentes de la fortaleza de Granada y de la capital Elvira, siendo extremadamente fuertes e inexpugnables". ${ }^{33}$ Pese a que el propio Valdés indica que "...el nombre de Esteban, cuando aparece aislado, siempre se refiere a una plaza de la cora de Elvira, no muy distante de su capital -hāẹirat llbīira, y de la propia Granada" y que la expresión que domina la capital de Elvira "conviene a la propia Elvira y aún a Granada (hișn Garnāța)", la conclusión es la siguiente: "el recinto habría formado parte del sistema de defensa fronterizo -limes- establecido por el reino visigodo de Toledo frente al territorio controlado por los bizantinos a partir de mediados del siglo VI d.C. Cuando las tropas imperiales abandonaron el territorio de la península ibérica 625- la fortificación de la Alhambra, levantada a extramuros de la también fortificada lliberri dejó de jugar un papel estratégico destacado, sólo reverdecido algunos años después de la conquista árabe, en virtud del reparto territorial realizado por los conquistadores $y$, ya en el siglo IX, por las guerras entre éstos y las poblaciones indígenas".

El discurso yuxtapone dos hechos. Por un lado establece la equivalencia entre topónimos alejados en el tiempo, de naturaleza bien diferente (basilica/fortaleza), que se referirían a un único contexto espacial; por otro, contrapone dos denominaciones rigurosamente contemporáneas (Aštīban / al-Hamrā'), ambas contenidas en el texto de lbn Hayyān, para definir dicho contexto. Parece claro que si se defiende un topónimo visigodo para referirse a la Alhambra en el siglo X se debería concluir que se trata de un contexto distinto de la Alhambra de Sawwār.

\subsection{HISṬN SACRO (HIȘN ŠĀQIR)}

Durante el siglo XIX se identificó otra fortificación en el Sacromonte. Para Eguílaz: (188I, p.55 nota I) "Según el autor anónimo del libro de Geografía (Códice del Sr. Gayangos), el Castillo Sacro (o Monte Sacro como se lee en otro historiador árabe) se hallaba situado sobre el monte Ipula (il-ipula), en el cual tenían lugar extraordinarios prodigios y maravillas. Este Castillo Sacro dominaba la Vía Romana que conducía de Elvira a Acci. En el siglo $\mathrm{XVI}$ aún se conservaban los muros exteriores, su fuerte central, unos y otro de fábrica romana".

Fue también defendida por Simonet (1896, pp.49-5I) en la que constituye de manera indirecta la última defensa de los hallazgos sacromontanos: "Por nuestra parte creemos que descartadas las indudables imposturas que han afeado las tradiciones del Sacro Monte, queda en ellas mucho de verdadero y respetable. Porque, además de los prodigios que acompañaron al descubrimiento de las grutas y cenizas en el siglo $X V I$, un documento no sospechoso, como de autor genuinamente arábigo, nos enseña que bajo la denominación sarracénica era celebrado aquel monte por

33 Citamos la versión recogida en el trabajo de Fernando Valdés, pags. 64-65. 
señales prodigiosas y notables maravillas.. y tampoco debemos callar que el autor arábigo a quien aludimos determina con toda seguridad el actual asiento, y, lo que es aún más notable, el nombre de Sacro Monte y de otro antiguo que se aplica a este santuario; puesto que coloca el lugar de aquellas maravillas en un castillo llamado Monte Sacro, situado en un monte llamado Abula o Ibula...Por donde se ve claramente que el nombre de Sacro Monte o Monte Sacro, con su aditamento de llipulitano, no es invención del siglo XVI, sino antigua denominación..".

No habríamos recordado esta atribución si no la hubiesemos visto apuntada en un texto reciente. Vallvé (1986, p.270) piensa que el "Munt Šāqir, Monte Sacro, Monte Santo,... tal vez no corresponda, como tradicionalmente se viene admitiendo a Montejícar, del partido judicial de Iznalloz y a unos 60 kilómetros de Granada, y haya que situarlo en el actual Sacromonte". ${ }^{34}$

Si asociamos los dos apartados vistos, núcleos de población y fortificaciones, resulta una imagen con una densidad de población extraordinaria, que ilustra bien una frase de Simonet (1896, pp. 57-58): "Para refrenar el espíritu independiente de los indígenas, y sobre todo de los ciudadanos de lliberri, que poblaban los collados de la Alcazaba y del Albaicín, los musulmanes fortificaron las opuestas alturas de la Alhambra, Torre de la Vela y Torres Bermejas, o reforzaron las torres y castillos que existían allí desde la antigüedad". La conclusión es que en los siglos VIII al X existiría un núcleo habitado con la misma extensión que la ciudad en tiempos nazaríes, sin embargo se niega una ciudad propiamente dicha prefiriéndose hablar de múltiples barrios. Si contraponemos este hecho a la existencia de otra población con funciones de capital Ilbìra- resalta aún más la contradicción entre el complejo defensivo descrito y la ausencia total de cualquier referencia al tipo de defensas que pudiera tener la ciudad habitada por los árabes.

\section{LOS RECINTOS URBANOS}

El fenómeno de los husūn es distinto del problema de las murallas urbanas. Aquellos serían anteriores al hecho urbano y establecen un momento de transición entre la ciudad antigua y la definitiva islámica mientras que éstas testimonian el modo de crecimiento de la ciudad y su progresiva complejidad espacial y funcional. En Granada los recintos urbanos originados en las primeras fases de formación de la ciudad islámica se identifican en un primer momento con el complejo castral preexistente, y en las siguientes fases con sendas "alcazabas", según la propuesta de Mármol: un primitivo asentamiento, hiș Roman, una primera expansión, Alcazaba Cadima, y otra segunda, la Alcazaba Gidida que completaría la ocupación de la colina del Albaicín. Este proceso implica que en la nueva configuraciòn espacial se integran, mediante cambio funcional, estructuras anteriores al hecho urbano, reconstruidas y alteradas en forma y modo desconocidos, y, a su vez, que en un momento posterior las nuevas murallas se entienden como recintos con funciones específicas que justifican la denominación de "alcazaba". Por ello desglosamos un mismo hecho material -una línea de murallas- en sendos apartados donde se analizan cada uno de los significados posibles.

La configuración urbana emprendida a comienzos del siglo XI implicaba un proceso largo que Luis de Mármol articulaba en una serie de fases a las que corresponderían recintos diferentes. La caracterización de dichos recintos se establece hacia finales del siglo XIX desde los presupuestos establecidos por Mármol.

Del estado de confusión existente antes de los estudios de Gómez Moreno es buena prueba lo que propone Eguílaz. Identifica el recinto de la ciudad antigua con el figurado en la Plataforma de Granada de A. de Vico, fija su correspondencia con una de las fases de Mármol y le da una cronología: "Esta

34 La distribución de los topónimos Munt- es recogida en plano por Acien Almansa ( 199 | p.369, fig.2). 
Alcazaba Gidida, pienso yo que fue construida durante el reinado de Abderrhaman III" (EGUILAZ, I88I, p.49).

En los Monumentos romanos y visigodos (1890) Gómez Moreno desarrolla su primera exposición del problema. El primer recinto sería construido "por completo a un tiempo" por "el wali de llbira Ased ben Abderrahman el Xeibani, que murió en el año 765, dejándolo sin terminar según se dice". Considera incorrectos los límites dados por Mármol y sus seguidores e identifica los siguientes restos: Puerta de Hernan Roman, cinco torres y algunas murallas hasta Bibalbonud de la que se conservaba una de sus torres y cimientos de la otra, una torre por encima de la iglesia de S. Juan, otra delante de su fachada oeste, en la calle de San Juan de los Reyes indica que existen trozos ocultos entre las casas, otros restos en la Cruz de Quirós y una torre en las Vistillas de S. Miguel... (sería el portillo del León). Ofrece datos sobre las características constructivas de esta muralla y señala cómo tanto en el macizo de la propia puerta como en los lienzos inmediatos aparecen fragmentos de tejas romanas cogidos en el tapial "lo cual indica que abundaba el cascajo romano en la Alcazaba cuando su recinto se construía".

En el resto del perímetro, donde sólo quedarían visibles las reconstrucciones del siglo $\mathrm{Xl}$, distingue Gómez Moreno dos momentos constructivos diferentes. Al más antiguo corresponde el tramo desde Puerta Monaita a Sta. Isabel la Real, que atribuye a Hābūs ( 1020-1037); el siguiente, en línea con el anterior, llega hasta el Arco de las Pesas y continúa por debajo de la Puerta de Hernan Roman, que inutilizaría; lo atribuye a Bādīs.

En 1907 Gómez Moreno presenta una teoría distinta. En el capítulo II de los Monumentos arquitectónicos, dedicado al período visigótico: siglos $\mathrm{V}$ a VII, incluye un apartado dedicado a la Alcazaba de Granada donde narra un episodio de la conquista musulmana. Enviado un ejército contra Eliberri "llamada por ellos Medina Elbira" que les había puesto resistencia es tomada la ciudad sin capitula- ción "quedando en ella un presidio mixto de moros y judíos para mantenerla sujeta." Una rebelión se produce poco después no volviendo a figurar la ciudad en ninguno de los acontecimientos posteriores; "Parece como si no existiera, o más bien como si estuviese desmantelada, que es lo probable.." Basándose en Ibn al-Jațîb señala que "el lugar sitiado y tomado por los moros era la Alcazaba cadima (ciudadela vieja), núcleo el más antiguo de la población de Granada". Se refiere a la reedificación por los ziríes de su recinto y al hecho de que "al lado de ello quedan vestigios de otra cerca más vieja, y con tal grado de solidez como si fuera peña viva, no obstante lo conservado son torres sueltas y cimientos de muro; nada más, habiéndose deshecho en absoluto largos tramos, y así estaba cuando se montaron encima las nuevas murallas... resulta de ello que sin duda el primer recinto fue desmantelado en grande antes del siglo Xl; y como no consta ni es verosímil otra ocasión que el referido suceso, parece creíble que Abdelalí apeló a tan eficaz recurso para desarmar una ciudad de muy difícil sujeción, dado su aislamiento. Indúcese así que databa de fecha anterior; pero más allá no permite la historia esclarecer este hecho" (p. 39)

Dicho recinto es el que ya describiera en los Monumentos romanos.. como el más antiguo aunque efectúa descripción más minuciosa. Los elementos pertenecientes al mismo y su distribución es la siguiente: "De este primitivo recinto la parte más erguida y notable cae hacia NE., donde se alínean cuatro grandes torres y el macizo de una puerta, unido a aquellas mediante un lienzo de muro; otros cimientos les rodean, por ejemplo en la que fue puerta de Bibalbonud; hacia SE. hay otras dos torres más, junto a S. Juan de los Reyes, y al $O$. quedan pequeños vestigios encima del Cenete, donde estuvo la puerta que llamaron Bibelecet".

Las características de las murallas son descritas de la forma siguiente: "Miden estas torres unos 6 metros de base por su frente, algo más por sus costados y un duplo de altura; resultan sin ligazón con la muralla, de I,40 
metros de grueso, que las unía, y a desiguales distancias unas de otras, siendo la mayor como de 20 metros. Su aparejo es de tapia, que se diferencia de la romana en que sus cantos son más gruesos y rodados, sin descacharlos en modo alguno, de suerte que, aún siendo por extremo dura su argamasa, la adherencia con aquellos parece menor. El alto de las tapias alcanza a unos 80 u 85 centímetros; verticalmente se cortan ellas a trechos, dando el aspecto de una sillería enorme, aunque mal trabada, y los paramentos dejan ver tan sólo argamasa, con quedar embutidos dentro los pedruzcos."

"Por cimientos entraron materiales de toda clase, y hasta sillares y trozos de fustes que por allí rodarían, y abundan también fragmentos de tégulas y ladrillos romanos, lo que no es extraño sabiéndose cuanto de ello retiene aún aquel suelo. Además, como si no fiaran bastante en la firmeza de la obra, adhirieron a las esquinas por abajo una especie de refuerzos hechos con lajas de arenisca de las canteras de la Malaha; más la precaución resultó fallida, porque éstas se desmoronan y arrancan con facilidad, mientras que el hormigón es indestructible."

"Las lajas vense dispuestas de dos maneras: ya de plano unas sobre otras y sujetas con mortero de cal, formando machones en las esquinas y en medio de algunas torres hasta la altura de 3 metros, ya puestas de pie sobre uno de sus cantos más largos y pegadas con yeso, lo que constituye sistema bien original; así en la puerta primitiva arriba dicha y esquinas de la torre inmediata".

En el apartado correspondiente a la mezquita mayor de Granada dice que "es verosímil que nuestra ciudad floreciese bajo los califas del siglo X; pero justamente las crónicas se vuelven mudas en los tiempos bonancibles, y tan sólo el Rāzī la describe con harta brevedad. Entonces probablemente, surgieron dos mezquitas que gozaban fama de muy antiguas: la una, dentro de la Alcazaba, se llamó Gima Marabiten, consagrada en honor de San José... La otra ostentaba categoría de mezquita o Algima mayor de la ciudad..." (p.5I) rompe así con la tradición que incluye el alminar de $\mathrm{S}$. José en el grupo de construcciones del grabado de Heylan y lo distingue de las construcciones del siglo Xl, estudiadas en capítulo aparte.

Lo más destacable por su novedad es la fecha que da al primitivo recinto: "Por conclusión, advirtamos que el recinto primitivo de Granada no posee carácter alguno de obra clásica; antes al contrario, sus diferencias de estructura son manifiestas. Según ellas, no puede negarse técnicamente que bajo los musulmanes hayan podido surgir, antes del siglo Xl; pero razones históricas inclinan a suponer más probable que lo fuesen dominando bizantinos o godos, hacia el siglo VI" (p.43). Mantiene lo mismo en I95I.

Torres Balbás efectuará un meditado análisis donde observamos un exquisito cuidado en evitar el menor encuentro con las propuestas de Gómez Moreno; ofrece argumentaciones propias que anulan las conclusiones de éste sin hacer la mínima alusión al hecho, o guarda silencio cuando la confrontación iba a ser evidente. Esta circunstancia la apreciamos en lo referente a dos temas: la primitiva muralla urbana y los origenes de la Alhambra.

Torres Balbás (194I, p.440 nota I) compila las distintas referencias contenidas en las fuentes árabes sobre la construcción de las murallas y distingue varias fases. Durante el reinado de Zāwī y de su sucesor Habūs (1016-1038) se construirían la torre de la mezquita mayor, la de S. José y las fortificaciones correspondientes a las puertas de Hernan Roman y de Elvira. A los reinados de Bādīs y cAbd Allāh ( 1038 1090) atribuye el Bañuelo, el puente del Cadí (Puerta de los Tableros), y las puertas Monaita y de las Pesas, con el paño de murallas que las une; apunta que los torreones cilíndricos de la misma tal vez fueran algunas de las mejoras introducidas por cAbd Allāh tras observar la fortaleza de Belillos, construida por los soldados de Alfonso $\mathrm{VI}$ al servicio de al-Muctamid de Sevilla, que pasa a su poder en 1075.

Los argumentos para distinguir dichas fases son de tipo constructivo. El primer grupo se caracteriza por la presencia de soluciones de 
cantería aparejada a soga y tizón y con talla en resalto que sigue modos cordobeses. Las puertas militares son de tramo recto y las murallas y torres de tapia "con cantos gruesos y rodados unidos por dura argamasa". En las obras del segundo grupo "ya no se encuentra el aparejo a soga y asta, ni el almohadillado. Prosigue la construcción de muros de tapia, si bien con argamasa mezclada a tierra arcillosa y grava de río... pero en las puertas.. la mampostería sustituye a la piedra labrada. Cuando ésta se usa en arcos o paramentos.. sigue aún cortándose en estrechas lajas, pero sin labra de resalto ni ordenación a soga y asta". El arco de las Pesas inicia las entradas en recodo, elemento que se mantiene en Puerta Monaita donde se añade otra novedad consistente en un patio intermedio. Por último la presencia del arco agudo frente al de herradura anterior. No existe la menor alusión a la propuesta de Gómez Moreno de ser la primera fase obra anterior a lo islámico.

En otro lugar (1940, p. 161) indica los elementos de las demás cercas anteriores al momento nazarí: "El resto de la cerca fue reconstruido casi totalmente en tiempos posteriores y ha desaparecido en su mayor parte, pero aún atestiguan su primitivo trazado: las Torres Bermejas, cuyos muros conservan todavía importantes restos de este siglo [XI]; el Puente del Cadí, construido en la misma época y que servía de ingreso en la ciudad al Río Darro, la Puerta de Bibarrambla, citada en la época almorávide, y la de Mauror, mencionada en $539=1 \mid 45 "$.

En 1974 Seco de Lucena reitera la versión de un núcleo formado en el siglo VIII. "De esta primitiva cerca se conserva casi todo el sector $N$., es decir, el paño de muralla que arranca de Bibalbonut y concluye en el arco de las Pesas, restos de un torreón en la calle Guinea y alguna que otra pequeña ruina aprovechada en la construcción de edificios adosa- dos a la cerca". Seco de Lucena sigue criterios ajenos al describir este supuesto recinto del siglo VIII y no percibe la contradicción en que cae. En 1890 las técnicas constructivas le permitieron a Gómez Moreno reunir un conjunto de estructuras que atribuye a dicho siglo; esas técnicas son para Seco de Lucena propias del siglo Xl: "Este aparejo, utilizado también en otras construcciones granadinas del siglo XI, corresponde a la época de Almanzor y acredita que la arquitectura zirí conservó la tradición califal". Son las conclusiones de Torres Balbás en 194I. Por tanto, la atribución al siglo VIII de un recinto, incluso distinto al definido por Gómez Moreno, es un error.

Quizá la nota más original de este trabajo de Seco de Lucena sea una frase que ha pasado desapercibida: "Restos de la muralla del primitivo recinto, que quedó interrumpida en el Arco de las Pesas y especialmente sus cimientos, se conservan casi paralelos al muro de ampliación [zirīi] desde el citado arco y hasta la placeta del Cristo de las Azucenas" (donde se encuentra el aljibe del Rey).

Para Malpica "Parece evidente que la madina se concentraba en la colina del Albaicín, aunque no debía ocuparla por entero, pues conocemos aumentos de la población. El problema estriba en saber si la zona más llana se fue ocupando por estas fechas y en qué medida"...(MALPICA, 1992, p.75). ${ }^{35}$ El proceso sería el siguiente: "hay tres fases claras en la fortificación de la ciudad. En la primera, del siglo XI se funda la Alcazaba Vieja, o alqașabat al-qadima. Entre finales de éste y durante el siguiente, se debió de cercar toda la madīna, o espacio central de Garnāța que se localiza a ambos lados del Darro, pero preferentemente en su margen derecha. Queda por resolver si el espacio más elevado de la colina y el inmediato, es decir la zona llamada de Axares y el situado entre Elvira y el alcázar de Bādīs (en torno a la Casa de la Lona), tení-

35 "El lapso de tiempo que va desde la época zirī a la almohade significa un progreso evidente en la ocupación de esta parte baja. Recuerdese que en la zona de Bibarrambla tenía una almunia o casa de campo periurbana el monarca Bādis, que ya existía en época de su padre, Habūs. En poco tiempo se edificó la mezquita mayor, que es anterior a 1055; un siglo después se construyeron los baños que había encima. Precisamente en el siglo Xll parece que se construyó el lienzo de muralla entre la puerta de Elvira y la de Bibarrambla. Es una prueba de que el núcleo urbano ya estaba conformado en esta área y que la madīna había alcanzado casi el máximo conocido en época medieval en esta zona."(MALPICA 1995a, p.88) 
an una sola muralla 0 era doble. Finalmente, es de tiempos nazaríes, de mediados del siglo XIII a principios del XIV, la creación de las cercas exteriores...".

Dos recintos serían los existentes: "el superior ocupado por la Qașabat al-Qadima.. y el inferior.." ... "la muralla que hoy se ve por la cuesta de la Alhacaba lo mismo se adcribiría tanto al recinto superior como al inferior". Las dudas que surgen ante un recinto de la Alcazaba que dejara fuera el Alcázar de Bādīs le conducen a otra propuesta: "También es posible que no hubiese nada más que un recinto, pues no es creíble que el alcázar se hallase fuera de la propia alcazaba".

En resumen, frente a los razonamientos de tipo lógico que escalonan el siglo XIX, Gómez Moreno dibuja un proceso histórico basado en la correspondencia entre las distintas fases de fortificación identificadas en las fuentes y las estructuras dispersas por el casco urbano visibles en su tiempo, las agrupa en función de sus características morfológicas y las asigna a los respectivos momentos históricos según un determinado modelo de expansión. La fecha que da Gómez Moreno no puede separarse del recinto que define, correspondiente en sentido estricto con la Alcazaba Gidida de Mármol, por tanto la segunda fase de expansión en la secuencia de Seco de Lucena. Sólo cabrían dudas en la vertiente Sur, paralela al río Darro, pero en cualquier caso ocuparía en su totalidad la cima de la colina.

Torres Balbás añade nuevos criterios analizando la correspondencia entre los distintos componentes formales y materiales de dichos grupos y lo existente en la arquitectura cordobesa omeya, cuyo estudio puede efectuarse de manera más precisa con el desarrollo de las excavaciones en Madinat al-Zahrā.' Los aparejos sirven para caracterizar el momento más próximo a la arquitectura del califato y las puertas con acceso en codo, cuyos primeros ejemplares serían precisamente los granadi- nos, el momento final. Se distingue además una fase intermedia en base a la ruptura de continuidad estructural y las variantes morfológicas existentes en los torreones, todo ello en correspondencia con las distintas campañas que cAbd Allāh indica en sus "Memorias". Se extrañaba de que fueran necesarias tantas reconstrucciones en tan poco tiempo. ${ }^{36} \mathrm{La}$ posible fase almorávide vendría a poner cierto orden en el tema. Torres Balbás no encuentra ningún motivo para asignar una fecha anterior al dominio islámico a ninguna de las fases diferenciadas.

Tanto en Gómez Moreno como en Torres Balbás la secuencia cronológica no correspondería a un proceso de expansión desde un núcleo ubicado en la zona alta de la ciudad puesto que a la primera fase pertenecerían elementos tan distanciados como la Puerta de Hernan Roman y la de Elvira y la segunda corresponde a la zona más occidental de la colina, entre Puerta Monaita y el palacio de Daralhorra. El lienzo entre éste último y la Puerta de las Pesas sería la fase final. Es decir, un proceso inverso al que derivaría de una primitiva fortificación.

La propuesta de Seco de Lucena rompe de forma radical con la línea argumental anterior. En ninguno de sus trabajos establece de manera explícita los criterios por los que no acepta las tesis de Gómez Moreno y Torres Balbás, así que sólo podemos deducirlos del conjunto de afirmaciones contenidas en La Granada nazarí. Creemos ver la raíz de la propuesta en el hișn Garnāța entendido como un primer paso hacia la Qașabat Garnāța, que junto con lo expuesto por Gómez Moreno en I 890 le permite un esquema evolutivo continuo en línea con la tradición decimonónica. Es la prueba del salto que efectúa hacia atrás, hasta el Plano de la Granada árabe de 1910, como esquema apriorístico que articula sus argumentaciones, prescindiendo de la línea establecida por Torres Balbás salvo para descripciones puntuales. La tesis ignora tres ele-

\footnotetext{
36 "Resulta difícil explicarse cómo pocos años después de levantado parcial o totalmente la cerca, y sin que parezca haber habido causas que motivaran su destrucción violenta, se construyera otra. Tal vez las obras se redujeronse a reconstruir, con mayor fortaleza, una parte -el paño comprendido entre las Puertas Monaita y Nueva- y a rectificar algo su trazado -contornos de la Puerta de Hernan Roman". (TORRES BALBÁS, 194I, p.442)
} 
mentos ubicados fuera del perímetro del supuesto hișn Garnāța que ya Gómez Moreno enumerara en 1890 como pertenecientes al recinto inicial (f.20): el basamento del Palacio de Daralhorra visible en el callejón de las Monjas (GÓMEZ MORENO 1992 II, p.267), la muralla en el interior de la Casa de la Lona (GARCÍA; MARTín 1975), y los restos de la Bāb alAsad o portillo del León (GÓMEZ MORENO 1892; VÍLCHEZ 1987). La opinión de Seco de Lucena pasará a las previsiones arqueológicas del Plan Especial de Protección y Reforma Interior del Albaicín y al plano del trazado de las murallas de Orihuela-Vílchez en 199| (f.26), el único realizado sobre planimetría moderna, a escala adecuada y que tenga en cuenta el parcelario, resultado de un serio trabajo de campo.

La adaptación de las teorías de Seco a la interpretación de las excavaciones en el Carmen de la Muralla dadas por sus directores, hace que las fases propuestas para las murallas del siglo XI en base a los textos árabes se hayan olvidado.

\section{LAS PUERTAS / CORACHA}

Aparte de la muralla propiamente dicha se han identificado otros elementos de tipología específica: varias puertas y una coracha, que incluso serían anteriores al siglo Xl.

\section{I. BĀB ILBĪRA}

Un tema que encontramos reiterado en un texto reciente (VARELA 1990) es la existencia de una Puerta de Elvira en el siglo IX que Eguílaz (1881, p.26) recoge de la biografía de Sawwār en la lhațā de lbn al-Jațīb cuando narra la batalla de la madīna: "..volvieron del monte de Alfacar en su persecución dirigiéndose a la Puerta del Sol de Granada, donde encontraron fuerte resistencia. En lo más encarnizado del combate, y cuando más encendido se hallaba, desapareció Saguar de la batalla con porción escogida de sus caballe- ros, y cargando con su enseña quedaron aquellos aterrados y sufrieron grandes perdidas, e imaginando que sus auxiliares (los de los árabes) habían venido a atacarlos por la espalda, retrocedieron derrotados y Saguar y sus compañeros los fueron acuchillando hasta la Puerta de Elvira". Para Eguílaz esta narración demuestra "con la clara luz de la evidencia la identidad de Elvira y Granada, poblaciones ambas que ocupaban la una los altos de la alcazaba Cadima y sus alrededores, y la otra la colina en cuya cima se alzan las Torres Bermejas o castillo de Maurora, como le apellida algún escritor del siglo XVI". Rechaza la lectura de Dozy "hasta las puertas de Elvira" de manera tajante y concluye de la siguiente manera: "el Bib Elvira de Ahmed ben Isa, hasta la cual fueron perseguidos y acuchillados los muladíes y cristianos de aquella ciudad, es la antigua Puerta de Elvira, ${ }^{37}$ cuyo nombre ha llegado hasta nosotros, la secular y magnífica puerta que daba entrada a la celebérrima urbs de Plinio, a la lliberi de Tolomeo, al Municipio Florentino Illiberitano, a la que en las postrimerías el siglo III de la era cristiana tuvo la inmarcesible honra de ver reunidos bajo las excelsas bóvedas de su gran basílica a los obispos de la Iglesia española" (p.29).

La Puerta de Elvira mereció figurar en el grabado de Heylan entre las reliquias de la antigüedad; los análisis de los modos constructivos la emparejan con la Puerta de Hernan Roman; pero se omiten sistemáticamente las consecuencias de este hecho, tanto por los que mantienen una correspondencia entre el recinto de la ciudad romana y un primero medieval en el siglo VIII, como los que lo atribuyen al primer momento constructivo hacia comienzos del siglo Xl: define un casco urbano de dimensiones excepcionales para su momento histórico. El único que actuó en consecuencia fue Eguílaz, incluyendo la Puerta de Elvira en los sucesos del siglo IX, los demás simplemente evitan tratar el tema. En el más reciente trabajo sobre la Puerta de Elvira (ALMAGRO; ORIHUELA; VíLCHEZ 199I) se alude a

37 Seco de Lucena (1942) al ir dando las referencias de las puertas en el siglo XIV indica que "aparece citada en otros textos árabes y documentos cristianos a partir de finales del siglo XIII, sin hacer ninguna referencia a momento anterior. Almagro; Orihuela; Víchez (1993) sólo indican una primera fase en el siglo Xl. 
una primera fase constructiva en el siglo $\mathrm{XI}$ sin incidir en el hecho de que ya Torres Balbás distinguió tres fases constructivas a lo largo de dicho siglo y que la hipótesis de la Alcazaba Gidida como fase intermedia que algunos defienden relega la Puerta de Elvira al último momento en la configuración del territorio urbano. Es por ello que Antonio Malpica situa la muralla entre esta puerta y la de Bibarrambla a caballo entre el siglo Xl y el XII, en base a un texto de época almorávide.

A pesar de todo ello, el grabado de Heylan no admite discusión: la Puerta de Elvira tenía elementos perfectamente asimilables a un grupo homogéneo de obras de las que aún se conservan el puente sobre el río Genil, cuya estructura original ha podido ser estudiada con motivo de su restauración, la Puerta de Hernan Roman y el alminar de la iglesia de S. José, habiendo desaparecido el alminar de la mezquita mayor y la propia Puerta de Elvira demolida parcialmente en el siglo pasado.

\subsection{BĀB AL ŠAMS (PUERTA DEL SOL)}

Respecto la puerta del Sol reproducimos el comentario de Seco de Lucena (1975 p.40 nota 15): "Eguilaz identifica esta puerta [Bāb al Šams] con un al-bāb al Šarqī (puerta oriental) citada en IHA (Ihāța), biografía de Sawwār b.Hamdūn; pero la lectura del texto árabe en que aparece la cita, no justifica a mi juicio tal identificación... pienso que acaso pudo ser nombre antiguo de una de las puertas de la vieja alcazaba". La Bāb al Šams "daba acceso al barrio del Mawrūr y fue conocida también con el mismo nombre del barrio". Seco de Lucena dice no haber encontrado ninguna cita de Bāb al Šams en textos árabes, "aunque en tiempos de la reconquista, los cristianos la denominaban puerta del Sol". Dicha puerta, de haber existido en el siglo IX, correspondería al arrabal judío.

Denominación muy similar tuvo al parecer otra puerta. Torres Balbás (1949) cita al respecto el manuscrito del Escorial publicado por Müller (1863) donde se narran las luchas a comienzos de 1487 entre Boabdil y su tío el Zagal: "por esta última puerta [Bāb al-Difāf] salió una tropa que, subiendo río arriba, entró en el recinto murado del Albaicín por Bāb alŠamis (Puerta de ila Solana?)". Seco de Lucena (1975, p.44) traduce Bāb al-Sumays como "del Solecito"; Orihuela-Vílchez (p.2I) la identifican con la puerta de Guadix.

\subsection{BĀB QASTAR (PUERTA DE HERNAN ROMAN)}

La denominación puerta de Hernan Roman procede del grabado de Heylan (f.4) y ha sido mantenida hasta nuestros días. En la Guía de Granada de 1892 aparece identificada con la Puerta de las Pesas (Bāb al-Ziyada), pero en 1907 Gómez Moreno corrige y piensa que la se trata de la denominada Puerta de Castar "con palabra no de su lengua, sino más bien derivada de castro", añade las referencias en fuentes islámicas del siglo XV (códice del Escorial traducido por Müller) a un portillo de la puerta de Castar que se abre "junto a la susodicha por consecuencia de haberse cerrado otra vecina" y la cita de al-Jațīb a un "cementerio de Socastar,.. y precisamente debajo del sitio en cuestión, donde hay unos huertos dominando la plaza Larga del Albaicín, consta que hubo un macáber o cementerio de moros". En las declaraciones efectuadas con motivo de los descubrimientos del Sacromonte encuentra citada la puerta, designada como "portada antigua de junto al portillo por donde se entra desde San Nicolás al Albaicín" e incluso resalta cómo en la Plataforma de Vico se marca la puerta sin nombrarla, pese a la relevancia que se le dio en la trayectoria granadina de S. Cecilio, sin embargo en el grabado de Heylan aparece ya como Hernan Roman (f.5).

"Su disposición era entre dos torres, de 6,50 por 7,35 metros de base, formando paso en línea recta, con igual largo y tres metros de anchura, cubierto por bóveda de cañón semicilíndrico, y afuera extendíase un muro, volviendo en ángulo recto hacia la derecha de quien salía, como pudo verse al excavar allí en años pasados; porque estas defensas exteriores, que serían a cielo descubierto, con la haz de la puerta y almenas, si las hubo, fueron demolidas, y sobre su cimiento fundose la muralla del siglo $\mathrm{XI}$, que arranca de allí en línea más exterior." 
"Las esquinas principales, en su parte baja; todo el pasadizo, con su bóveda, y mucho de la escalera que en él se abre para subir a la plataforma, están hechos con lajas de arenisca, cuyo tamaño medio es de 70 por 35 centímetros de cara y 9 de grueso, que se disponían en grupos de a cuatro generalmente, plantadas sobre uno de sus cantos largos, ya de cabeza, ya de llano, y pegadas con yeso unas a otras, de tal suerte que se obtenía mucha trabazón y apariencia de sillería grande; además, entre hilada e hilada suele mediar otra de lajas tendidas. La escalera susodicha cubriose haciendo avanzar mucho la última hilada, que toda es de losas de canto, y puestas encima otras de plano a modo de cobijas; en el ángulo que forma hay un dintel adovelado, como son los de las ventanas de la Mezquita de Córdoba".

Pavón (1993) da dimensiones distintas: "Está flanqueada por sendas torres distantes entre sí 4,60 m; miden 5,60 por $2,50 \mathrm{~m}$., sensiblemente inferiores a las torres vecinas del mismo muro que arrojan $6 \mathrm{~m}$. de frente por 5,54 de profundidad".

Seco de Lucena defiende la propuesta del Plano de Granada árabe de 1910 frente a lo que dice la Guía de Gómez Moreno y piensa que es un acceso perteneciente al castillo de Hernan Roman. ${ }^{38}$ Torres Balbás siempre se refiere a ella como Puerta de Hernan Román y su dependencia de Gómez Moreno parece grande.

La Bāb Qaštar reitera desde otra perspectiva la polémica del hișn Roman. Detrás de ambos términos subyace la misma idea: una fortaleza anterior al dominio islámico. Se trataría de un elemento que el grabado de Heylan identifica como puerta de dicha fortaleza y cuya denominación árabe ratificaría su origen romano. ${ }^{39}$ El hallazgo de fortificaciones ibérica y romana en 1984 sería la confirmación definitiva de dicho origen. El problema que se plantea es con qué grado de certeza se pueden proyectar las referencias textuales medievales a las estructuras que han llegado hasta nosotros. No se puede concluir que todas las teorías sobre los distintos recintos, basadas en el hișn Roman, son correctas porque ahora se haya visto que coincide con una muralla romana, pues los razonamientos que justificaron dichas teorías se referían a estructuras demostradas islámicas, por tanto evidencian un fenómeno de distinta naturaleza al que deriva de las murallas excavadas.

La Bāb Qaštar fue embutida en cemento, probablemente en las obras de |960-196| (FUENTES, 1989, p.65) lo que hace irreconocibles los elementos que justificaron su cronología. Quedan dos fotos que incluyó Gómez Moreno en el tomo III de Ars Hispaniae y otra, ya con la esquina de cantería oculta, publicada en un libro de fotografías (f.5) (GRANADA (s.f.), p.292, n³38).

\section{4. $B \bar{A} B$ AL-ASAD}

Gómez Moreno (1890, p.4 nota I) incluye "una torre en las Vistillas de S. Miguel" entre los restos correspondientes a la fortaleza del siglo VIII. En la Guía de 1892 precisa: "aquí estuvo la puerta dicha Bib Elecet o del León y después postigo de S.Miguel, de la cual subsiste el cimiento de una torre, de construcción del siglo VIII". Seco de Lucena (1974) la sitúa en el segundo momento de expansión urbana durante el siglo $\mathrm{Xl}$, ignorando que su aparejo corresponde al que describe como característico del siglo VIII. La denominación de la puerta no procede de fuentes árabes. Seco de Lucena (1975, p.38) dice no haberla encontrado

38 Cita "Bāb Qaštar (del Qastar) en el callejón de S. Cecilio, junto al Castillo de Hernan Roman". En nota desarrolla sus argumentos: "Ignoro el significado del original árabe, acaso transcripción del latín castrum. Seco de Lucena Escalada la sitúa en el lugar en que estaba la que los cristianos llamaron Hernan Roman.. G. Moreno piensa que fue el nombre árabe de la que actualmente denominamos Arco de las Pesas (Guía p.437); pero tal supuesto está en desacuerdo con documento árabe contemporáneo.. que es donde aparece citada Bāb Qaštar". (SECO DE LUCENA 1975, p.4I) Más adelante insiste: "Bāb Qaštar, acaso puerta del castro, flanqueada por los dos torreones del Castillo de Hernan Roman y de la que se conservan... una parte de la puerta y ambos torreones, en el callejón de San Cecilio" y en nota: "en todo caso el nombre del castillo no afecta al de la puerta que los árabes llamaron Bāb Qaštar"(p.I09). Llamamos la atención sobre la incongruencia que supone hablar de Castillo de Hernan Roman.

39 "...quedó inhabilitada la puerta de hișn Roman (la Castela Romana), cuyo nombre se conservó hasta los últimos tiempos de la denominación árabe en el de Bib-Caxtar, Puerta de Castro" (EGUILAZ, I88I, p.52). Ver también nota 8. 
en ningún texto, por lo que se trataría de la restitución del topónimo usado en época cristiana. La torre fue excavada en 1983 por Carlos Vílchez cuyos resultados comentamos más adelante. La documentación gráfica existente es una foto (GARCíA; MARTIN 1975) y los dibujos de la excavacion (VíLCHEZ 1984).

\subsection{CORACHA / BĀB AL DIFĀF}

El Puente del Cadí es elemento determinante en la configuración de territorio urbano, tanto por lo que implica su pertenencia a un recinto amurallado que conecta fortificaciones como por definir un casco urbano consolidado que sobrepasa la colina de la Alcazaba Cadima.

Su análisis se produce en varias fases. Torres Balbás le dedica varios estudios. Un primer trabajo (1934) distingue entre el Puente del Cadí (Qanțarat al-Qāọil) citado por lbn alJațïb en la Ihața como construido en junio de 1055, y la Bāb al-difāf recogida por al-Umarī hacia finales de la primera mitad del siglo XIV. Traducida como Puerta de los Tamboriles o de los Panderos, en nota de la redacción de la revista -sin duda García Gómez- se comenta, indicando que "Las dos traducciones son buenas. Más etimológicamente podría todavía traducirse por Puerta de los Adufes". La conclusión es que los restos conservados pertenecen a una puerta con funciones defensivas, junto a la cual habría estado el Puente del Cadí. Al desaparecer el puente, su nombre habría pasado al arco inmediato. Pese a ello, en un párrafo final se identifica como obra del siglo XI aplicándole la caracterización del puente. En el estudio de las construcciones ziríes (TORRES BALBÁS 194I) denomina sin más Puente del Cadí los restos conservados e incluso aplica a la iglesia de S. Pedro la referencia de Ibn al-āațib a una mezquita inmediata.

En 1949 regresa sobre el tema en un trabajo mucho más exhaustivo para el que contó con la colaboración de Manuel Ocaña. Pasa revista a las distintas interpretaciones dadas por la historiografía hasta ese momento y fija el origen del apelativo "de los Panderos" en la edición de 1872 de la Descripción del reino de Granada de Simonet y su reafirmación "siguiendo la ley del mínimo esfuerzo" por todos los que siguieron, salvo Eguílaz y Leví-Provençal, quien apunta significado distinto (puerta de madera). Un estudio etimológico -probablemente de Ocaña Jiménez-, se completa con el análisis funcional de la puerta para establecer una correspondencia que permite darle la nueva acepción de Puerta de los Tableros o de las Compuertas. Somete a revisión su correspondencia con el Puente del Cadí, y concluye que éste es el que tras la conquista castellana recibió la denominación "de Santa Ana", inmediato a la iglesia y desaparecido con el embovedado del río Darro en el siglo XIX ${ }^{40}$ De esta manera las referencias en la lhăța a una obra del siglo XI quedaban desligadas de los restos conservados. Su adcripción a dicho siglo se establece sólo en base a sus componentes formales. La atribución a los últimos momentos del dominio zirí se debe a su pertenencia a un recinto urbano identificado como obra de cAbd Allāh según sus "Memorias".

Seco de Lucena en su trabajo sobre las puertas de la muralla granadina en el siglo XIV (1942); sigue el criterio de Torres Balbás en 1941. Años después aborda de nuevo el problema con motivo del estudio de la qawraya que conectaba la Alcazaba Cadima con el río Darro, (1968) lo que añade un nuevo interés al entorno de la Puerta de los Tableros, apelativo ya consagrado.

El estudio de Seco de Lucena es enfocado como una justificación de los limites de la Qașabat Garnāța, hacia el Sur. Parte Seco de Lucena de las referencias en documentos de los siglos XIV y XV a un "barrio de la coracha", así como la existencia de dos mezquitas Cauracha alta y Cauracha Baja. Los estudios previos de Ricard sobre la significación del término le llevan a concluir que se trata de un dispositivo de acceso al río Darro para abastecer de agua la población asentada en la cima de la colina, y a considerarla contemporánea del primitivo recinto. Con la primera

\footnotetext{
40 El último trabajo aparecido sobre el tema es el de Antonio Orihuela (1993).
} 
ampliación zirí parte del espolón quedaría dentro del caso urbano, dando lugar a la denominación del barrio; más tarde en tiempos de Bādīs se construiría la Bāb al-Difãa ${ }^{41}$ y por último en tiempos de cAbd Allāh la muralla "que enlazaba con las fortificaciones de la colina Roja y protegía los núcleos urbanos de Ŷrra y Mawrūr". Comenta el hecho de que ya Gómez Moreno (1951) indicase la existencia de un espolón hasta el río desde la Alcazaba Vieja, pero que no llega a precisar si arrancaba del recinto zirí "o de su primitivo recinto", ignorando que Gómez Moreno rechazó siempre la existencia del segundo.

El trabajo de Seco fija un elemento condicionante en el proceso de configuración urbana en cuanto establece límites físicos entre zonas que sin duda debieron tener un proceso independiente al menos hasta que desaparece el elemento separador, sin preocuparse en exceso por las características morfológicas del dispositivo, tema que ha centrado la atención de Pavón Maldonado durante los últimos años. Su adscripción funcional al primer momento de población musulmana constituye otra novedad destacable.

La última tendencia es entender la Bāb alDifäf como resultado de la modificación de una coracha de la primitiva Alhambra. Fernando Valdés (1995) contempla la posibilidad de una subordinación funcional a la Alhambra como fase posterior, en el contexto de cierre del perímetro urbano indicado por cAbd Allāh y en consecuencia la reforma general si no la reconstrucción por completo de la estructura preexistente, es decir de la coracha urbana, para dar lugar a la Bāb al difāf tal como la conocemos. Para A. Malpica la asociación entre la Bāb al Difāf o Puerta de las Compuertas, y la muralla que baja de la Alhambra y se une a la Alcazaba, se explica para abastecimiento de la fortaleza. (1995b, p. 120)

Es claro que los restos visibles: un pasadizo en el interior de un torreón ubicado en la ribera de la Alhambra, no admiten duda. A falta de verificar si en el costado opuesto exis- tía una organización similar -el texto de alZuhrī parece indicar que así era-, la constatación del hecho nos muestra que en el problema de la coracha debemos contemplar dos momentos diferentes: a) subordinación a un núcleo inicial de población en la colina del Albaicín. b). Función al servicio de la fortaleza de la Alhambra. Si la primera es sólo hipotética y referida a un momento indefinido, anterior a las primeras décadas del siglo XI, la segunda es verificable y se iniciaría en las últimas décadas del siglo $\mathrm{XI}$.

Es importante que consideremos con atención los criterios que permiten fechar el segundo momento. La atribución de la obra al siglo XI se debió a un error interpretativo que proyecta sobre unos restos conservados unos datos de la Ihațā. Cuando Torres Balbás deshace el error, los criterios pasan a ser formales. Las Memorias de cAbd Allāh ofrecen un nuevo referente que sitúa de nuevo la obra en el contexto de los acontecimientos del siglo $\mathrm{Xl}$, aunque en momento más tardío: el cierre del perímetro urbano durante el gobierno del último zirí de Granada. Dicha proyección sin embargo, es tan subjetiva como la primera cuando se refiere a una coracha al servicio de la Alhambra. La coracha encuentra su razón de ser en la construcción y organización de una fortaleza, con independencia del grado de desarrollo de las murallas urbanas, es más, la conexión de los dos organismos -recinto urbano de la Alcazaba Cadima y Alcazaba de la Alhambraobliga a modificar su estructura, como apunta Valdés. Así que de aceptarse la existencia de una coracha, el cierre del recinto urbano atribuido a cAbd Allāh se limitaría a la puerta sobre el río y no a la muralla inmediata pues sería elemento preexistente.

Otro factor determinante deriva de la toponimia entendida como un dato significativo del proceso urbano. La distinción Coracha Baja/Coracha alta para denominar dos barrios vendría justificada por la existencia de una división física que se identifica con la muralla inmediata a la calle San Juan de los Reyes,

${ }^{41}$ La fecha se debe a que aplica a la puerta las afirmaciones referidas al Puente del Cadí contenidas en la Ihāța. 
correspondiente al segundo momento de expansión urbana. No obstante, nuestros estudios sobre el Maristan (GARCÍA, SALVATIERRA, 1986) mostraron que ya a mediados del siglo XIV no existía ninguna coracha urbana, pues sobre su recorrido montaba el hospital nazarí, que a su vez reaprovechaba una construcción anterior (GARCíA, SALVATIERRA, 1990). Pese a ello, la idea de coracha como función útil se mantenía en los primeros años de dominio castellano (GARCÍA, TRILLO, 1990); por tanto, cabe la posibilidad de que la toponimia recogida por Seco de Lucena se refiera a un hecho distinto de la supuesta coracha anterior al siglo XI.

A todo ello debemos añadir que en la configuración final de las recintos propuesta por Seco de Lucena (f.23) existe una conexión de la Bāb al difāf con el recinto del arrabal de Ajšāriš, levantado en un momento desconocido. Orihuela-Vílchez (1990) fechan en el siglo XII el cierre del arrabal, en base a un proceso teórico de expansión que no tiene que corresponder a lo sucedido en realidad. La tardía construcción de la Bāb al difāf pudo contemplar ya el amurallamiento del arrabal, en cuyo caso la función de coracha sólo tendría razón de ser en la vertiente de la Alhambra. En contra de esta hipótesis está la descripción de al-Zuhrī.

\section{LAS ALCAZABAS URBANAS}

La idea de alcazaba implica la existencia de un recinto diferenciado de la muralla urbana con unas funciones específicas.

Según Eguílaz (I88I, p.57) "Desde las fundaciones respectivas de lliberis y Granada, tuvieron cada cual de estas poblaciones sus respectivos recintos fortificados o alcazabas...La Cadima ...era la de la Urbs celebérrima de Plinio; el Alhizan, Alcala-Alhamra o el Maquil, como le llama Ben Aljatib, con sus obras avanzadas del castillo Mauror, era la de su grande arrabal Garnata".

En la versión de Seco de Lucena "A fines del siglo Xl, en tiempos de cAbd Allah, último monarca zirí, el crecimiento demográfico de
Granada había desbordado ampliamente las lindes de la vieja fortaleza en la que Zāwī, fundador de la dinastía..., hubo de establecer su corte, despues de reparar murallas que encontró desmanteladas. Esta primitiva fortaleza, construida, a lo que parece, hacia la mitad del siglo VIII y conocida entonces por hịșn Garnāța (Castillo de Granada), tenía su centro en la explanada donde hoy se halla la iglesia de S. Nicolás... los sucesores de Zāwī ensancharon el primitivo recinto convirtiéndolo en Qasabat Garnāța... y en la cerca que defendía esta ampliación...fueron abiertas otras tres puertas, Bāb al-Asad...Bāb al Hassārin... y otra cuya denominación ignoramos cerca del templo de S. Juan de los Reyes"(1975, pp.37-38). Así pues, el alcázar zirí coincidiría con el hișn Garnāța, o al menos se encontraría en su interior.

En 1966 Seco de Lucena rechaza la existencia de la al-qașaba al-ŷadīda o Nueva: "los escritores árabes que en obras literarias o históricas se ocupan de Granada, nos informan de que en esta ciudad, en tiempos musulmanes, había dos alcazabas, cada una de las cuales coronaba sendos cerros que se elevan a ambas riberas del río Darro.. la alcazaba del Albayzín (qașabat al-Bayāzīn) y la alcazaba de la Alhambra qașabat al-Hamrā). Algunos de estos escritores denominan también a la primera alcazaba vieja (al-qașaba al-qadīma), sin duda aludiendo a su más antigua fundación, porque como es sabido, la alcazaba del Albayzín fue obra del siglo Xl, ejecutada por orden de los monarcas zirieses, quienes establecieron en ella su palacio y corte, en tanto que la de la Alhambra se reconstruyó dos siglos más tarde, cuando Muhammad I el nașrī acordó trasladar su residencia a la frontera Colina Roja..". "Tanto en el cerro sobre el que se extiende el actual Albayzín, como en la Colina Roja, asiento de la Alhambra, hubo fortificaciones con anterioridad al siglo XI, las cuales, en dicho siglo, debían encontrarse poco menos que arruinadas. Al establecerse en Granada la capital de su reino, el zirī Habbūs consolidó las del Albayzín y su hijo y sucesor Bādīs completó el recinto amurallado que amparaba a sus moradores, construyendo dentro del mismo un alcázar para sede de su monarquía. A este 
recinto amurallado le llamaron primeramente qașabat Garnāța "alcazaba de Granada" y más tarde, cuando Ibn al-Ahmar trasladó su residencia a la fortaleza que hubo de reconstruir en la Colina Roja, al-qașaba al-qadíma y también qașabat al-Bayāzinn, para distinguirla de la qașabat al-Hamrā' "alcazaba de la Alhambra", como ya he indicado". En consecuencia ahora el alcázar zirí se encontraría en el ámbito de la primera ampliación urbana. (f. 28b)

En la ya larga polémica sobre las alcazabas nunca se ha introducido un elemento importante como es la construcción de "la fortaleza de la Alhambra" por el visir judío Ibn Nagrela narrada en las "memorias" de cAbd Allăh (p. $|3|$ ), hecho que, con independencia del significado que queramos darle, muestra ya desde el siglo XI la configuración urbana que se atribuye al siglo XIII, y que permite a al-Zuhrī hacia comienzos de la segunda mitad del siglo XIl hablar de una alcazaba sagîra y otra kabīra ubicadas en ambos lados del río Darro, aparte de su papel en las luchas de los años I I 45 y I I 62. En su trabajo más reciente A. Malpica (1995b) resalta los dos hechos que se deducen de las Memorias de cAbd Allāh: la Alhambra se configura "como una alcazaba, en la que se hacen obras durante toda la dinastía zirí, a lo largo del siglo XI", y la edificación de un palacio por el visir judío lbn Nagrela.

Pavón Maldonado ha interpretado la denominación alcazaba tal como se presenta en la historiografía granadina en un sentido hasta ahora inédito. En 1983 indicaba que la identificación de una alcazaba urbana con un barrio en el caso granadino constituye una anomalía de difícil explicación: "entiendo que el nombre de Alcazaba Qadinna no se aplicaría a todo el cercado del Albaicín, sino a una mínima parte de él, donde estarían los palacios de los soberanos zíries, porque es disparatado llamar Alcazaba Qadima a toda una ciudad montuosa y agregar a continuación Alcazaba de la Alhambra o Alcazaba Nueva, cuyas dimensiones nos son bien conocidas; quiero decir que se podría llenar el cercado del Albaicín con veinte o treinta alcazabas de las dimensiones de la de la Alhambra." (PAVÓN 1983, p.227). En su última propuesta (PAVÓN, 1994, p.656) el razonamiento se invierte: "Lo de aplicar el término qașaba a una madīna era, por lo visto, bastante usual en al-Andalus", de acuerdo con lo que ya avanzara en 1992: "la alcazaba o las alcazabas, además de sus funciones prácticas.. eran el símbolo del poder y encarnaban la centralidad política; de ahí que en ciertas crónicas árabes se aplique el término qașabat con el significado de capital o capitalidad, equiparándose a la madinna".

Los seis planos que incluimos (figuras 2126), a los que se podrían adjuntar el de los hermanos Oliver Hurtado y otro con lo propuesto por Gómez Moreno, resumen un siglo de discusiones. Tres elementos se discuten en ellos: I) la existencia, límites y extensión del recinto inicial, 2) el perímetro de un segundo recinto, 3) la denominación de cada uno de ellos. Este último punto es el más significativo puesto que se refiere a las fuentes textuales medievales. La contraposición de las distintas denominaciones propuestas por los autores evidencian el caos toponímico vigente. Llegamos a la conclusión de que no es posible, en base a los datos disponibles, ninguna conclusión definitiva y excluyente sobre el significado espacial de las referencias contenidas en las fuentes medievales.

\section{LA REVISIÓN ARQUEOLÓGICA}

La gran novedad que se introduce en la década de los ochenta es la incorporación de nuevos datos, producto de excavaciones arqueológicas, que permiten revisar en amplitud las distintas teorías sustentadas en la crítica filológica y en la observación de las estructuras monumentales conservadas.

Las estructuras medievales localizadas entre los años 1984 y 199| junto a la Puerta de las Pesas (Bāb al-Ziyada) (HUELVA 1993, pp.|I3-1/4) nunca han sido objeto de análisis pormenorizado ${ }^{42}$ El interés exclusivo del

\footnotetext{
42 La relación entre niveles romanos, muralla medieval, viviendas islámicas y reformas cristianas hace de esta zona el lugar donde mejor pueden estudiarse en toda su extensión y complejidad los cambios espaciales existentes en el proceso urbano granadino.
} 
equipo de investigación en la Antigüedad relegó toda la problemática concerniente a las fases medievales a un estudio posterior por especialistas ajenos al desarrollo del proyecto de investigación.

El hallazgo en la primera campaña de excavaciones de "..una torre que debe pertenecer al recinto árabe primitivo que mandó construir el vali de la provincia de Elvira, Ased ibn Abd-al-Rahman al Saybani, que murió en el año 765" (SOTOMAYOR; SOLA; CHOCLAN, 1984, p.47) vuelve a poner en juego todos los argumentos sobre una primitiva fortaleza: "El hallazgo de este torreón perteneciente a un recinto granadino anterior al del siglo XI/XII (único visible hasta ahora) plantea en nuevos términos la cuestión de los límites de la auténtica y primitiva Alcazaba Cadima... Si el recinto descubierto es efectivamente como parece, el construido a mediados del siglo VIII, cabe también suponer que su trazado coincida substancialmente con el del recinto romano de lliberri." (p.48).

Detrás de la conclusión de Sotomayor subyace toda la literatura del siglo XIX sobre el proceso de configuración de la ciudad islámica, y en especial la teoría del hiṣn Garnāța de Seco de Lucena. La tesis de que pudiera ser obra del siglo VIII se apoya en lo mantenido por Gómez Moreno en los Monumentos romanos de 1890. Un correcto conocimiento del estado de la cuestión hubiera conducido a aplicar el criterio analítico de Torres Balbás y fechar el hallazgo hacia finales del siglo $X$ comienzos del XI. Para nada hay que referirse al hișn estatal del siglo VIII, pues lo mismo pudiera haberse citado el hișn Garnāța. Lo correcto, a nuestro entender, hubiera sido revisar en profundidad los distintos criterios usados hasta el momento para distinguir fases en el proceso de configuración de la ciudad durante el siglo XI, sin embargo bajo el supuesto basado en los Monumentos Romanos se ha desarrollado la interpretación de los hallazgos y la teoría alcanza rápidamente una extraordinaria difusión.

No se trata sólo de las estructuras propiamente dichas sino del espacio que definen. Hasta ahora se creía en la sustitución de las estructuras más antiguas por otras nuevas, sin que se modificara la superficie abarcada, tal como muestra el plano de Seco de Lucena (f.23). Los lienzos Oeste y Sur del supuesto núcleo inicial se ubicaban en base a las inflexiones visibles en el recinto del siglo XI, interpretadas como ajustes con las estructuras sustituidas, pero la excavación ha mostrado que el primer recinto es independiente de las murallas posteriores, invalidando cualquier deducción efectuada en base a las mismas.

Si nos atenemos a los distintos textos elaborados por el equipo de investigación en los años 80 , no se produce ninguna novedad que modifique las conclusiones de 1984. En 1987 se reitera la teoría de Sotomayor: "los cortes efectuados habían evidenciado la existencia... de una torre perteneciente a un recinto árabe anterior al del siglo XI-XII, quizá de mediados del siglo VIIII" (ROCA; MORENO; LIZCANO, 1987,p.40). En 1988 se remite de nuevo a Sotomayor, a pesar de que se reconocen tres fases constructivas en la muralla, sin duda anteriores a la torre a ella adosada; dato suficiente para proponer la permanencia de la población hasta el siglo VIII. Además se elabora una hipótesis sobre los límites y organización de la ciudad romana (ROCA; MORENO; LIZCANO, 1988, pp.63-70) que de manera implícita recupera el primitivo hișn Garnāța identificado con el solar de la ciudad romana.

La última fase de las investigaciones, iniciada en 199|, se ha caracterizado por la dispersión de criterios. ${ }^{43}$ En cuadro ofrecemos nuestra propia interpretación.

\footnotetext{
43 Un solo dato sobre la situación existente: Investigaciones arqueológicas en Andalucía. 1985-1992. Proyectos. Huelva 1993. Proyecto: "La ciudad iberorromana y medieval de Granada". En el listado de presupuestos y bibliografía (p. II3) figuran como directores Mª Auxiliadora Moreno Onorato, Antonio Malpica Cuello y Juan Antonio García Granados. En el texto resumen Consideraciones generales (pp.66I-668) se indica la primera fase bajo la dirección de Mercedes Roca Roumens y Auxilio Moreno Onorato y la posterior "ampliación de los objetivos originales y la integración en la dirección del proyecto de Margarita Orfila Pons, Antonio Malpica Cuello y Juan Antonio García Granados". El texto va firmado por Ma Auxiliadora Moreno Onorato, Antonio Burgos Juarez y Pablo Jesús Casado Millan. Sobran los comentarios.
} 


\begin{tabular}{|c|c|c|}
\hline \multicolumn{3}{|c|}{$\begin{array}{c}\text { PRIMITIVA MURALLA DE GRANADA } \\
\text { Secuencia constructiva (según García Granados) }\end{array}$} \\
\hline HECHO MATERIAL & HECHOS ACCESORIOS & CARACTERÍSTICAS \\
\hline I. Muralla ibérica & & Grandes mampuestos.Sillarejos \\
\hline 2. Muralla romana & & Sillería de piedra de Alfacar \\
\hline 3. Reforma tardorromana/altomedieval & & $\begin{array}{l}\text { Mampostería encintada con } \\
\text { reaprovechamiento de piezas } \\
\text { monumentales arquitectónicas }\end{array}$ \\
\hline 4. Reforzamiento altomedieval & & $\begin{array}{l}\text { - Esquinas de ladrillo y lajas } \\
\text { de piedra de La Malá } \\
\text { - Lienzos de mampostería con } \\
\text { verdugadas de piedra de La Malá }\end{array}$ \\
\hline 5. Adosamiento de torres & & $\begin{array}{l}\text { - Tapial con mampuestos } \\
\text { - Esquinas de ladrillo y lajas de } \\
\text { piedra de La Malá } \\
\text { - Separación horizontal de las } \\
\text { tapias con líneas de ladrillo }\end{array}$ \\
\hline & $\begin{array}{l}\text { - Construcción del recinto interior. } \\
\text { (Aparece el foso entre murallas) } \\
\text { - Canalizaciones de agua en el foso }\end{array}$ & \\
\hline $\begin{array}{l}\text { 6. - Reconstrucción de torres interiores } \\
\text { - Restauración zona alta del torreón }\end{array}$ & & $\begin{array}{l}\text { - Tapias de arcilla de poca cohesión } \\
\text { - Mampostería encintada }\end{array}$ \\
\hline 7. Pérdida de funciones militares & $\begin{array}{l}\text { - Adosamiento y superposición } \\
\text { de construcciones } \\
\text { - Relleno del foso }\end{array}$ & \\
\hline
\end{tabular}

El período medieval de la muralla descubierta (ROCA, MORENO, LIZANO, 1987, 1988) muestra -en nuestra opinión- al menos cuatro fases. La más antigua se caracteriza por el uso de piezas arquitectónicas de acarreo en un aparejo de mampostería pseudoencintada; la siguiente, por el uso de piedra de La Malá en las cintas de los cajones. Como la muralla exterior del siglo XI muestra técnica distinta y en ninguna otra obra granadina, islámica o posterior, se encuentra dicho aparejo nos inclinamos a que debe ser anterior al siglo $\mathrm{XI}$. La similitud entre la fase siguiente -definida por dos torreones con esquinas de lajas de piedra de La Malá, según el tipo de la Bāb Qaštar ${ }^{44}$ - y otros restos visibles en el extremo Oeste de la colina indica que el recinto pertenece ya a una población. Más tarde, dos torreones serán reconstruidos y otro sufrirá una restauración, sin que sea posible establecer el orden cronológico de dichas intervenciones.
El estado actual de las investigaciones permite valorar las teorías historiográficas en un doble sentido:

A. La idea del hișn Roman se basa en la pervivencia a comienzos del siglo XVII de un recinto interior cuya adscripción cronológica se basará en una supuesta técnica constructiva fenicia.

B. Existió una fortificación ibérica rehecha en época romana y al menos en otras tres ocasiones antes de la construcción de otra muralla exterior, que no aprovecha las estructuras preexistentes, donde se abren las puertas de Las Pesas y Monaita.

Las estructuras excavadas permiten reconstruir el recinto correspondiente a la Bāb Qaštar, interrumpido por la construcción del Arco de las Pesas, y hacen comprensible la

44 No se ha publicado el alzado del segundo torreón descubierto, cuyo aparejo de piedra de La Malá en las esquinas establece correspondencia más clara con la Bāb Qaštar, al tiempo que prueba la variedad de formas que adoptó dicho aparejo cuando es parte accesoria en estructuras de tapial. 
planta que Gómez Moreno incluye en sus Monumentos Arquitectónicos.. (f. I7) y, por otro lado, se relacionan con los restos del Portillo del León (Bāb al-Asad). Se define así un complejo al que se debería aplicar la cronología propuesta por Torres Balbás.

El portillo del León ha permanecido visible, aunque semienterrado, y fue excavado en I 983 por Carlos Vílchez (VílCHeZ 1984). Las conclusiones publicadas de dicha intervención son las siguientes: "Don Manuel Gómez Moreno González en su Guía afirma que el torreón es de época califal -entiéndase emiral- basándose en la cimentación de cantería, es decir, que sería parte de la cerca del primitivo recinto amurallado que construyó el Wali de Ilbira Asad ibn Abd al-Rahman al-Saybani, en el siglo VIII (GÓMEZ MORENO 1982, p.54I). Don Luis Seco de Lucena Paredes hace una clara diferencia entre los núcleos fortificados según las denominaciones que halla en los textos árabes, y de la primera hișn Garnāța y la Qașabat Garnāța pasa a la definitiva al-Qașaba al-Qadima, nombre que surge para diferenciarla claramente de la al-Qașaba al-Hamrā' (1975 pp. 108,123 y 124). Sin embargo las últimas excavaciones, léase las realizadas por el padre Sotomayor (1984, pp.105-106), han venido a corroborar una idea que estaba en la mente de los que nos ocupamos del Albayzín, esto es, que las distintas reformas llevadas a cabo desde el siglo VIII en adelante han guardado en general una estructura amurallada que no se amplía en el siglo XI con los ziríes (subrayado nuestro) sino que aprovecha algunos lugares para hacer una doble muralla paralela. Este es el caso de la zona Norte de la Alcazaba desde la bāb al-Unaydar o puerta Monaita hasta la bāb al-qaštar, pasando por la reforma posterior que supuso la construcción de la bāb al-Ziyada o arco de las Pesas en la época almorávide (TORRES BALBÁs 1952)".

La limpieza efectuada por Carlos Vílchez permite conocer en toda su amplitud una estructura dada a conocer por nosotros (GARCÍA; MARTíN 1975)(f.I 3) que junto con los restos de otro torreón en el interior de la Casa de la Lona (f. I 8) definen un espacio ocupado hasta el borde Oeste de la colina, dife- rente del reconocido a la ciudad romana. En consecuencia, quienes mantienen una cronología entre los siglos VI al VIII para el recinto descubierto, deben reconocer la ruptura con la teoría basada en el hișn Garnāța que defiende Seco de Lucena.

En 1990 A. Orihuela y C. Vílchez reafirman la teoría del hișn Garnāța como núcleo fortificado en torno a la Plaza de S. Nicolás; construido en el emirato omeya, la razón de su existencia sería mantener sometida a una población autóctona que ha sido desalojada del núcleo urbano. Desde el primer momento dicha fortaleza se enfrenta a una primitiva Alhambra, que surge dentro de un conflicto entre autóctonos y árabes. En el siglo $X$ una tercera fortaleza, hiṣn Mawrur, se construye para vigilancia y defensa de un barrio judío "extramuros" de la ciudad. El Hișn Garnāța "no se conforma todavía como una medina árabe propiamente dicha, con sus elementos típicos, sino que tendría todo el aspecto de una alcazaba... Al estar asentada sobre ciudades precedentes (ibérica, romana y visigoda), sí tendría algunas viviendas utilizadas por la guarnición, aunque no sabemos en qué estado se conservaría, pero imaginamos que en completa ruina" (p.16). El perímetro del hișn sería la muralla de la ciudad romana (f.26).

Según Orihuela-Vílchez, con Zāwī Ibn Zīīi (1012-1019) "comienza la reconstrucción y reforma del hiș̣n Garnāța, que pasa ahora a denominarse Qașabat Garnāța." como ampliación del primer recinto. Como tal alcazaba aloja el palacio de los gobernantes ziríes. La Alhambra se configura "como fortaleza de entidad en la etapa de Badis cuando el visir judío Samuel Ibn Nagrela fortifica en la colina de la Sabika". Hișn Mawrür permanece como elemento de control del barrio judío. Al final del período las distintas fortalezas se enlazan con la muralla de la ciudad.

Para Malpica las excavaciones en el Carmen de la Muralla "Aparte de diferentes horizontes anteriores al mundo árabe, están poniendo de relieve la evolución én época medieval. Uno de los problemas que se plantea y que está en fase de resolución es la exis- 
tencia de una muralla anterior a la hoy visible. Los torreones descubiertos ponen de manifiesto que hubo una importante modificación en este conjunto hasta ahora no suficientemente evaluada. Téngase en cuenta que aún no ha avanzado mucho el estudio de la cerámica aunque parece de un primer examen que no la hay de época anterior al siglo XI. ¿Sería la primitiva muralla de ese siglo y la hoy visible de época inmediatamente posterior, con motivo de una transformación no conocida, pero importante? iSe trata de una muralla anterior al siglo Xl y la que emerge es la zir?. Estas preguntas han de ser resueltas a partir del análisis arqueológico" (MALPICA 1992, p.93). ${ }^{45}$

Respecto a las estructuras asociadas "Se ha señalado que allí estaba el hișn al-rumān, o castillo del granado, por la versión que da Mármol, considerándolo uno de los vestigios más importantes de una muralla anterior al mundo zirí. No hay por qué desechar la idea de algún in anterior al siglo $\mathrm{Xl}$, pero es preciso apoyarse en pruebas arqueológicas, ya que los textos son confusos. Aquellos que hablan de una Granada más antigua son fundamentalmente posteriores a esa época."(p.93). ${ }^{46}$

La solución del problema en el caso de las excavaciones comentadas, a nuestro entender, no puede apoyarse en los materiales cerámi$\cos ^{47}$ No existe conexión entre la estratigrafía correspondiente a los niveles de construcción de la muralla y los medievales interiores que se han podido reconocer. ${ }^{48}$ Bien se trate del siglo VIII o de comienzos del siglo Xl, su construcción se produce sobre niveles de asentamiento antiguo y en el estado en que ha sido posible analizar el contexto arqueológico -que no era el más adecuado- no existe continuidad entre la muralla y una vivienda medieval inmediata con varias fases de uso.

La "solución arqueológica" en lo referente al contexto del Carmen de la Muralla sólo decidirá entre dos opciones planteadas hace tiempo por la historiografía: a) existencia de un primer recinto medieval apoyado en el perímetro de la ciudad romana; que algunos atribuyen al siglo VIII, sustituido en el siglo XI por otro más avanzado (SECO DE LUCENA 1974); b) construcción de un recinto a comienzos del siglo XI sustituido en época almorávide por otro con dos puertas en sus extremos Monaita y de las Pesas que definen un nuevo tipo (TORRES BALBÁS, 1941,1952). En ninguno de los casos habría poblamiento anterior y los depósitos cerámicos siempre daran fechas post quem. ${ }^{49}$

El único investigador no granadino que ha introducido en un trabajo los datos de las excavaciones de la primitiva muralla ha sido Basilio Pavón. Afirma en síntesis:

\footnotetext{
45 Las dudas se extienden a todo lo relacionado con el poblamiento de la zona: "cabe suponer asimismo, pues no podemos pasar de la conjetura hasta que no se lleve a cabo un estudio pormenorizado de los conjuntos cerámicos procedentes de las excavaciones del Albaicín, que hubiese un asentamiento en la colina situada a la derecha del Darro, y que fuese sucesor del ibero-romano" (MALPICA 1995a, p.87).

46 Completamos la cita: "Para Gómez Moreno aquí estaba una puerta llamada de Hernán Roman, porque allí cerca tenía en 1537 unos huertos un indivíduo llamado así. La construcción de la capilla en el siglo pasado la ha modificado y no la deja ver claramente. En medio de la muralla de tapial que continúa por esta parte había otra. Es una puerta en recodo, como la anterior. Debe tratarse de la Bāb al-Qaštar, citada en la crónica árabe que describe el final del reino granadino."(MALPICA, I992 p.93)

47 En el Carmen de la muralla y en el solar de la comunidad musulmana apareció cerámica verde y manganeso, tanto figurativa (una liebre) supuestamente representativa de Elvira, como epigráfica (al-mulk) que algunas opiniones atribuyen a talleres cordobeses. El período zirí abarca en Granada desde 1010 hasta 1090. El primer núcleo de población, supuestamente alojado en la zona inmediata a las excavaciones, procedería de madīna Illīira. ¿Qué criterios deberían usarse para distinguir la cerámica correspondiente al núcleo inicial de la nueva ciudad durante las primeras décadas del siglo XI de la propia de un asentamiento del siglo $X$ en el mismo lugar?. Recordemos una afirmación a propósito de los hallazgos en la girola de la catedral de Granada (MALPICA, 1994, p.200): "... aunque hay piezas seguramente del siglo $X$, las cronologías con que operamos en la cerámica medieval no son tan ajustadas como para permitir una distinción tan precisa entre éste y el siglo Xl."

48 Insistimos en algo que ha pasado desapercibido. En la zona interior de la muralla aneja al torreón descubierto por Sotomayor habría sobre los niveles romanos, según Mercedes Roca, "un relleno con abundante material cerámico, formado por aportaciones en momentos muy diversos, pero siempre de época moderna"(|987, p.5 I). Sin embargo, a continuación se añade: "Dentro se pueden identificar con claridad piezas fechables en el siglo XII" (p.5I) lo que no coincide con la primera afirmación. Las conclusiones del informe sobre los materiales que entregamos a la dirección del proyecto se recogen más correctamente en el segundo trabajo: "el conjunto de fragmentos obtenidos en la zona no sobrepasa una cronología almohade" (I988, p.53).

49 A este respecto son significativos los datos que disponemos. Gómez Moreno (1907) ya observó la notable presencia de cascajo romano en la construcción de las torres. En la excavación de 1984 se comprobó que las tapias que constitúan el macizo de la zona alta de la torre identificada contenían exclusivamente materiales ibéricos y romanos (SOTOMAYOR; SOLA; CHOCLAN I984)
} 
I. Existió un hiṣn Garnāța en el siglo X que corresponde al hișn Roman de Luis de Mármol.

2. En el siglo XI se amplia y pasa a ser alcazaba. Es lo que se denominará más tarde alcazaba Cadima.

3. La muralla descubierta en el tramo inmediato al Arco de las Pesas es preislámica. Sobre ella monta la muralla islámica correspondiente al primer recinto.

4. La muralla descubierta confirma el perímetro de la alcazaba Cadima propuesto en el Plano de Granada árabe de 1910.

Se atribuye la puerta de Hernan Roman al hișn Garnāța que al menos se fecha en el siglo VIII. Se alude a Eguílaz, a Pocklington y al Gómez Moreno de la Guía de Granada y a la posible datación en época visigoda, efectuada en 1907 por este último y reiterada en 1951 , aunque se omite que no son razones técnicas o morfológicas sino de oportunidad histórica las que llevaron a dicha propuesta.

Pavón sabe que la puerta de Hernan Roman (Bāb Qaštar) constituye la clave del primer recinto, pues es la única estructura que conserva en alzado suficientes elementos susceptibles de ser analizados en sus aspectos formales. Reconoce asimismo la incompatibilidad entre lo que hasta ahora mantenían los investigadores y lo que evidencian las excavaciones, si se acepta la fecha del siglo VIII para la muralla descubierta, por ello revisa los criterios que fechaban la puerta para ajustarlos a los datos proporcionados por las excavaciones, según la interpretación del equipo investigador ya que la muralla excavada desde 1984 necesita ser incorporada al proceso de "ondas expansivas" que van delimitando el territorio urbano.
Establece Pavón dos modalidades en el aparejo reconocido como característico del siglo XI granadino desde que lo fijara Torres Balbás, quien propuso una cronología en función de los aparejos cordobeses: "el aparejo en el que alternan sillares de frente con grupos de cuatro y cinco de tizón, como en la torre de S. José y en la parte inferior -única visible- de la puerta de Hernan Roman, no aparece en Córdoba hasta la época de Almanzor, de modo que en la provincial Granada no puede suponerse anterior" (TORRES BALBÁS 1941, p.442 nota I), aunque años más tarde puso en duda la dependencia granadina: "En Córdoba los muros en los que alternan un sillar de frente con tres o más de canto no son anteriores a Almanzor, pero en Granada ignoramos si ocurría lo mismo" (TORRES BALBÁS 1957b, p.605). También apuntó la posibilidad de que entre las construcciones de la antigüedad granadina hubiese paramentos de cantería almohadillada, lo que podría implicar "copia" de modelos locales. La intuición de Torres Balbás está demostrada: la portada exterior de Puerta Monaita tiene sillares romanos almohadillados, siendo un caso más de uso de elementos romanos en edificios ziríes.(f. I6)

Piensa Basilio Pavón que Torres Balbás se equivocó al asociar todos los ejemplares granadinos dentro de un mismo período, hacia finales del siglo $X$. Distingue entre uno de los aparejos visibles en la Puerta de Hernan Roman (f.7) asociado al puente del río Genil, la puerta de Elvira y unos supuestos restos de la Bāb al-Bunūd, incluso "algo se ve en el interior del Bañuelo", y el de los alminares del siglo XI. Remonta hasta las excavaciones del siglo XVIII para definir una técnica constructiva local, originada en la Antigüedad, frente a la cordobesa de los alminares. Considera la muralla descubierta obra preislámica "dada la profundidad de este muro" 50, caracterizada por "fajas... estrechas de mampostería entre

\footnotetext{
50 Las excavaciones habrían puesto al descubierto "una muralla en cimientos" que tendrían más de seis metros de profundidad. "Dada la profundidad de este muro debió ser levantado en época preislámica asentándose sobre él la muralla árabe del primitivo recinto con sus puertas de Hernan Roman y Bāb al-Bunūd. De aceptarse esta tesis, la muralla de tal recinto islámico iría por la calle de las Minas hasta la del Pilar Seco, dejando dentro aquel foro romano del huerto de Lopera y el aljibe del Rey. El muro seguiría en dirección Sur para torcer entre el callejón de las Tomasas y las calles de Trillo y del Aljibe y desde el estremo de esta última buscar la puerta de Bunud y la de Hernan Roman... En conclusión, creo que el muro de la calle de las Minas viene a confirmar el perímetro de la alcazaba qadima defendida por los hermanos Oliver y más tarde por Seco de Lucena padre, en su plano del año 1910" (PAVÓN 1994, p.659).
} 
verdugadas de ladrillo"... "La alternancia de lajas planas y dos y hasta cinco colocadas de canto, a modo de tizones, entre hiladas de otras tendidas que figuran en los paramentos del puente sobre el río Genil, evocan muy de cerca las fajas estrechas de mampostería cajeada o "cloisons" de origen tardorromano y bizantino popularizadas luego en iglesias medievales griegas y mezquitas otomanas... si bien en estos casos los cantos puestos de pie y las hiladas horizontales son de ladrillo, conforme se alcanza a ver en ciertos muros de las alcazabas de Almería y Málaga que se fechan en el siglo IV/XI. Estas mamposterías reaparecen en zona toledana, quizá a partir del siglo IV/X..."; pese a la ambigüedad de las referencias se insiste: "..El paramento, con fajas estrechas de piedra o mampostería e hiladas horizontales de piedra o ladrillo con piezas intercaladas puestas de pie, es un concepto arquitectónico que nace en la arquitectura tardorromana y la bizantina; es un concepto distinto al aparejo de sillares aparejados a soga y tizón que desde Córdoba penetraría en Granada a través de los alminares de la mezquita de San José y de la Mayor del Llano". Con estos argumentos se justifica la atribución al hiṣn del siglo VIII-X de unas estructuras que hasta ahora eran indudables de finales del siglo $X$ o comienzos del Xl.

La distinción de aparejos que se introduce carece de sentido pues ambas modalidades se encuentran en la misma estructura -Bāb Qaštar- y fase constructiva. La supuesta tradición local se apoya también en una premisa arbitraria: la identificación como obra romana de unos aparejos descubiertos en las excavaciones del siglo XVIII, cuando al referirse a ellos los excavadores pretendían probar la existencia de edificios semejantes a las obras "fenicias" descritas por Luis de la Cueva y Bermúdez de Pedraza, que no son otras que las islámicas del siglo $\mathrm{XI}^{5 !}$.
En las estructuras excavadas (ff. 10 y $\mid \mathrm{I}$ ) -que no son cimientos-, existen tres modalidades de mampostería encintada, aparte de otras de ladrillo y de tapial, y no sabemos con exactitud a cual de ellas se refiere Basilio Pavón. La comparación con Puerta Monaita es el único dato que podemos valorar. Para Basilio Pavón (1994, p. 662) "esta mampostería (de puerta Monaita) y la que ha aparecido en la muralla de la calle de las Minas son las más antiguas de Granada". Tanto la zona alta del torreón excavado por Sotomayor en 1984 (f.l 0$)$ como el aparejo de Puerta Monaita son reformas tardías. Con mucha probabilidad corresponden al mismo momento de reconstrucción que los torreones del lienzo Norte de la Alcazaba de la Alhambra (PAVÓN, 197I. p. 31).

Es cierto que por motivos estratigráficos podría distinguirse una fase altomedieval probablemente preislámica, como indicamos en la secuencia constructiva propuesta, pero corresponde a un pequeño fragmento de lienzo, insuficiente para extraer conclusiones generalizadoras.

¿Qué sucede si a los torreones descubiertos se les aplica la fecha que Torres Balbás propone para la Puerta de Hernan Román/Bāb Qaštar?. Implica que el recinto de una ciudad romana, que aprovecha elementos ibéricos, con reformas bajorromanas, es reaprovechado a comienzos del siglo XI para construir el recinto de la nueva ciudad añadiéndole torreones y una puerta que definen un espacio hasta el borde Oeste de la colina, como prueba la Bāb al-Asad. Dichas obras, efectuadas con cierta premura, se asientan en la parte alta de un barranco muy inestable, con cimentación muy débil, como han evidenciado las excavaciones, y en un segundo momento son sustituidas por una cerca que se levanta desde la base del barranco sobre una poderosísima cimentación. Todo ello con-

5 I El argumento retoma lo que expusiera Torres Balbás en 194I (p.435 nota I): "En un informe pericial del edificio descubierto en la Alcazaba de esa ciudad, escrito en 1760 por el arquitecto don Diego Sánchez Sarabia y publicado por Medina Conde en su obra cartas del Sacristan de Pinos de la Puente (|76|, carta 3a, p.|53), se dice que las losas halladas en esa ocasión, de más de cinco palmos por tres, tenían sus juntas primorosamente labradas; de la misma manera de construcción, aunque con muy dificultosos enlaces, y usando yeso en lugar de estuque, eran la torre de S. José y el castillo de Hizna-Roman (se cita los Monumentos romanos y visigóticos de Granada, de Gómez-Moreno pp.23-24, n.5)". Pavón remite para los datos sobre las excavaciones del setecientos a los hermanos Oliver Hurtado ( 1875 ) y a Gómez Moreno (1890). Los textos esenciales sobre el tema son los de Manuel Sotomayor (1986 y 1988), a los que debemos añadir el importante trabajo de Delfín Rodriguez (1992). 
firma la naturaleza de la segunda muralla construida en el siglo XI y justifica el orden de las sucesivas reconstrucciones en la línea planteada por Torres Balbás (ver nota 36).

Los análisis de Basilio Pavón no añaden un solo argumento a los datos conocidos desde hace tiempo sobre la extensión y perímetro de un hipotético recinto de la Alcazaba Cadima. Para explicar el proceso se elige una argumentación basada en la Guía de Granada de Gómez Moreno (1892) en vez de los Monumentos Arquitectónicos de 1907. En el segundo texto se defiende para el recinto más antiguo un perímetro que abarca toda la cima de la colina y la que considera denominación correcta de la puerta de Hernan Roman: Bāb Qaštar, que no corresponde al Arco de las Pesas como afirma Pavón remitiendo a la Guía. La propuesta de Pavón corresponde al trazado propuesto por Roca Roumens y Vílchez Vílchez en el Plan Especial de Reforma Urbana del Albaicín y, como el propio Pavón señala, a la propuesta de 1910 de Seco de Lucena Escalada, ignorándose ahora lo que dijera Gómez Moreno en 1890 cuando identifica como partes correspondientes al primitivo recinto elementos que superan en mucho la superficie indicada, como hemos comentado más arriba. Sin embargo, la aplicación de la tesis de Torres Balbás a la muralla descubierta define el recinto inicial del siglo XI con una extensión que no corresponde ni al supuesto in Garnāța ni a la hipotética superficie de la ciudad romana.

\section{INTERPRETACIONES HISTORIO- GRÁFICAS Y MODELOS URBANOS}

Hasta ahora hemos mantenido el sistema de discursos paralelos que caracteriza la historiografía sobre Granada. La individualización de complejos estructurales y espaciales supone entrar en el juego positivista donde la acumulación de elementos evidenciaría una realidad de orden superior: los hechos urbanos correspondientes a las distintas épocas estudiadas. El resultado es que el proceso de desurbanización en la transición del mundo antiguo al medieval se presenta como un vaciado del núcleo principal para constituir núcleos periféricos fortificados $y$, en estricta continuidad con esta propuesta, los primeros tiempos islámicos muestran tres fortalezas, en el mejor de los casos. Parece claro que no se ajustan a los modelos conocidos de organización urbana para los períodos indicados.

En este último apartado queremos sintetizar las distintas propuestas historiográficas desde una posición metodológica diferente: Desde la consideración de los modelos urbanos $y$, en general, de estructura del territorio aplicables a cada momento histórico, con especial atención a los criterios que nos permitan identificar una problemática potencialmente resoluble por vía de la investigación arqueológica, según el principio de que la calidad de la investigación arqueológica no depende sólo de la calidad del trabajo de campo, sino que no menos importante es basar el programa de investigación en una problemática claramente formulada desde el principio, expresada en hipótesis y propuestas de explicación que puedan ser verificadas empíricamente en el transcurso de la investigación.

Nos parece claro que buena parte de las teorías vigentes tienen su origen en los siglos $X V I$ y XVII. Se añade a ello que la tradición historiográfica del siglo XIX nos ha legado una serie de afirmaciones donde se confunde la información de las fuentes medievales con la interpretación fuertemente ideologizada del momento. El arrabal judío como entidad diferente de la población antigua se debe a la idea de un predominio del cristianismo en la zona y a la proyección de la judería del siglo $\mathrm{XV}$, según la referencia de Münzer, a los primeros momentos medievales. Al ser los judíos una minoría, las referencia a su asentamiento no podrían extenderse a la población principal sino a un núcleo específico, barrio o arrabal, hecho que vendría favorecido por la topografía del territorio granadino. El perverso-judío debe estar siempre en recintos separados bajo control militar; el resto de la población autóctona mayoritaria -mozárabe- no preocupa. Bajo este principio el texto de al-Rāzī es utilizado de forma tendenciosa en contra de lo que otras fuentes, como el Ajbār Maŷmūca, 
afirman. La acepción del hịșn Garnāța como fortaleza para controlar un asentamiento judío es una invención basada en la existencia de dos núcleos de población simultáneos de distinta etnia y una caracterización de la población judía absolutamente aberrante. ${ }^{52}$

En resumen, las distintas corrientes historiográficas han afrontado el problema del proceso urbano granadino desde tres posiciones diferentes, donde la muralla se entiende como significante del modelo urbano y de su proceso diacrónico:

I.- Como evolución del núcleo originado en la Antigüedad. Establece una permanencia de la población hasta la llegada de los musulmanes.

2.- Derivada de las fuentes árabes. Desarrolla sus argumentos en torno al in Garnāța entendido como una realidad distinta de la ciudad romana.

3.- Desde la consideración de Granada como ciudad fundada ex novo en el siglo XI. Es la reciente propuesta de Antonio Malpica.

Fuera de las argumentaciones contrarreformistas y decimonónicas, la consideración de las primeras estructuras de fortificación como obra anterior a lo islámico tendría su apoyo en Gómez Moreno, quien las atribuye a época visigoda, no por las estructuras en sí, sino por la necesidad de ajustar los distintos grupos diferenciados a los respectivos acontecimientos que justificaban su construcción. En un primer momento (1890) dice que son del siglo VIII porque piensa que se trata de la fortaleza del wali de llbīra. Como más tarde la ubica en la alcazaba de la Alhambra, ya que los acontecimientos del siglo IX se refieren a ella como cosa vieja que es necesario reconstruir, no queda ocasión que justifique una fortaleza islámica en la colina del Albaicín, y pasa los restos allí visibles al contexto visigodo. Siempre se refiere al recinto que más tarde se conocerá como Alcazaba Cadima.

El hișn Garnāța, indicador de un núcleo de población judío, sería el ejemplo más significativo de un proceso de encastillamiento que enlaza la época visigoda con el primer momento islámico. Las argumentaciones específicas que ha generado se han proyectado después sobre la interpretación general del proceso urbano. En síntesis, el hișn Garnāța ha sufrido el siguiente proceso interpretativo:

a.- Se parte de la judería del siglo XV y en base a su ubicación de piensa que forma unidad topográfica con Torres Bermejas, que sería la fortaleza de la Garnāța al-Yahūd.

b.- Gómez Moreno rechaza el arrabal. La referencia de al-Rāzī identificaría una ciudad fortificada, la comunidad judía formaría parte del núcleo principal de la ciudad y la alcazaba de la Alhambra sería la fortaleza de referencia, permaneciendo la población autóctona en su lugar.

c.- Seco de Lucena propone un desalojo del núcleo urbano, que adquiere funciones militares mediante la construcción de la fortaleza (hișn) en el siglo VIII, que recibiría el nombre de Garnāța. Aunque no se dice abiertamente en ninguna parte, existe una razón por la que Seco no identifica el hiṣn Garnāța con Torres Bermejas, y es porque piensa que éstas son la Alhambra del siglo IX, por tanto, descartada la alcazaba de la Alhambra actual, donde no habría nada, sólo queda la antigua población romana para situar el hișn. Hoy, alguien podría completar esta tesis incorporando al paisaje el hișn Aštiban en el lugar de la alcazaba alhambreña. Seco de Lucena mantiene la existencia del barrio judío topográficamente diferenciado.

\footnotetext{
52 "La tenebrosa conjuración tramada por aquella raza desleal diez y siete años antes de la invasión musulmana con objeto de asesinar a Egica y hacer de España un Estado judío independiente, obligó al gobierno visigodo a adoptar todo linaje de precauciones para evitar que aquella ralea, grandemente propagada por tierras de España, consumara, puesta de acuerdo con la gente árabe que dominaba al Africa, su perdición y ruina. No otra explicación tiene a nuestros ojos el fenómeno de no encontrarse judíos en nuestras poblaciones del litoral al ser conquistadas por los árabes, y el que en las ciudades del interior habitasen arrabales separados de los grandes centros de población bajo la inspección y vigilancia de numerosas guarniciones, que espiando sus tráfagos y manejos, pudieran sofocar cualquier amago de insurrección. Este fue el motivo de que el presidio godo se hallase, cuando fue sitiada lliberis por los árabes, en la Alcazaba de Granada, llamada por Rasis la villa de los judíos.." (EGUILAZ I 88 I, p.45, nota I).
} 
d.- Por último, se mantiene que el hișn Garnāța, identificado con la fortaleza del siglo VIII, corresponde con el recinto de la ciudad romana en base a la interpretación de las excavaciones arqueológicas realizadas.

Entendido el hiṣn Garnāța como fortaleza, las distintas localizaciones que recibe corresponden a las opciones historiográficas correspondientes: Torres Bermejas (la mayoría de los autores del siglo XIX y primeros años del $X X$ ); La primitiva Alhambra (Gómez Moreno, Torres Balbás, Gallego Burín); el recinto de la ciudad romana reformado (Seco de Lucena, Roca Roumens, Orihuela-Vílchez)).

La idea de Torres Bermejas como fortaleza no se apoya en datos positivos. La tipología arquitectónica no corresponde a la supuesta época de fundación. Lo que vemos hoy es una construcción nazarí. Los aparejos que sustentan la antigüedad de la construcción serían relacionables con el siglo XI -si no son restauración de época cristiana pues su carácter actual lo adquiere a finales del siglo XV (MALPICA,A:; BERMÚDEZ.j. 1995)- y no es argumento suficiente para concluir una fortaleza autónoma en vez de una estructura más o menos desarrollada perteneciente al recinto urbano levantado entonces. Cualquier consideración sobre el tipo existente antes del siglo XIV se limita a hipótesis que requieren una investigación sobre el terreno nunca efectuada.

El origen de la Alhambra en el siglo IX, obra de Sawwār ibn Hamdūn, ha sido presentado recientemente como producto de las intenciones feudalizantes de un señor que aspira a dominar un amplio territorio, lo que le lleva al enfrentamiento con el emirato omeya y la vecina Pechina. Sawwār crea un sistema de fortalezas que incluyen Wadi-As (Guadix), Basta (Baza), Mentesa (La Guardia) y penetra en la kūra de Jaén (ACIEN 1992); por tanto existe un sistema defensivo que por su origen debe poseer ciertas homogeneidades formales $y$ constructivas, así, las alcazabas de Guadix ${ }^{53}$ y
Baza son referentes esenciales para el estudio de la primitiva Alhambra. En cualquier caso, su tipología, si nos atenemos al criterio de Acién Almansa, tendría cierta complejidad espacial propia de los ummahāt al-husụunn, pues hay referencia a que acogen "buen número de pobladores, alcazabas y arrabales", expresión que Acien asimila a la existencia de diferencias sociales. El paradigma de Bobastro define un asentamiento con morfología urbana que establece una subdivisión dentro del tipo de los ummahāt al-hussūn. En Granada debemos suponer alguno de los dos modelos: la población fortificada, o fortaleza urbanizada, que tiene a Bobastro como referencia-tipo, o un hișn "complejo" donde elementos como el albacar es muy improbable que pudieran estar ausentes. Una población fortificada sería más acorde con un asentamiento en el solar de la ciudad antigua, que mantiene en algún grado sus defensas; el otro modelo sería la Alhambra, que en ningún caso correspondería a la imagen que nos ha transmitido la historiografía por la elementalidad de su organización, pero mucho menos puede aplicarse a Torres Bermejas. Nuestras investigaciones en la Alcazaba de la Alhambra apuntan una organización anterior a la definitiva nazarí, y junto con la interpretación de la coracha como elemento de la fortaleza puede corroborar la existencia de la tipología indicada por Acien.

No se puede cambiar de ubicación el hișn Garnāta sin destruir los fundamentos de la existencia del barrio judío, de ahí que, identificado por Seco de Lucena con el hișn Roman de Mármol y ubicado sobre la ciudad romana, en la propuesta de Orihuela-Vilchez sea necesaria la duplicación de fortalezas con el añadido de Torres Bermejas (hịṣn Mawrūr), además de la Alhambra, para mantener el sentido que el siglo XIX dio al texto de al-Rāzī.

La acumulación de defensas en un territorio no urbanizado carece de sentido, ya que las supuestas funciones de control del territorio no requerían un castillo en cada cerro; se

\footnotetext{
53 El paralelo de Guadix con la Alhambra fue hecho notar hace ya bastante tiempo. Cuando Gómez Moreno (1907, p.70) trata de las murallas de Guadix no alcanza a fecharlas "por falta de datos técnicos e históricos", pero distingue dos recintos, "el recinto alto es obra quizá del siglo XIII, constituido por tapiales de tierra con algo de cal..", el recinto bajo "..es de tapias de argamasa con tandas de cantos rodados por dentro, como lo primitivo de la Alhambra".
} 
ejercían con una sola fortaleza en cualquiera de los tres lugares: Mauror, Alhambra o colina del Albaicín. A ello debemos añadir que la comarca granadina acoge una fuerza militar: los ŷndies de Damasco. El impacto de este grupo en las relaciones de producción de la comarca granadina es importante pues se les otorga el tercio (idos tercios?) de los bienes de los "cristianos" (VALLVÉ 1986)/ mucahidin (ACIEN 1993, pp. I63-164) de la kūra, por tanto son parte interesada en los acontecimientos. Su ubicación, muy discutida, parece según Acien Almansa que se efectúa con dos modalidades: lugares de poblamiento antiguo -Acien cita los casos de Caparacena y Sinyana- y otros en los que "esa relación no es posible, vislumbrando su origen en un simple dār o dār al-mansūb (casa del linaje), que aluden a un poblamiento nuevo" (ACIEN 1993, pp.164), afirmación que matiza la ubicación urbana que otros dan a los miembros del $\hat{y} u n d{ }^{54}$. Su posible correspondencia con la estructura que va a adquirir el poblamiento de la Vega, en su estado último totalmente subordinado al asentamiento principal, la ciudad de Granada (f.l), pudiera ser indicio de la existencia del referente en los primeros momentos de la dominación islámica o mostrar una jerarquía espacial independiente del mismo, pero este problema no ha sido investigado. A nosotros nos interesa aquí resaltar la presencia en la comarca de una fuerza militar no encastillada, quizá con ciertas funciones administrativas, que hace aún más dudosa la necesidad de tanta fortaleza.

Pese a que encontramos alusiones a una población fortificada nunca se ha desarrollado la idea del hișn Garnāța como asentamiento con naturaleza de madina. En el estado actual de las investigaciones (BAZZANA; CRESSIER; GUICHARD 1990) el texto de al-Rāzī debe interpretarse como topónimo de una población, y por tanto el problema a resolver no es la identificación de un perímetro amurallado sino la naturaleza urbana del asentamiento de la cita del siglo $X$ y los cambios espaciales originados en el proceso de islamización.
Tanto la argumentaciones sobre distintas fases de la cerca urbana como los referentes al hiṣn Garnāța se han basado en criterios "lógicos", que intentan acomodar estructuras y espacios a los acontecimientos históricos conocidos. No existen criterios objetivos en base al análisis de las propias estructuras que sustenten las respectivas tesis. Gómez Moreno diferenció grupos de estructuras, pero su cronología la establece en función de criterios acomodaticios. Por eso, las excavaciones en el Carmen de la Muralla ofrecían la posibilidadad de establecer criterios objetivos, científicos, que fijaran la cronología y permitieran reconocer la teoría más correcta. Lo publicado hasta ahora no ha solucionado nada. La atribución al siglo VIII de la muralla descubierta se hizo desde la proyección de la propuesta del Gómez Moreno de 1890 y de los escritos de Seco de Lucena, ignorando que los razonamientos usados en su momento no eran aplicables al caso, debido a que ya existía un trabajo donde el análisis de las propias estructuras aportaba los criterios para fijar una cronología. Ese fue el gran valor de la contribución de Torres Balbás. Lo que concluye Torres Balbás es que las estructuras visibles de la muralla más antigua, supuestamente correspondientes a tiempos visigodos o al siglo VIII, no podían ser fechados antes de los últimos años del siglo $X$ en base al análisis de los aparejos y su correspondencia con la arquitectura omeya, por tanto, los razonamientos lógicos en base a los acontecimientos históricos ya habían dado paso a razones propiamente arqueológicas que estaban a disposición de los investigadores cuando se iniciaron las excavaciones. Sin embargo prescindieron por completo de ellas. Es por esto que nos atrevemos a afirmar que las investigaciones arqueológicas desarrolladas en Granada, en lo referente al problema de las murallas, no sólo no ha solucionado ninguno de los problemas planteados, sino que ha hecho retroceder un siglo el estado de los conocimientos.

54 Según Manzano (1993 p.332) a los sirios se les encomendó la recaudación de los tributos en las zonas que les habían sido asignadas. Además "el ŷund establecido en cada uno de dichos distritos no permaneció en la capital de su circunscripción, sino que, por el contrario, se diseminó por los territorios de cada uno de sus kūra-s. Tal medida sólo es comprensible si de todo ello se desprende que el ŷund pasó a ocuparse de la percepción de los impuestos que eran la base de su propio mantenimiento". 
Buena prueba de lo sucedido es que cuando alguien que conoce el problema, Basilio Pavón, se enfrenta a la necesidad de plantear el estado de la cuestión, no puede dar por buenas las conclusiones de Sotomayor y de Mercedes Roca sobre la muralla descubierta sin rehacer por completo la propuesta de Torres Balbás. La argumentación de Pavón en 1994 no necesita para nada las excavaciones de los años 80 , puede desarrollarse con los mismos datos que conoció en su momento Torres Balbás; incluso la fecha del siglo VIII o anterior la tiene en Gómez Moreno. Es la aceptación a priori de las referidas conclusiones lo que fuerza a buscar nuevos argumentos pues no existe ningún problema que impida aplicar la propuesta de Torres Balbás a las estructuras descubiertas, sólo que en este caso se tendría que revisar en profundidad las teorías vigentes, incluso la delimitación de la ciudad romana propuesta. Lo que pone en evidencia el trabajo de Pavón es que si para aceptar las conclusiones de los excavadores -no efectuadas en base al análisis científico de los restos materiales descubiertos sino de la proyección del estado de la cuestión existente al inicio de las investigaciones- es necesario modificar dicho estado de la cuestión en sus conclusiones más firmes, estamos ante un círculo vicioso.

Hay una cuestión importante. Con independencia de los datos que proporcionen las excavaciones, las líneas de murallas correspondientes a la Bāb Qaštar y a la Bāb alZiyada (Puerta de las Pesas) definen fases consecutivas. La apertura de la segunda puerta implica una reforma substancial en el espacio inmediato. Una puerta en la muralla es uno de los elementos más rígidos de la estructura urbana, por su influencia en la definición del viario. La causa por la que se inutiliza no la conocemos, pero es sin duda clave para entender el proceso de configuración de la ciudad islámica. La evidencia del hecho repercute, además, en las hipótesis de la ciudad romana. Uno de sus ejes se basa en la puerta levantada en la fase más reciente, cuando todas las argumentaciones se apoyan en la Bab Qaštar, supuesta permanencia romana, por tanto debería ser el elemento de referencia para definir el viario anterior, nunca la puerta y calle generadas por una reforma medieval tardía, la última del período zirí o ya almorávide.

Respecto de la refundación de la ciudad en el siglo Xl, la teoría de los anillos propuesta por Luis de Mármol nos viene a decir que existe un crecimiento de extraordinaria importancia que obliga durante el siglo XI a dos expansiones sobre el asentamiento inicial y que cada una de las mismas queda fijada por sus correspondiente recinto fortificado. El rechazo de la alcazaba Gidida por Seco de Lucena no tiene ninguna influencia en la caracterización de los hechos, porque se ha interpretado como un error de toponímia, dando por correcto el proceso descrito. Un crecimiento de esas características implica una reorganización general del territorio que nos parece difícil que se efectuara de forma tan rápida salvo que responda a una decisión del poder instituido. En cualquier caso carece de sentido que se produzca un cierre del perímetro urbano limitado a la zona edificada cuando aún no ha finalizado el proceso, en lugar de atender a la configuración final del área urbana, donde entran en juego jerarquías espaciales y funcionales.

Una ciudad no es una amalgama de viviendas sino que requiere una vertebración funcional y espacial. Cada fase expansiva no sólo origina una "corteza" en forma de murallas, sino la reubicación de los elementos funcionales o una duplicidad de los mismos. En Sevilla, por ejemplo, la primitiva mezquita mayor cede su categoría a la gran construcción almohade, desplazándose el centro urbano. En base al modelo de ciudad islámica los sucesivos crecimientos deberían ser entendidos como arrabales que sólo en un segundo momento reciben una muralla, y por tanto dispondrían de sus propios elementos funcionales, pero lo que nos ofrece la teoría de los "anillos" es una configuración urbana en dos momentos separados por una ruptura en la organización espacial: una primera ciudad asentada en la colina que traslada en un momento posterior su centro al llano. 
Las hipótesis de trabajo sobre el modo como se produjo el traslado desde Madinat llbira a Granada son dos que definen modos de crecimiento y distribución espacial completamente diferentes:

a) Traslado general sistematizado y organizado. Se diseña un espacio urbano que requiere la definición de unos elementos articuladores básicos: alcázar, mezquita mayor, recinto de murallas, un sistema hidráulico y un viario básico articulado por dichas emergencias urbanas.

b) Desplazamiento gradual y aleatorio. Se produce una ocupación militar del territorio estableciendo un núcleo fortificado donde se asientan los nuevos señores. La progresiva densificación de su entorno mediante el traslado de los habitantes de Illïira hace que en un segundo momento adquiera una estructuración urbana, entendiendo por tal una jerarquización espacial y funcional. El recinto de murallas es consecuencia final de este proceso.

Vamos a observar el proceso referido a los dos elementos más significativos: la mezquita mayor y el alcázar.

a). El alcázar. El alcázar zirí está ausente en las discusiones sobre la estructura urbana granadina. Antes de la ocupación del llano la madina propiamente dicha es una alcazabapoblación que ocupa el antiguo hișn Garnāța y pasa a denominarse Qașabat Garnāța. No creemos que haya duda en que el alcázar del siglo XI tendría un perímetro amurallado y que debería ser considerado como una forta- leza urbana, sin embargo jamás se ha ubicado en el plano. ${ }^{55}$ Una vez situado (f.28.b), su presencia anula la posible acepción como espacio político-militar que supone la Qașabat Garnāța, entendida como una fase donde dicha alcazaba constituye la población. El problema es distinto si dicha zona se refiere a un contexto mayor que abarca la ocupación en el llano pues entonces el alcázar junto a un recinto amurallado inmediato puede entenderse como ciudadela de estructura urbana.

b). Ubicación de la mezquita mayor. No cabe pensar que la capital de un reino recién instituido prescinda de una mezquita mayor como referente destacado en su trama urbana. La configuración de una ciudad a partir de una entidad de población menor con un sistema de barrios independientes, frecuente en las alquerías musulmanas, pudiera dar lugar a que la mezquita quedara desplazada de mantenerse su ubicación original, pero jamas podemos aceptar dicha posibilidad en el programa edilicio de fundación de la capital de un reino por las implicaciones políticas que conlleva la institución religiosa. El cierre del área urbana con una muralla implica la existencia de los elementos dominantes en su interior, por ello debería existir una primera mezquita mayor correspondiente a las primeras fases de asentamiento en la colina, sustituida hacia mediados de siglo por otra definitiva inmediata al río Darro. Gómez Moreno apunta algo en esta línea en 1907. A. Malpica ha percibido el problema y deduce de los datos disponibles un proceso largo en el que se construye una mezquita en posición periférica que el posterior desarrollo urbano reconvertirá en posición central. ${ }^{56}$

55 Es este un problema donde queda en evidencia la fragilidad de las conclusiones historiográficas vigentes. Torres Balbás (I94I) se limita a decir: "De otra obra de los reyes zîries, el palacio o alcázar de Bādīs, situado en la Alcazaba, en las inmediaciones de la iglesia de San Miguel el Bajo, no queda más que el recuerdo legendario y unos cimientos, en el corral hoy llamado de la Lona y en el palacio de Daralhorra", de donde deducimos que son datos ya probados con anterioridad; en la Guia de Gómez Moreno (I892, p.45 I) leemos: "Casa del Gallo. Este vulgar nombre se daba al célebre palacio del rey zirita Badis, que ocupaba gran trecho al occidente de dicha iglesia y el extenso corral de vecindad nombrado cada de la Lona, entre cuyas paredes subsisten restos de los muros del alcázar, como también a la parte contraria de la plaza de S.Miguel". Es inútil buscar los argumentos que justifican la atribución. El origen de todo es una vez más Luis de Mármol: "el primero (barrio) y más alto está junto con la Alcazaba antigua, en la parroquia de San Miguel, y allí fueron los palacios de Bendici Aben Habuz, en las casas del Gallo, donde se ve una torrecilla, y sobre ella un caballero vestido a la morisca... y los cristianos llaman aquella casa la casa del Gallo".

56 "La mezquita mayor estaba en la zona llana, en la orilla derecha del Darro, en realidad un espacio excentrico a la madīna, lo que plantea grandes problemas de interpretación espacial" "...la mezquita mayor estaba, como hemos dicho fuera del centro urbano del siglo XI, lo que no es normal en una ciudad islámica, aunque no excepcional..."(MALPICA, A. 1992, p-74). "...se puede decir que en la orilla derecha del Darro la mezquita mayor es el elemento primordial, que no único. Con respecto a ella hay que señalar que comenzó a construirse en el siglo Xl y ello debe ser prueba de que la ciudad ya estaba establecida en tales fechas en esta área (MALPICA, A. I994, p.20 I). 
No podemos caer en la trampa del puzzle y presentar la ciudad como una forma acabada -la ciudad musulmana- resultado de un proceso lineal acumulativo que se remata en época nazarí, donde la investigación se reduce a verificar en qué momento se ocupa una zona determinada, sino que debemos establecer qué principios sigue el proceso de configuración urbana en cada uno de los períodos islámicos y qué dinámicas se desarrollan en su interior. Nosotros pensamos que la propia concepción de barrios y arrabales de la ciudad islámica, con cierta autonomía funcional, hace que, frente a la expansión en mancha de aceite que cuando alcanza cierta densidad se cierra con murallas, podamos plantear el problema desde la configuración de grandes unidades espaciales con su propios procesos evolutivos. La muralla no sólo define el área urbana, sino un conjunto de unidades topográicas que articulan las jerarquías espaciales interiores y exteriores. En Granada la correspondencia entre recintos de murallas y accidentes topográficos es evidente, por tanto la construcción del recinto viene dada por un programa espacial que no implica necesariamente una ocupación sistemática de zonas homogéneas por fases ni tiene que estar condicionado por la densidad de ocupación.

Las distintas propuestas historiográficas han hecho que la fortificación inicial granadina se interprete:

I.- Como fortificación romana rehabilitada en época islámica. Recurre a los argumentos de Castella y del hișn Roman.

2.- Como fortaleza del siglo VIII producto de la nueva relación de poderes, que es usada en el siglo XI para asentar el primer núcleo de población.

3.- Como alcazaba inicial del siglo XI en torno a la cual se desarrolla la urbe.

Lo que se plantea en la propuesta de configuración del siglo Xl es el aprovechamiento de una organización preexistente, recinto romano o fortaleza de los siglos VI u VIII según las teorías, al que se añade otra cerca, previa al recinto general de la madīna correspondiente a la ocupación en el llano, y que sólo se justificaría por el desarrollo de la nueva ciudad. Esta línea, asumida por el proyecto arqueológico que estudia la ciudad iberorromana, va en contra de las conclusiones de los dos únicos investigadores que han contemplado en sus análisis los restos materiales conservados: Gómez Moreno y Torres Balbás pues la Bab al-Asad permite afirmar que las primeras obras de fortificación islámicas identificadas -con independencia de la fecha que se les quiera dar-forman un conjunto que abarcaban ya toda la colina hasta su borde Oeste. Se discute si el primer recinto tuvo uso exclusivo militar o es un asentamiento urbano, lo que implica tanto definir la tipología del mismo como las funciones desarrolladas en su interior.

La verificación del fenómeno urbano anterior al siglo XI implica otras líneas de investigación no desarrolladas, que escapan a la práctica de las "urgencias" urbanas. A. Malpica viene insistiendo en que no es posible entender el proceso urbano sin comprender el alfoz, que en el caso de Granada tiene características complejas para el momento que nos interesa debido a la existencia de otro núcleo urbano muy próximo, llbīra, que a su vez se encuentra cerca de llurco. Habría que comprobar si la polaridad entre los dos centros de población (f.I) permite distinguir áreas de influencia en una fase anterior al siglo Xl.

La especificidad del sistema de regadío en los "awahz de las ciudades donde el esquema de comunidad campesina clánica o tribal no sería adecuado" (KIRCHNER; NAVARRO, 1994, p. 170 ) sería un dato que probaría la existencia de una ciudad. A su vez, Patrice Cressier (1991) ha indicado que en contextos periurbanos, como la Vega de Granada, el territorio de la alquería enmarca unidades de poblamiento de rango inferior como las cortijadas y almunias. $\mathrm{Ha}$ presentado los resultados de su investigación en el área de Pinos Puente, donde existiría un modelo de relaciones entre asentamientos rurales condicionado por la presencia del núcleo urbano. El problema reside en que no se trata tanto de establecer la configuración 
final del proceso como sus distintos momentos. No obstante, bajo esta perspectiva hallazgos como los efectuados en la girola de la catedral de Granada, incluso entendidos como almunia, adquieren un significado que debe ser tenido en cuenta.

Una ocupación tan antigua como la que se establece en la Vega de Granada supone que en el estado final se suman elementos que corresponden a períodos históricos muy diferentes. El ejemplo de Pinos Puente es claro, pues la organización en época nazarí incluye elementos como una presa asociada a un fortificación (Belillos) configurada siglos antes. Ibn al-Jatīb en el siglo XIV puede enumerar hasta cuarenta casas (dar/s) de las familias árabes, algunas de origen sirio, asentadas en la comarca (VALLVÉ, 1986 p.196 nota 45) Cuya distribución también es un dato a tener en cuenta. El desarrollo de las investigaciones en este ámbito nos parecen tan esenciales para la comprensión del proceso urbano como las excavaciones en el interior de la ciudad.

\section{BIBLIOGRAFÍA}

ACIEN ALMANSA, M.(I989) "Poblamiento y fortificación en el Sur de al-Andalus. La formación de un pais de husụūn". Actas III Congreso de arqueología medieval española. i Ponencias. pp. I35-150. Oviedo.

ACIEN ALMANSA, M. (199|) "Recientes estudios sobre arqueología andalusí en el Sur de Al-Andalus". Aragón en la Edad Media, 9. Zaragoza. pp. 355-369.

ACIEN ALMANSA, M. (1993) "La cultura material de época emiral en el Sur de Al-Andalus. Nuevas perspectivas". en Malpica Cuello, A. (ed.) La cerámica altomedieval en el Sur de al-Andalus. Granada. pp. I55- 172.

ARGOTE, Simón de (s.f). Nuevos paseos históricos, artísticos, económico-políticos por Granada y sus contornos. Granada.

ALMAGRO, A; ORIHUELA, A; VÍLCHEZ, A. (1992). "La Puerta de Elvira en Granada y su reciente restauración". Al-Qantara, XIII. Madrid. pp.505-535.

BAZZANA,A.; CRESSIER,P.; GUICHARD,P. (1988): Les châteaux ruraux d'al-Andalus. Histoire et archéologie des husūūn du sud-est de l'Espagne. Madrid.

BERMÚDEZ DE PEDRAZA ( 1608$)$ : Antiguedad y excelencias de Granada. Granada.
BERMÚDEZ DE PEDRAZA ( 1638): Historia Eclesíastica de Granada. Granada.

CABANELAS, D.(1965): El morisco granadino Alonso del Castillo. Granada.

CONDE, J. A. (1784): Historia de la dominación de los árabes en España sacada de varios manuscritos y memorias arábigas. Madrid.

CONTRERAS, R.(1898). Estudio descriptivo de los monumentos árabes de España. Madrid.

CRESSIER,P. (|99|) Agua, fortificaciones y poblamiento: el aporte de la arqueología a los estudios sobre el Sureste peninsular. Aragón en la Edad Media. 9. Zaragoza, pp.403427.

CUEVA. L de la (I603): Diálogo de las cosas Notables de Granada. Sevilla.

ECHEVARRÍA, Juan (I764): Paseos por Granada y sus contomos. Granada.

EGUÍLAZ Y YANGUAS, Leopoldo (I88I): Del lugar donde fue lliberis. Madrid.

ESPINAR MORENO, M. (199|) "Del urbanismo musulman al urbanismo cristiano.ll. Andalucía Oriental". Simposio internacional sobre la ciudad islámica. Zaragoza, pp. 203-231.

FERNÁNDEZ-CAPEL BAÑOS, B. (197I): "Un fragmento del Kitāb al-ŷurāfiyya de al-Zuhrī sobre Granada". Cuadernos de Historia del Islam, 3. Granada, pp. 109-124.

FUENTES (1989): Fuentes documentales para el estudio de la restauración de monumentos en España. Ministerio de Cultura. Madrid.

GARCÍA GRANADOS, J.A.; MARTÍN GARCÍA, M. (1975): "La Casa de la Lona". Cuadernos de Arte de la Universidad de Granada. XII. Granada, pp. 141-162.

GÓMEZ MORENO, M. (I 888): Medina Elvira. Granada

GÓMEZ MORENO, M.(1890): Monumentos romanos y visigóticos de Granada. Granada.

GÓMEZ MORENO, M.(I 892): Guia de Granada. Granada. Facsímil con volumen de notas. Granada 1982.

GÓMEZ MORENO, M (I 897): "La alcazaba". Diario El Defensor de Granada. 9 septiembre 1897.

GÓMEZ MORENO, M.(1905): "De lliberri a Granada". Boletín de la Real Academia de la Historia, 46. Madrid. pp. 44-61.

GÓMEZ MORENO, M.(1907): Monumentos arquitectónicos de España. Granada y provincia. (Inédito).

GÓMEZ MORENO, M.(|95|): "El arte árabe español hasta los almohades". Ars Hispaniae, III. Madrid.

GONZALO MAESO, D. (1963): Garnaa al-Yahud. Granada en la historia del judaismo español. Granada. 
GONZALBES CRAVIOTO, E. (1992): "Establecimiento de barrios judíos en las ciudades de al-Andalus. El caso de Granada". Revista del centro de estudios históricos de Granada y su reino. 6, 2época. pp. I 1-32. Granada.

GRANADA (1995): Arte Islámico en Granada. Propuesta para un museo de la Alhambra. Granada.

JIMENEZ MATA, Ma C. (1990): La Granada islámica. Granada.

KIRCHNER, Elena; NAVARRO, Carmen ( 1994): "Objetivos, métodos y práctica de la Arqueología hidráulica". Arqueología y territorio medieval. I. Jaen, pp. I59-182.

LAFUENTE ALCÁNTARA, M. (I 843- | 845): Historia de Granada. Granada.

LÉVI-PROVENÇAL, E. (1930): A propos du Pont du Cadi de Grenade. Hespéris, $X$

LÉVI-PROVENÇAL, E. (1953): "La Description de l'Espagne d'Ahmad al-Rāzī. Essai de reconstitution de I'original arabe et traduction française". Al-Andalus, XVIII, pp. 5 |- 108 .

MADRID (1992): Al-Andalus. Las artes islámicas en España. Madrid.

MARMOL, Luis (I600): Historia del Rebelión y Castigo de los moriscos. Malaga.

MALPICA CUELLO, A.(1992): "Las murallas de Granada". Nuevos paseos por Granada y sus contornos. pp. 68-97. Granada.

MALPICA CUELLO, A. (1995a). "El río Darro y la ciudad de Granada: las tenerías del Puente del Carbón". AlQantara, XVI. pp. 83-I05.

MALPICA CUELLO, A. (1995b). "El agua y el poblamiento de la Alhambra de Granada". El Agua y la agricultura en Al-Andalus. Granada. pp. I 19-130.

MALPICA CUELLO, A.; BERMÚDEZ LÓPEZ,J. ( 1995 ): "Transformaciones cristianas en la Alhambra". Acculturazione e mutamenti. Prospettive nell'archeologia medievale del Mediterráneo. Florencia. pp.285-3।4.

MANZANO MORENO, E.(1993). "El asentamiento y la organización de los $\hat{y}$ undīs sirios en al-Andalus". AlQantara, XIV. pp. 327-359.

MORENO GARRIDO, A. (1976) El grabado en Granada durante el siglo XVII. I. La calcografía. Cuademos de Arte de la Universidad de Granada, 26-28. Granada.

ORIHUELA UZAL, Antonio; VÍLCHEZ VÍLCHEZ, Carlos (|99|): Los aljibes publicos de la Granada islámica. Granada.

ORIHUELA, A. (1993): "Restos de la Granada islámica ocultos por las bóvedas del río Darro". Al-Qantara, XIV. Madrid, pp. 293-309.

PAVÓN MALDONADO, Basilio (197I): "La Alcazaba de la Alhambra". Cuadernos de la Alhambra, 7. Granada, pp. 3-34.
PAVÓN MALDONADO, Basilio (1983): "Notas sobre arte y arqueología hispanomusulmana en Andalucía. V. Consideraciones arqueológicas en torno a Granada y el alminar de San José". Andalucía Islámica, II-III. Granada, pp. 219-228.

PAVÓN MALDONADO, Basilio. (1990): Tratado de arquitectura hispano-musulmana. I. Agua. Madrid.

PAVÓN MALDONADO, Basilio (I 994): "El arte". Historia de España Menéndez Pidal vol. VIII. Los reinos de taifas. Al-Andalus en el siglo XI. Madrid. pp. 654-666.

POCKLINGTON. Robert (1988): "La etimología del topónimo «Granada»". al-Qantara, IX. Madrid, pp. 383402

QUESADA GÓMEZ, J.J. (1994): Bibliografía sobre arqueología de la ciudad de Granada (siglos XIII-XVI). Granada.

ROCA, M.; MORENO, Ma.A.; LIZCANO, R. (1987): "Nuevos datos para el conocimiento de la Granada iberoromana y árabe". Revista del Centro de Estudios Históricos de Granada y su Reino, I. Granada, pp. 37-5I.

ROCA,M.; MORENO,Ma.A.; LIZCANO,R. (1988): El Albaicín y los origenes de la ciudad de Granada. Granada.

RODRIGUEZ RUIZ, Delfín (1992). La memoria frágil. José de Hermosilla y las antigüedades árabes de España. Madrid.

ROLDAN HERVAS, J.M. (1983): "La Antigüedad". Historia de Granada. I. De las primeras culturas al Islam. Granada.

ROLDAN HERVAS, J.M. (1988): "Estudio introductorio" a Gómez Moreno Monumentos romanos y visigóticos de Granada. Granada, pp. VI-XXXIII.

SALVADOR VENTURA, F. (1990): Hispania meridional entre Roma y el Islam. Economía y sociedad. Granada.

SECO DE LUCENA, Luis (1910): Plano de Granada árabe. Granada.

SECO DE LUCENA, Luis (1942): "Las puertas de la cerca de Granada en el siglo XIV". Al-Andalus, VI. Madrid, pp. 438-458.

SECO DE LUCENA, Luis (1966): "Las alcazabas de Granada y las mezquitas del Zenete". Cuadernos de la Alhambra, 2. Granada, pp. 43-51.

SECO DE LUCENA, Luis (1968): "Acerca de la qawraya de la Alcazaba Vieja de Granada". Al-Andalus, XXXIII. Madrid, pp. 197-203.

SECO DE LUCENA, Luis (1974): Puertas y cercas de Granada. Granada.

SECO DE LUCENA, Luis (1975): La Granada nazarí del siglo XV. Granada.

SIMONET, F.J. (1860): Descripción del reino de Granada bajo la dominación de los naseritas. Madrid.

SIMONET, F.J. ( 896): Cuadros histórico-descriptivos de Granada. Granada. 
SOTOMAYOR, M; SOLA, A; CHOCLAN, C. (1984): LOS más antiguos vestigios de la Granada ibero-romana y árabe. Granada.

SOTOMAYOR, M. (1986): "Excavaciones arqueológicas en la alcazaba de Granada (1754-1763)". Miscelánea Augusto Segovia. Granada, pp.243-283.

SOTOMAYOR MURO, M.(1988): Cultura y picaresca en la Granada de la llustración. D.Juan de Flores y Oddouz. Granada.

SOTOMAYOR MURO, M. (1992): "La Granada romana". Nuevos paseos por Granada y sus contornos. Granada. pp.54-66.

TORRES BALBÁS, L. (1934): "El Puente del Cadi y la Puerta de los Panderos en Granada". Al-Andalus, II. Madrid, pp.357-364.

TORRES BALBÁS L. (1940): La Alhambra de Granada antes del siglo XIII. Al-Andalus, V. Madrid, pp. I55- 174.

TORRES BALBÁS L. (194I): El alminar de la iglesia de S.José y las construcciones de los ziries granadinos. AlAndalus, VI. Madrid, pp. 422-446.

\section{RESUMEN}

El trabajo busca aclarar el origen de las teorías hoy vigentes sobre la configuración urbana de Granada en los primeros tiempos de dominio islámico en función de un elemento caracterizador: la muralla urbana. Se establecen los distintos elementos espaciales y arquitectónicos que en uno u otro grado condicionan la estructura urbana altomedieval y sus distintas interpretaciones. Se contrastan las propuestas efectuadas desde criterios filológicos, de análisis de estructuras conservadas y arqueológicos y su relación con un determinado modelo de ciudad y de proceso urbano.

PALABRAS CLAVE: Granada, hisn Garnata, alcazaba Cadima, lliberri, murallas, Siglo XI
TORRES BALBÁS L. (1949): "La supuesta puerta de los Panderos y los puentes de la Granada musulmana". AlAndalus, XIV. Madrid, pp.419-430.

TORRES BALBÁS L. (1952): "Nuevas perspectiva sobre el Arte de al-Andalus bajo el dominio almorávide". AlAndalus, XVII. Madrid, pp.402-433.

TORES BALBÁS, L. (1957a): "Arte hispanomusulmán. Hasta la caída del califato de Córdoba". Historia de España de Menéndez Pidal, V. Madrid.

TORRES BALBÁS, L. (1957b): "Cementerios hispanomusulmanes". Al-Andalus, XXII. Madrid, pp. I31-191.

VALDÉS, Fernando (1995): "La edad oscura de la Alhambra". En GRANADA (1995), pp. 63-73.

VALLVE, Joaquín (1986): La división territorial de la España musulmana. Madrid

VARELA, Ma.E. (1990): "Estudio introductorio" a GONZALO MAESO (1963)

VÍLCHEZ VÍLCHEZ, C. (1987). "Memoria de la excavación realizada en el torreón de la Bāb al-Asad o puerta del león de la Qasabat Garnāta". Homenaje a Darío Cabanelas, II. Granada pp. 297-302.

\section{ABSTRACT}

The aim of this work is to explain the origin of today's prevailing theories about the urban configuration of Granada during the early times of Islamic dominion, taking into account a characteriser element: the Town wall. A study is made about the different space and architectonic elements that to some extent determined the early mediaeval urban structure, and their various interpretations. Proposals based on philological and archaeological criteria, as well as on an analysis of the preserved structures, are contrasted, and their relation with a specific model of town and urban process. 


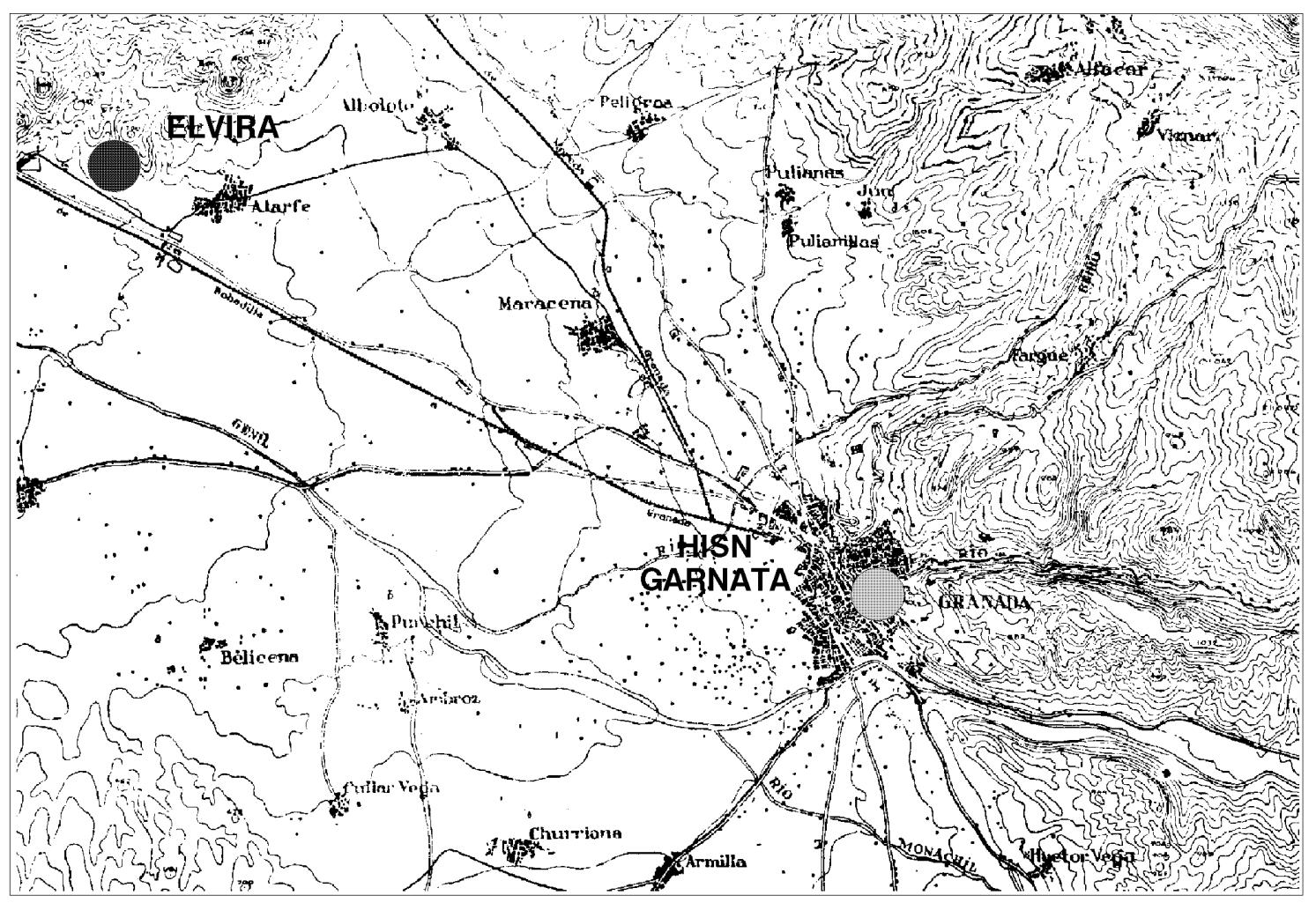

I. Relación territorial entre Ilbīra y Granada. Plano base BOSQUE MAUREL 1962.

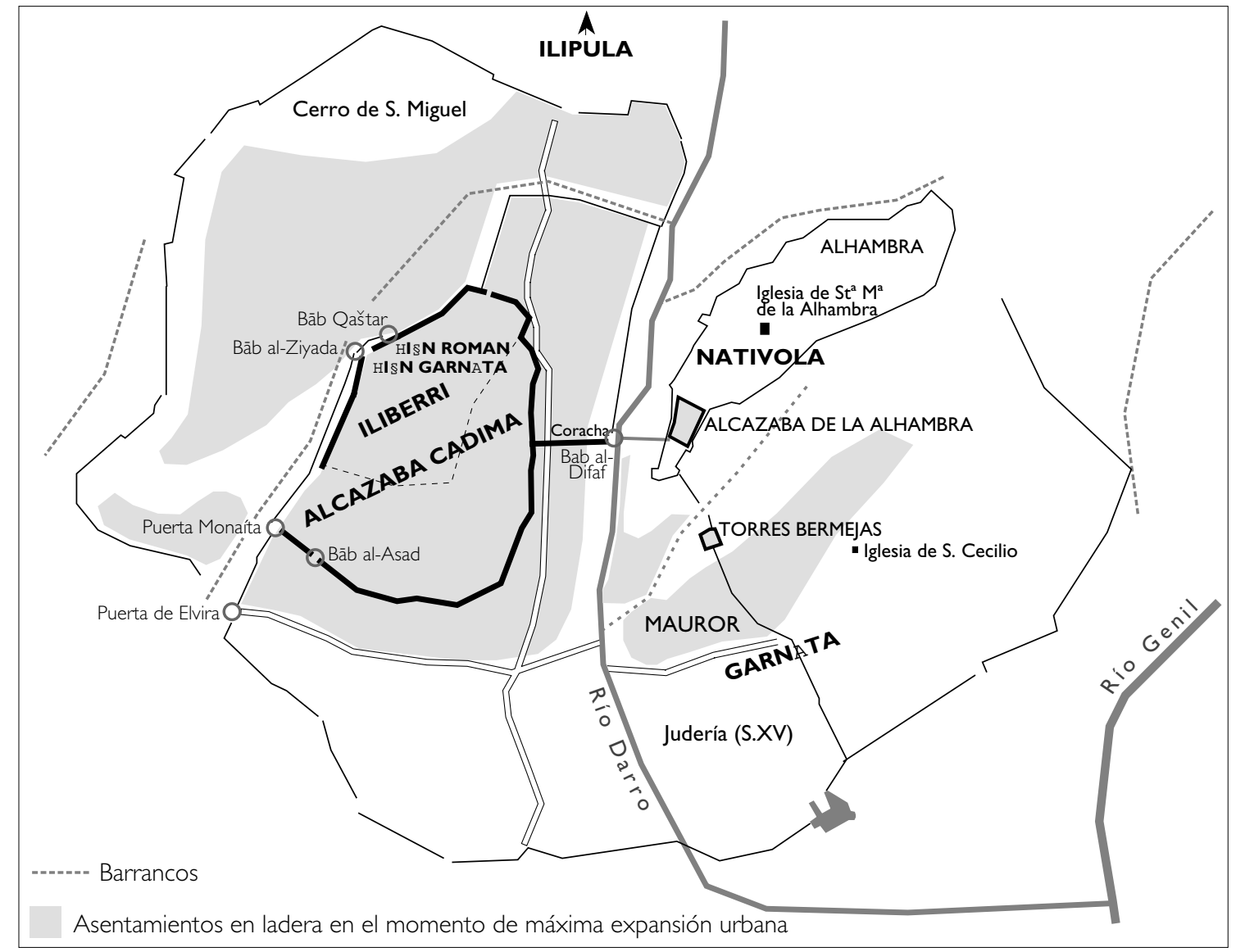

2. Estructura urbana de Granada. Localización de los supuestos núcleos de poblamiento preislámicos. 

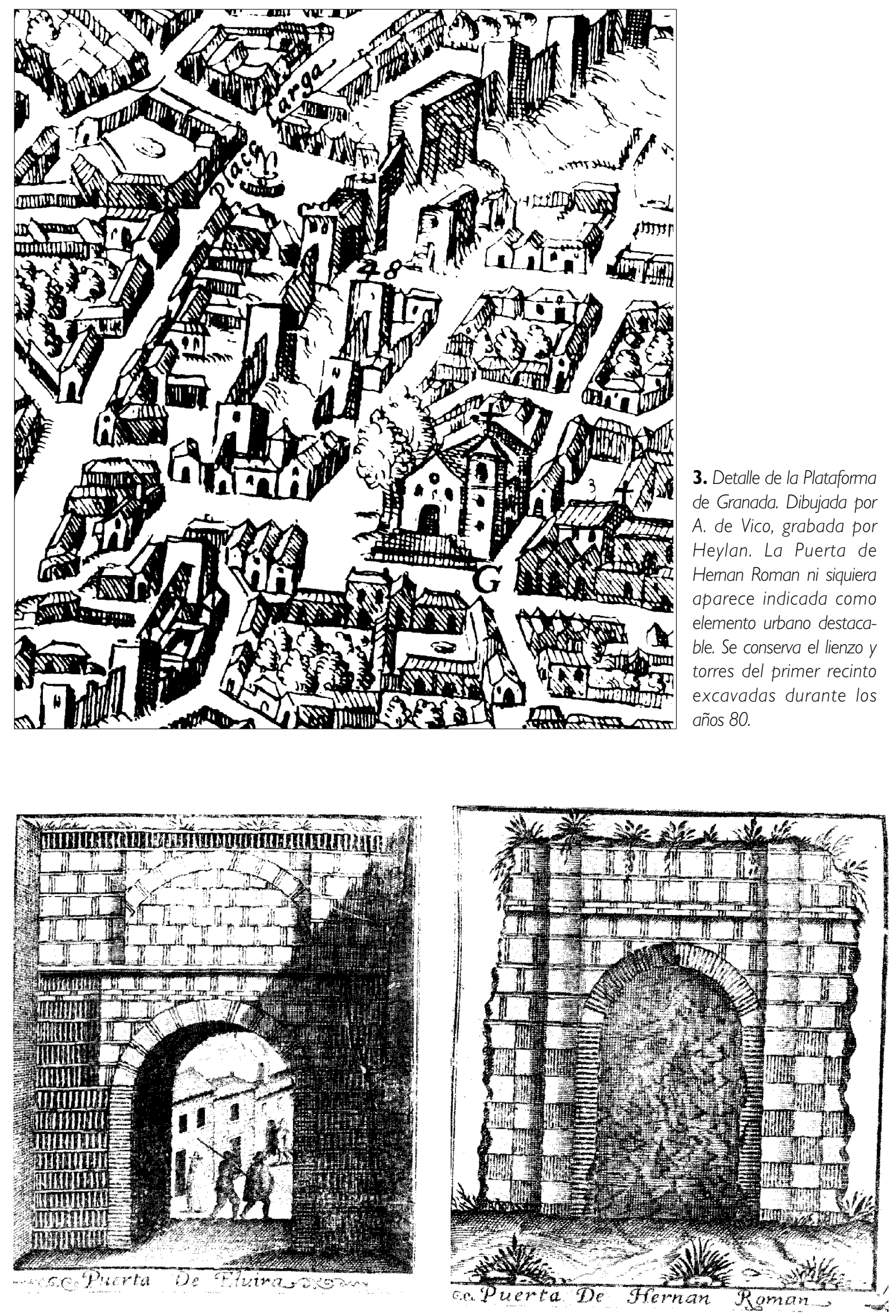

4. Las puertas de Herman Roman y de Elvira como monumentos fenicios de Granada. Detalle de un grabado de Heylan. 


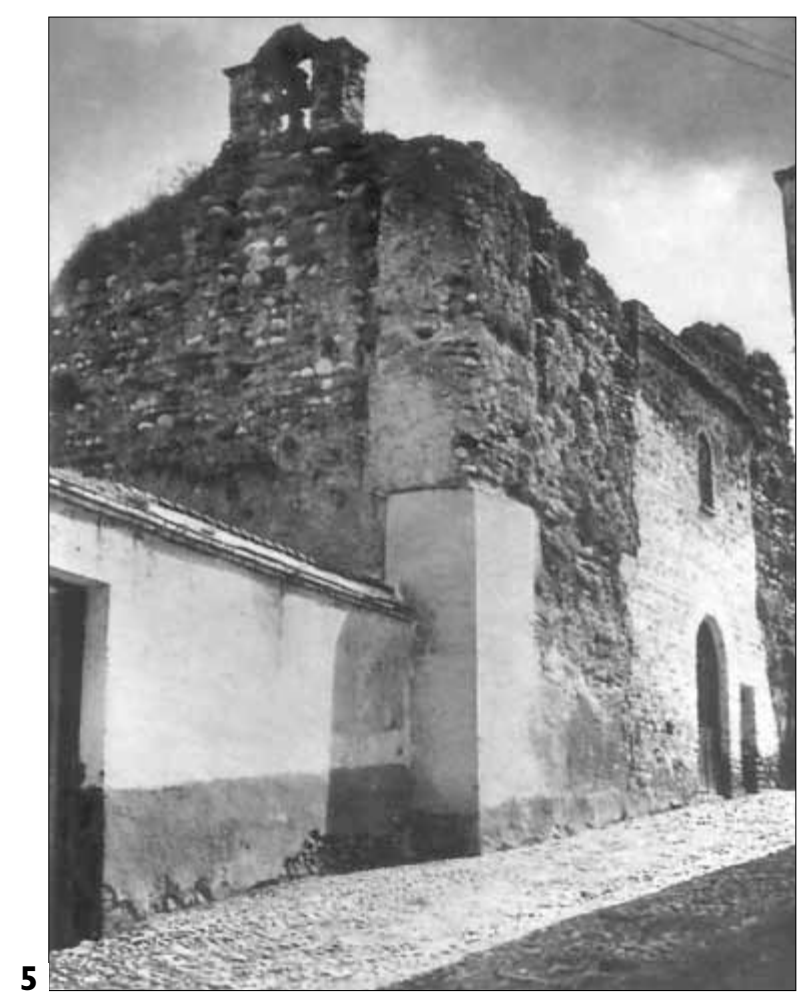

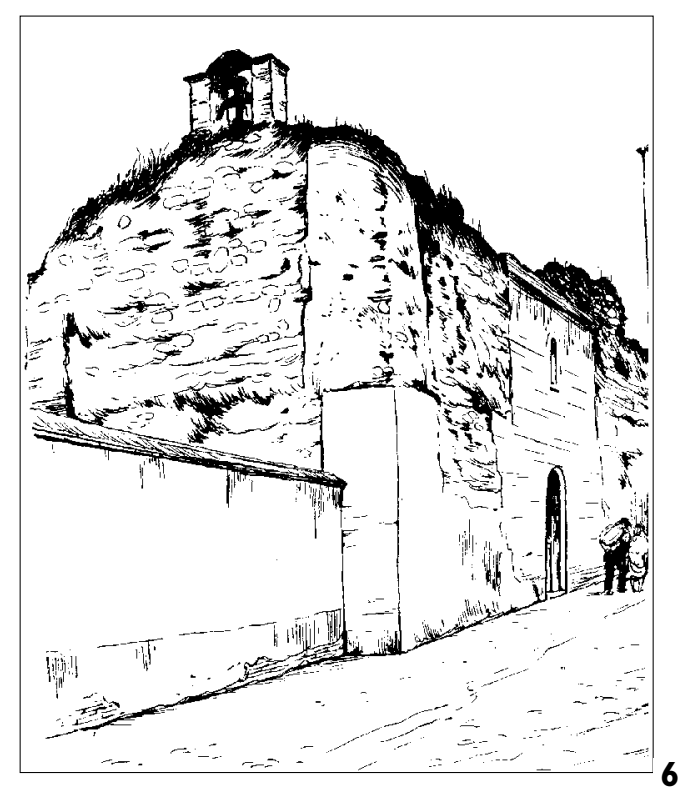

5. Puerta de Hernan Roman ya con la esquina de cantería restaurada y antes del forrado general de los paramentos. Foto anterior a 1960. (Granada, s.f.). 6. Puerta de Hernan Roman. Dibujo de E. Villar Yebra. (Albaicín, 1966). 7. Planta y detalle de esquinas de cantería. (Gómez Moreno 1907). 8. Planta de la ermita en el interior de la puerta de Hernan Roman. (Informe, 1939) 9. Puerta de Hernan Roman. Planta y alzado según Pavón Maldonado (1994)
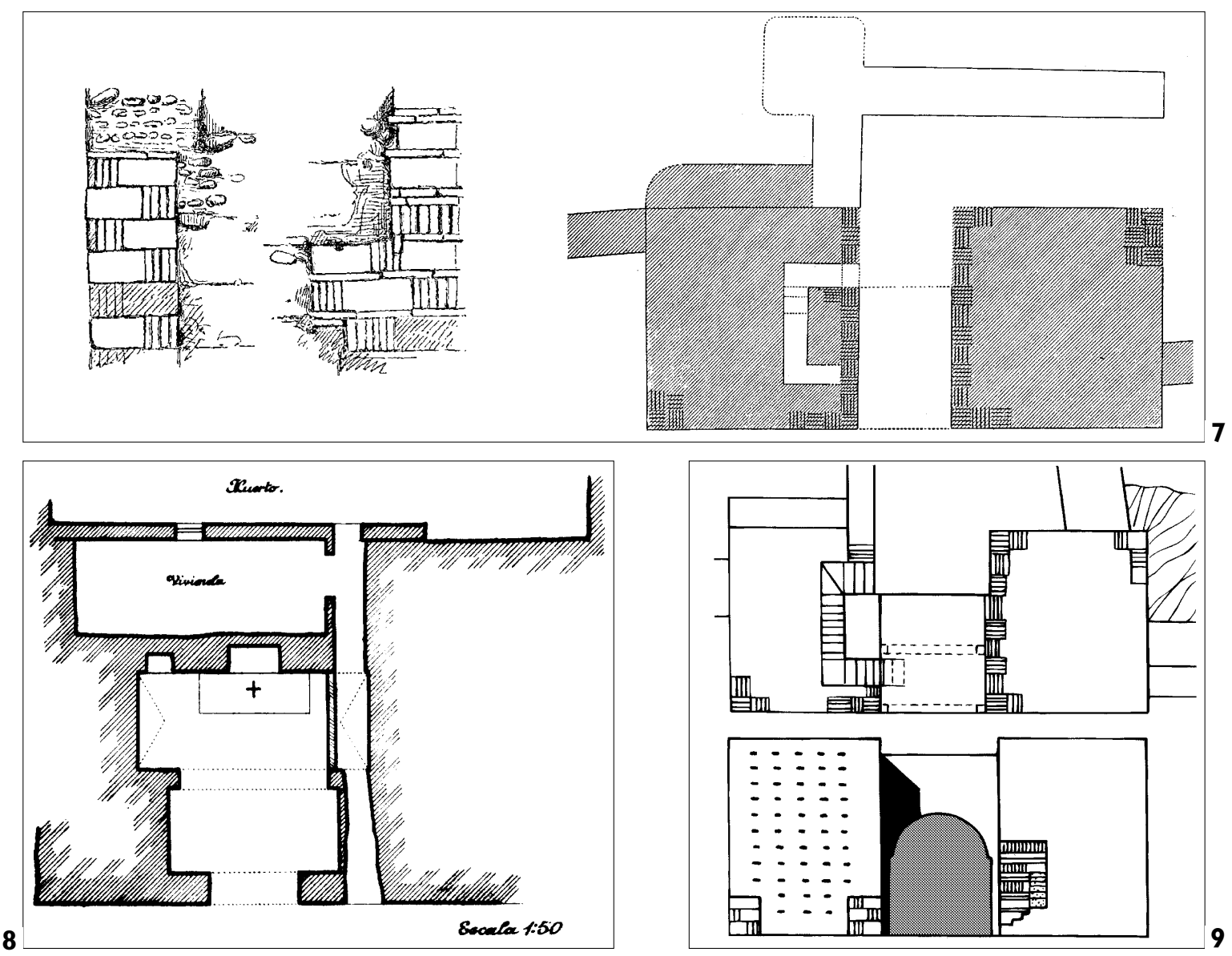


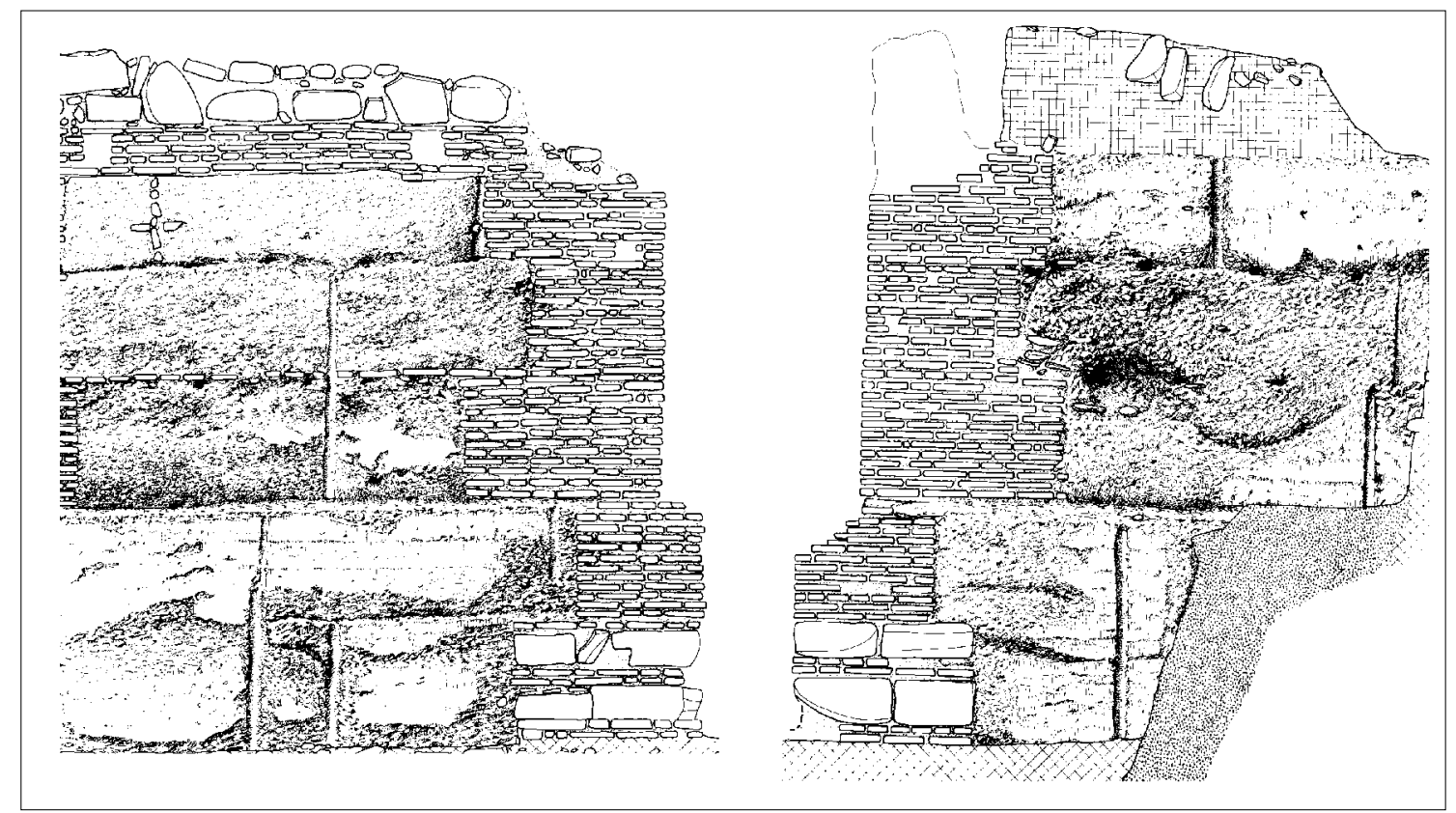

10. Torreón correspondiente al primer recinto. Alzados frontal y lateral. Según ROCA; MORENO; LIZCANO 1988

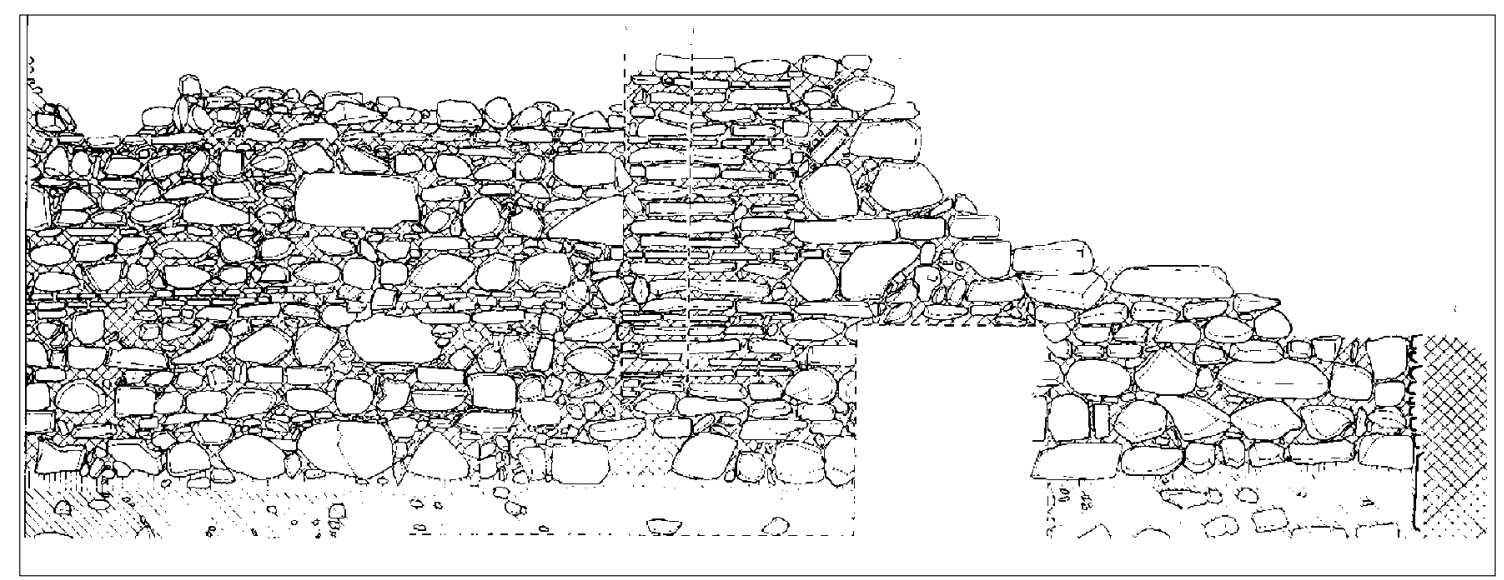

I I. Lienzo de muralla inmediato al torreón anterior. ROCA; MORENO; LIZCANO 1988.

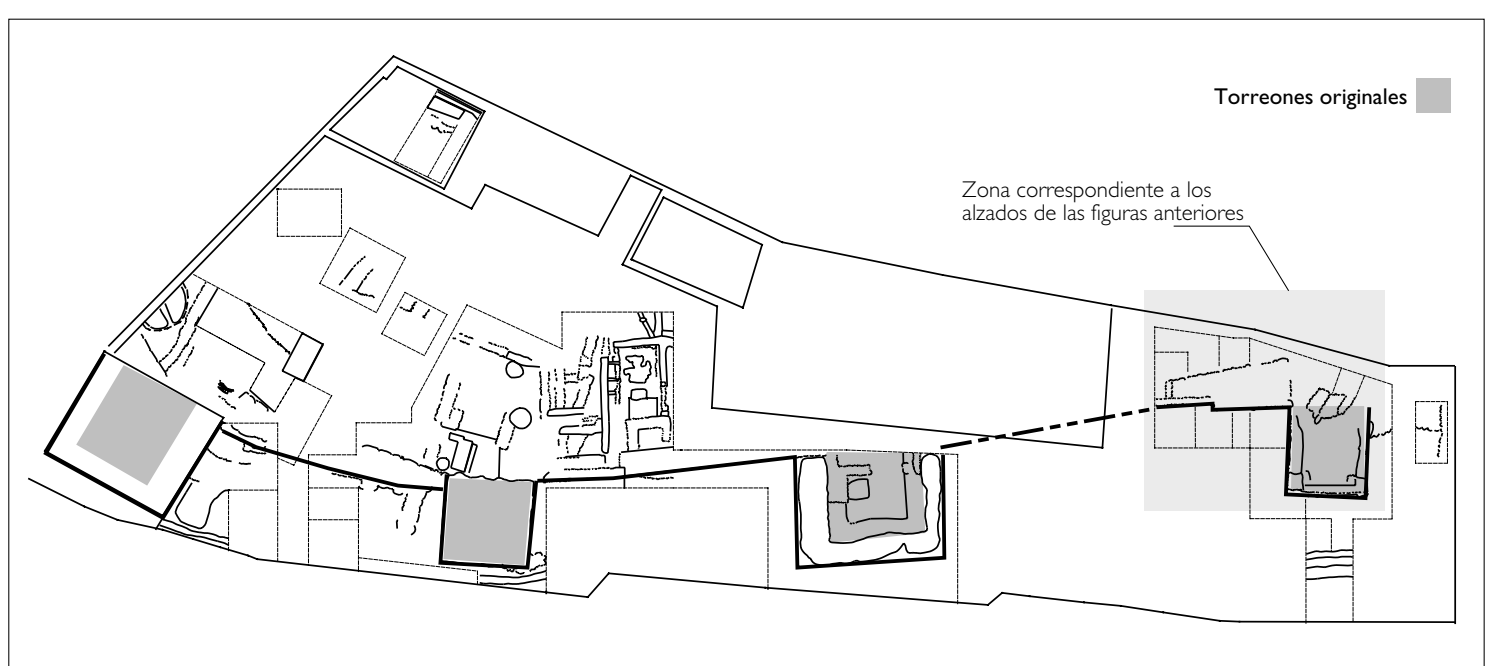

12. Primitiva muralla. Planta general de la zona excavada.

(MORENO; BURGOS; CASADO, 1993) con indicaciones añadidas. 


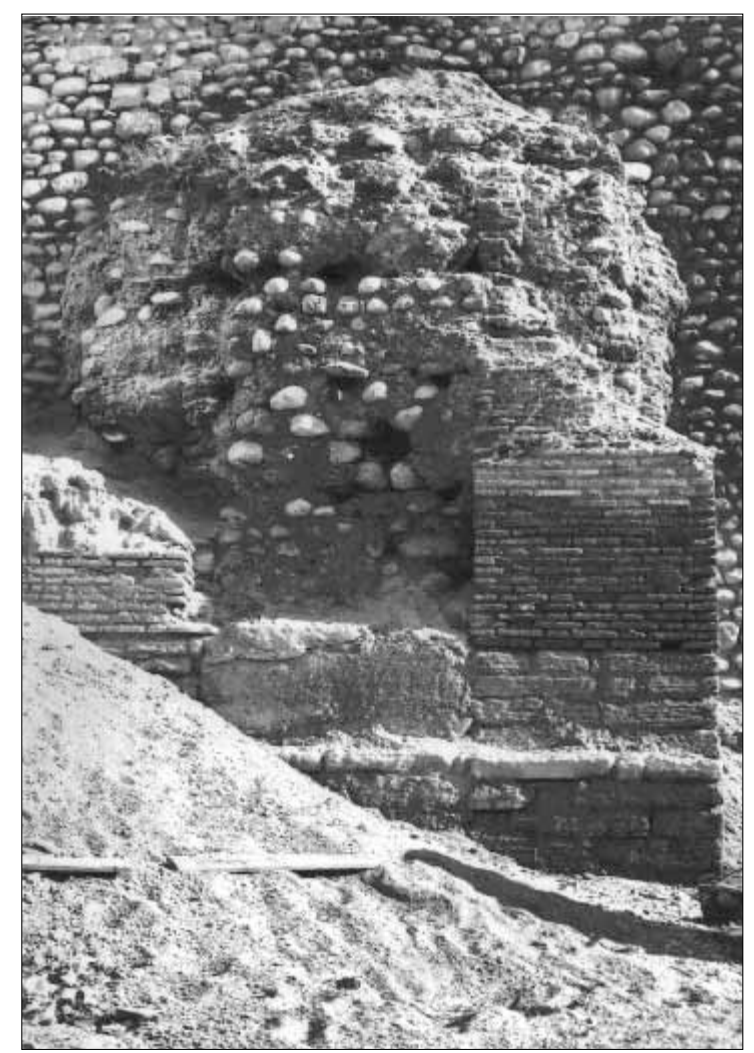

13. Restos del "Portillo del León" (Bāb al-Asad) antes de su excavación. (GARCÍA; MARTíN 1974).

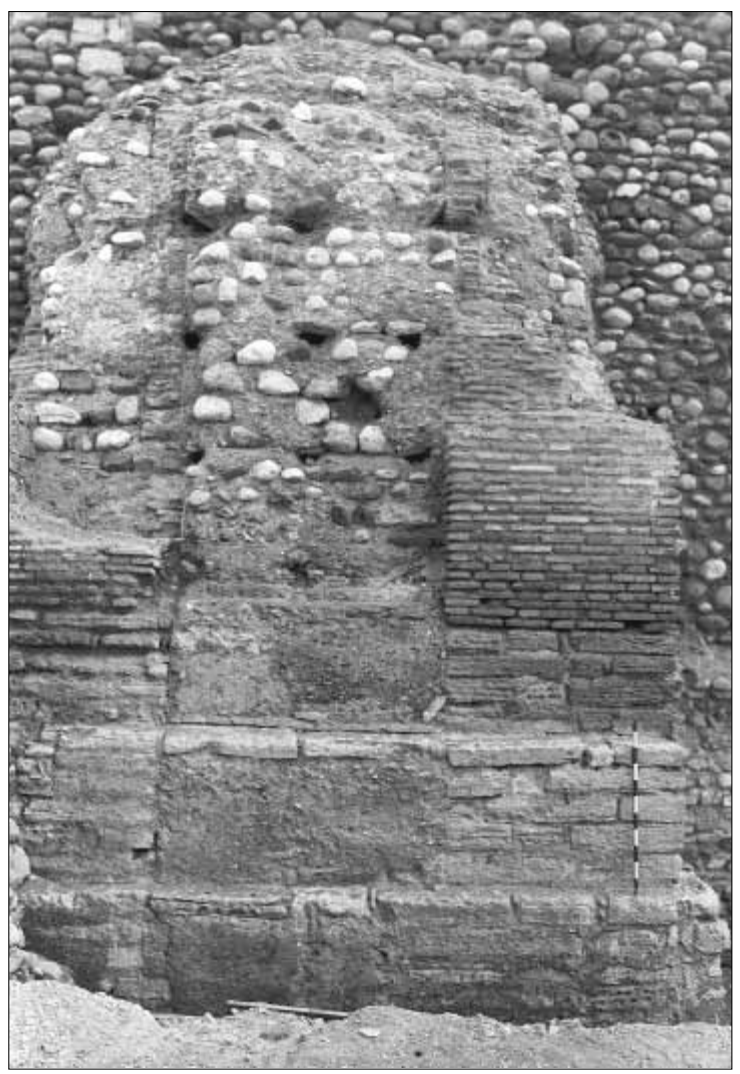

15. Portillo del León. Vista frontal después de la excavación.

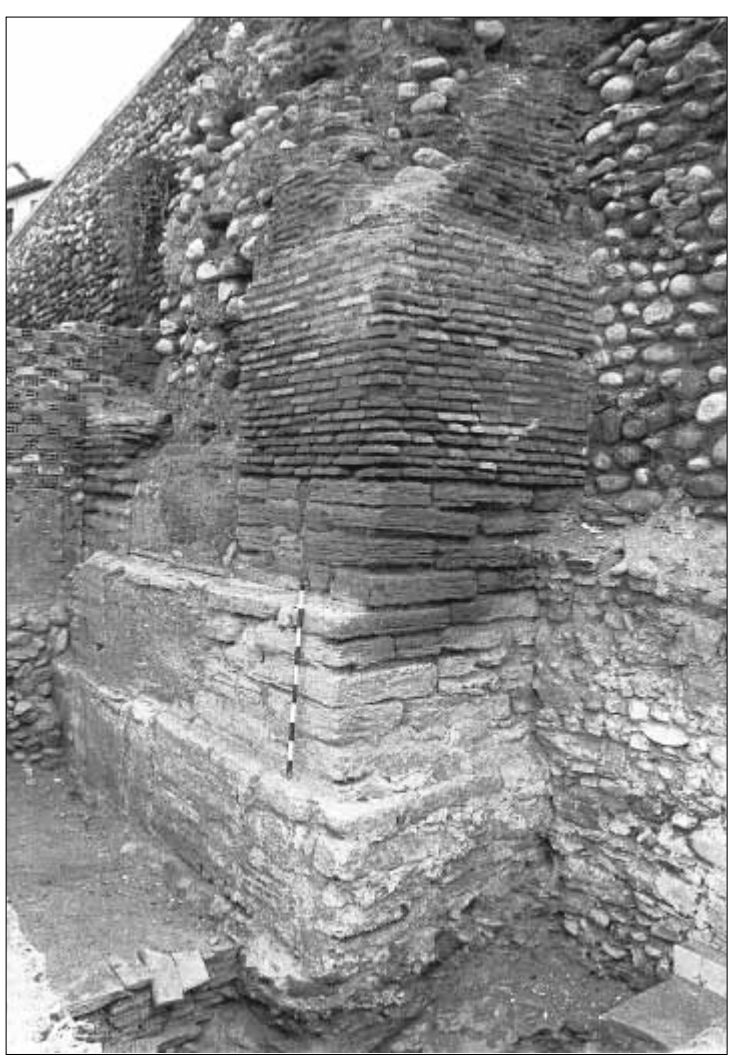

14. Portillo del León. Estado tras la excavación.

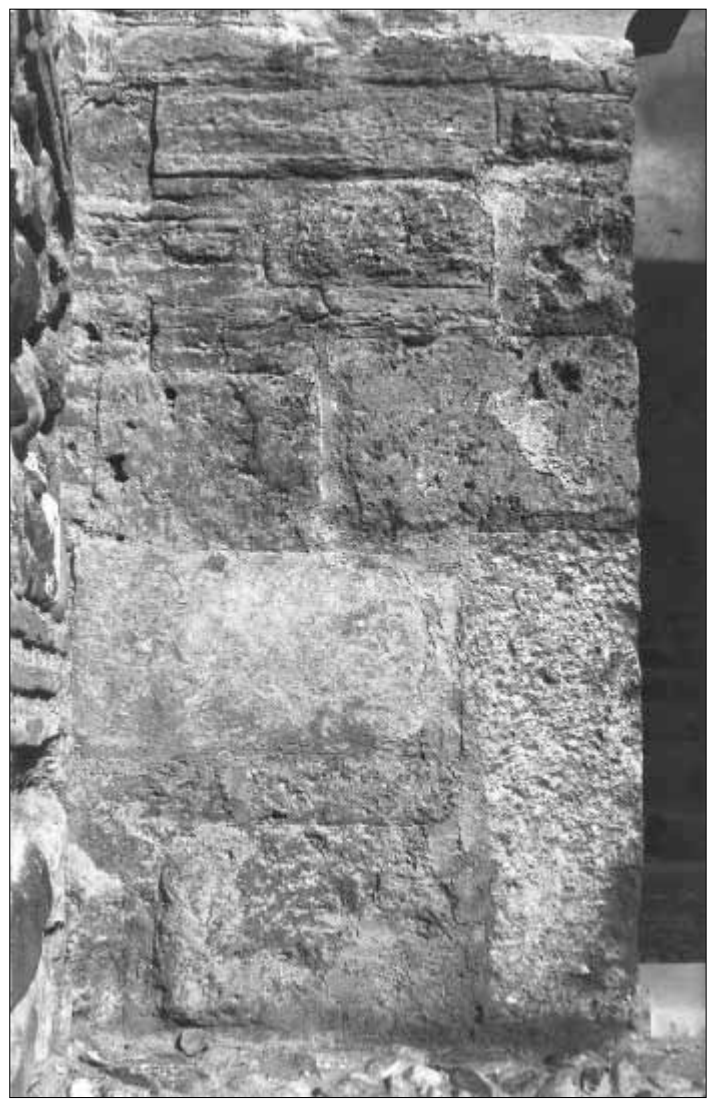

16. Puerta Monaita. Jamba con

sillares romanos almohadillados. 

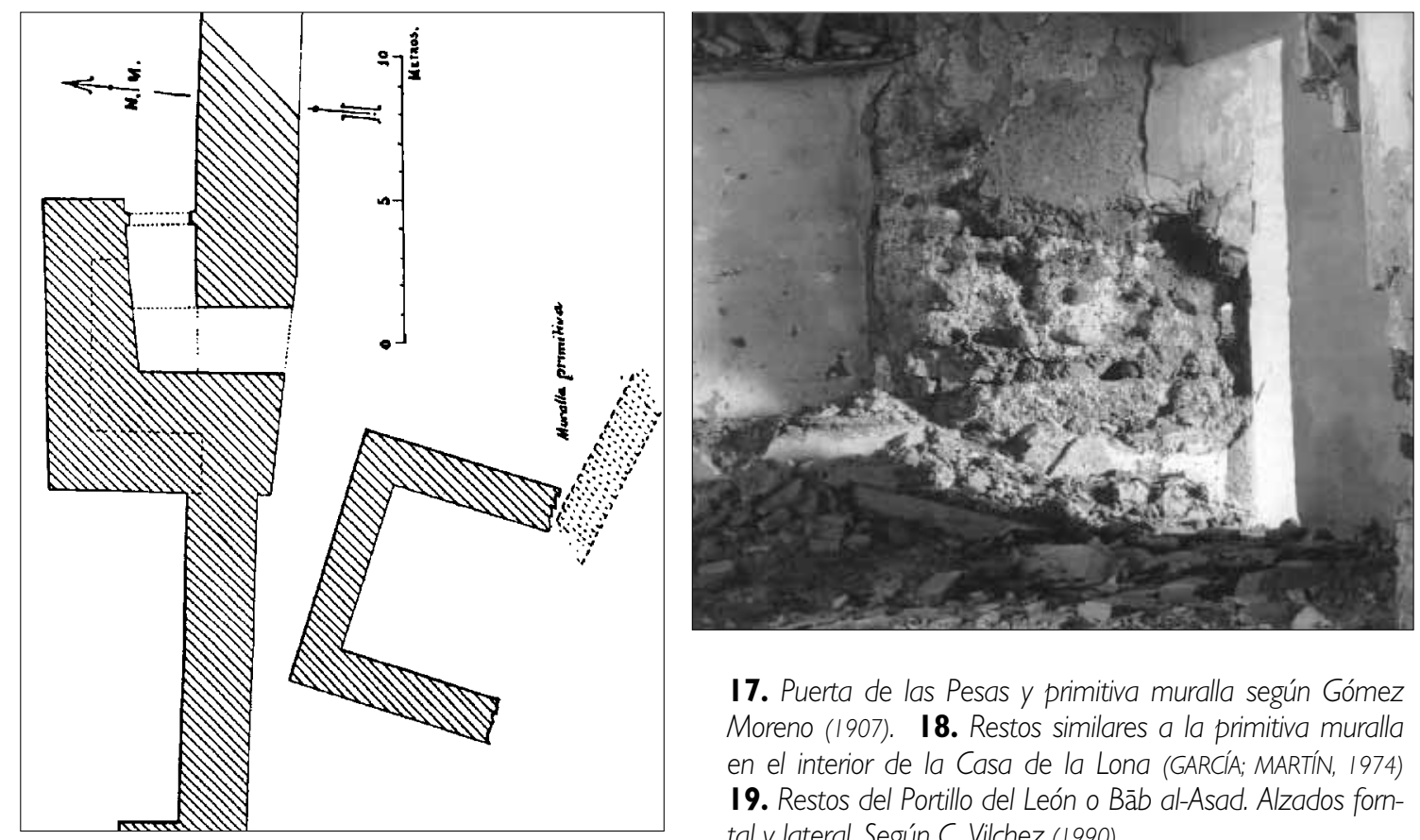

17. Puerta de las Pesas y primitiva muralla según Gómez Moreno (1907). I 8. Restos similares a la primitiva muralla en el interior de la Casa de la Lona (GARCÍA; MARTíN, 1974) 19. Restos del Portillo del León o Bāb al-Asad. Alzados fomtal y lateral. Según C. Vilchez (1990).

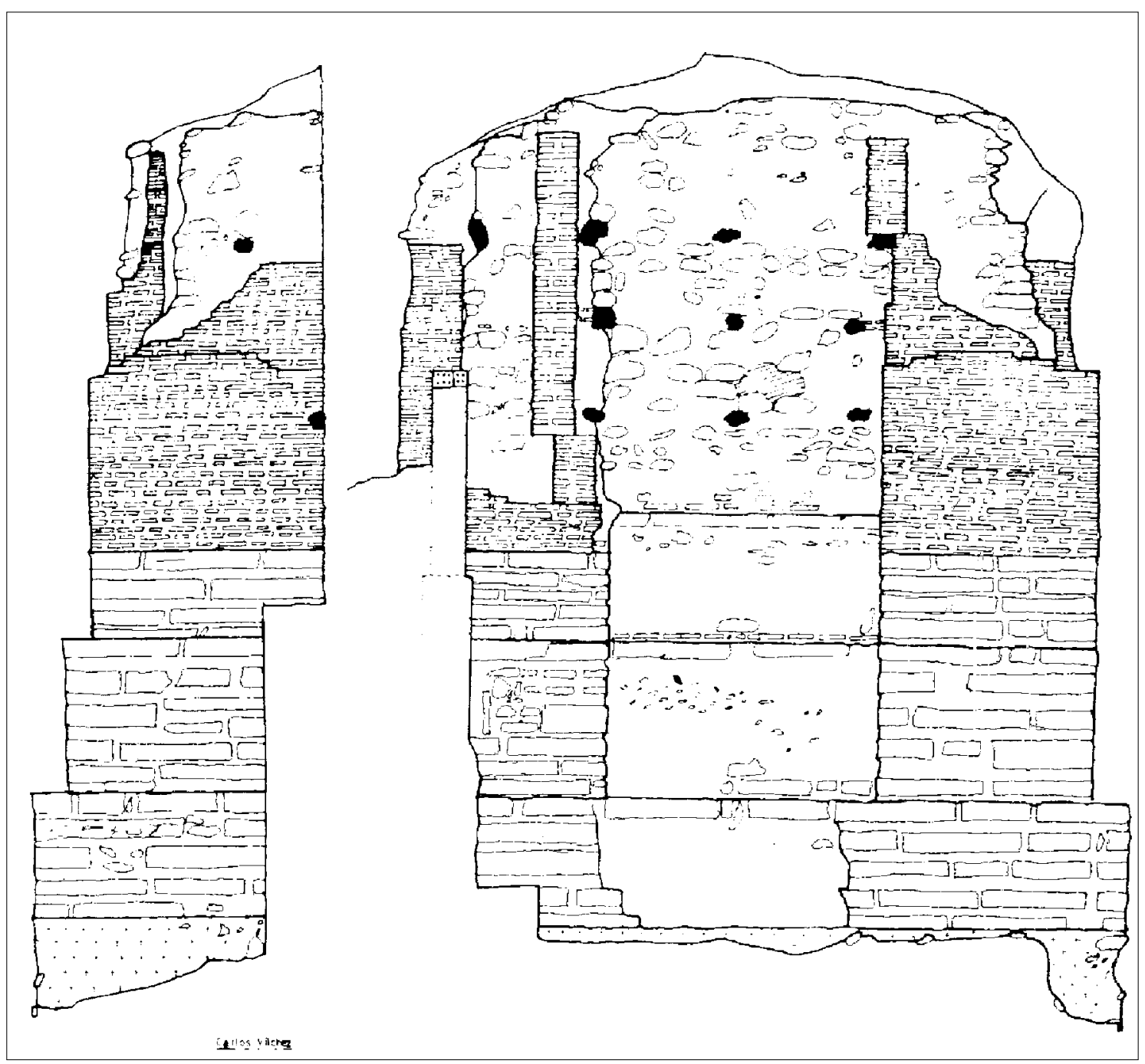




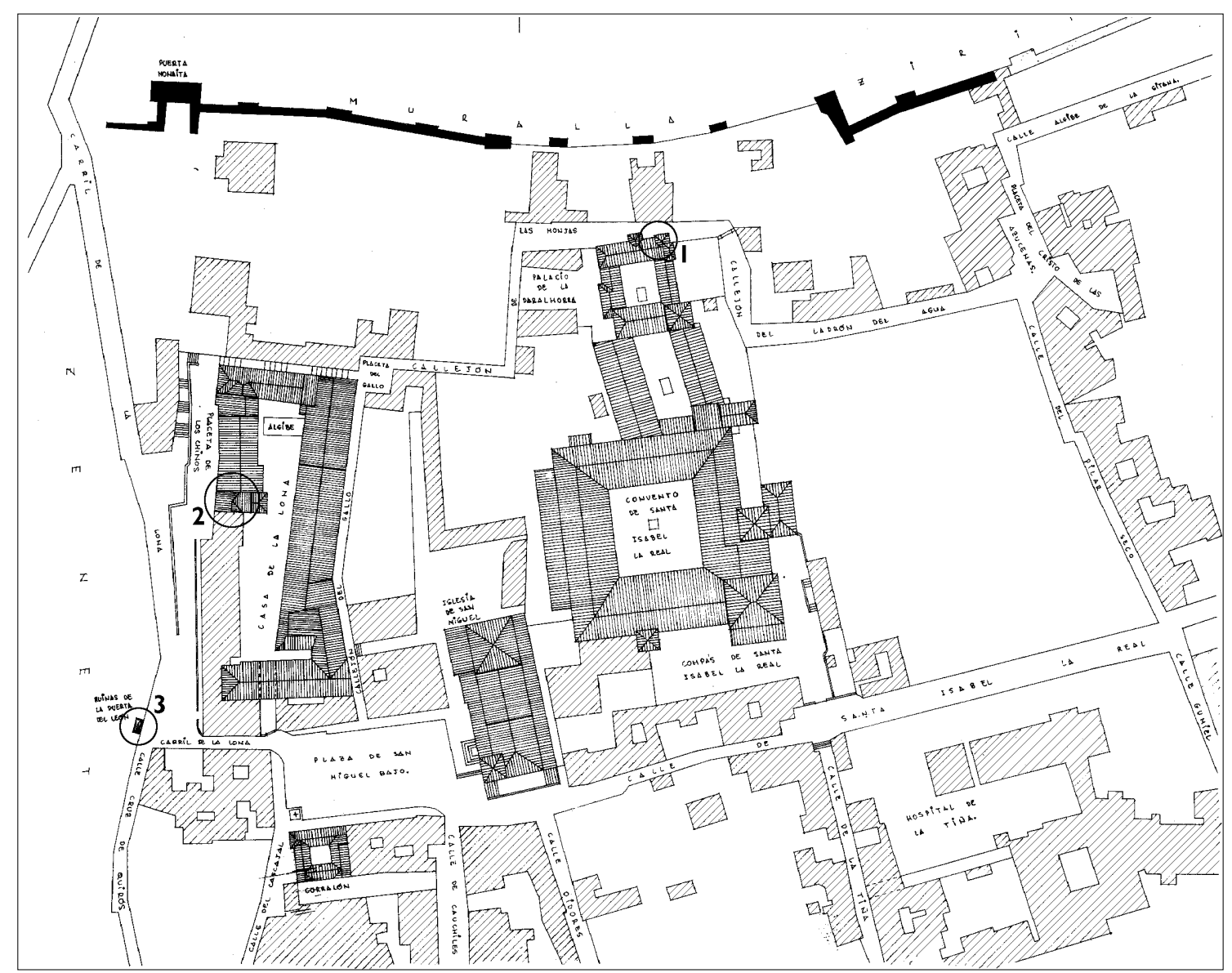

20. Restos similares al primer recinto fuera del ámbito del hisn Garnātā.

1. Dar al-Horra, 2. Casa de la Lona, 3. Portillo del León. Plano GARCíA, MARTíN, 1974, con añadidos

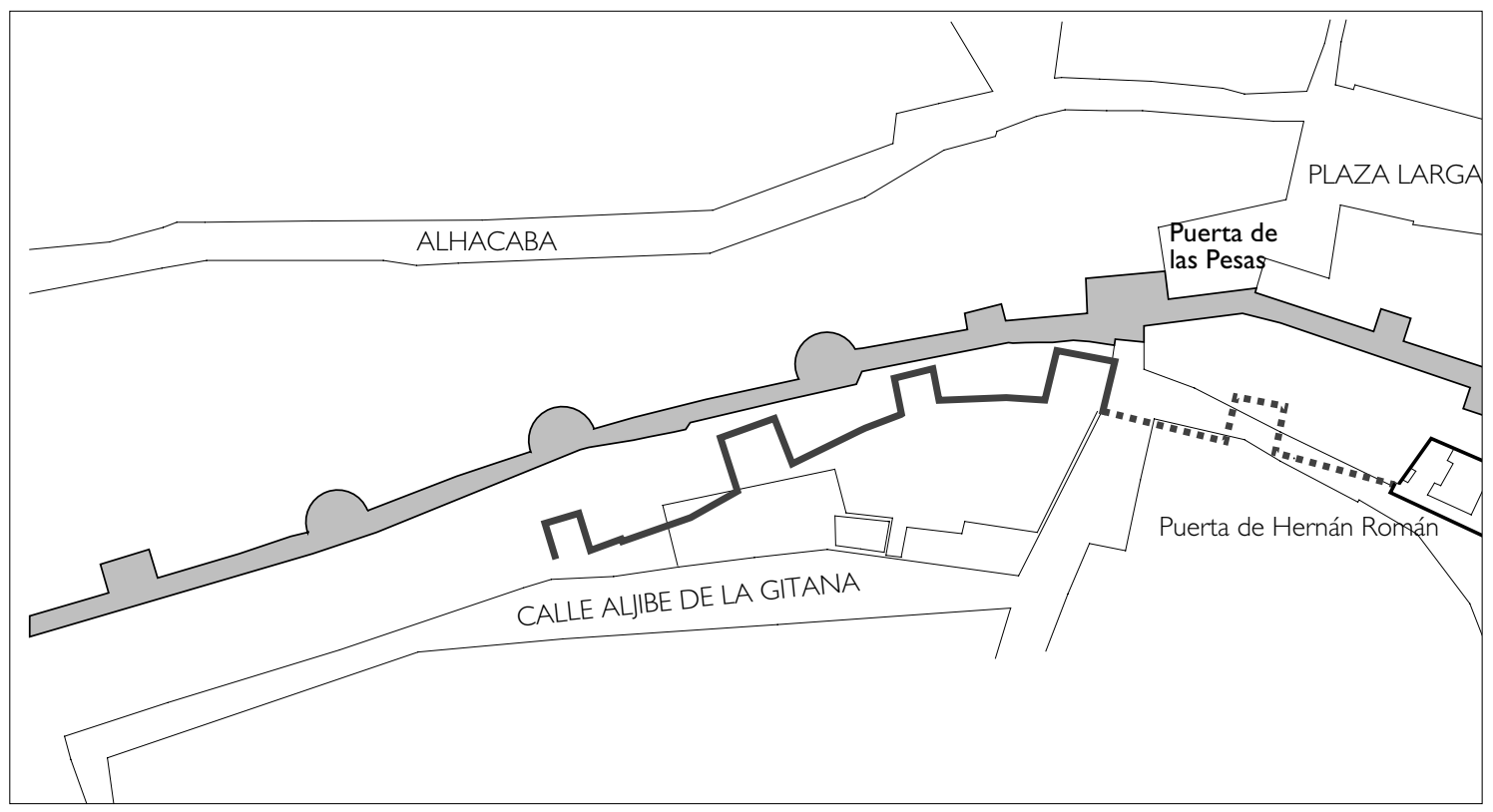

2 I. Orígen del hisnn Roman. Relación entre el primer recinto y la muralla urbana del siglo XI. 
22. Detalle del Plano de Granada árabe. SECO DE LUCENA ESCALADA, 1910.

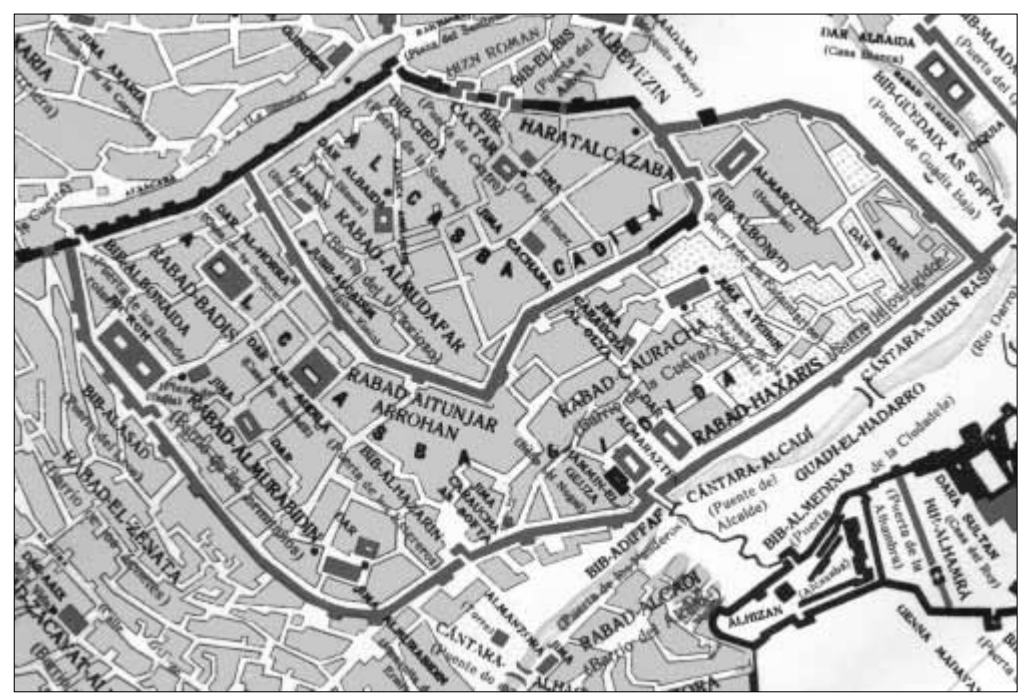

23. Detalle de Las cercas de Granada y sus puertas. L. SECO DE LUCENA PAREDES, 1975.

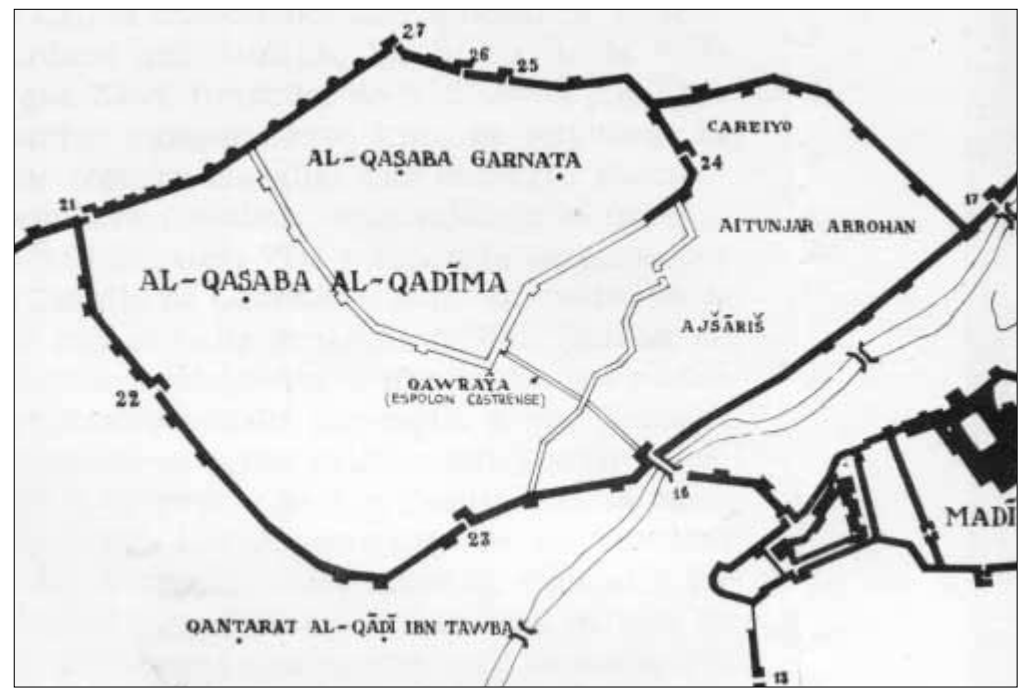

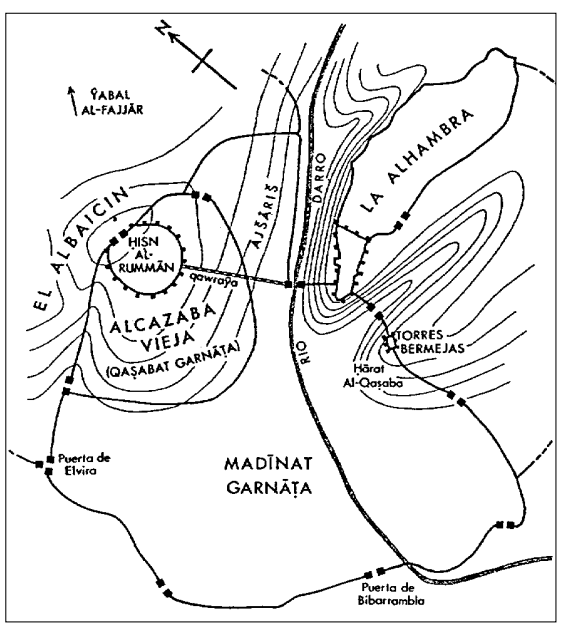

25. "Recintos del Albaicín (Granada)". Según BASILIO PAVON, 1994.
24. ROBERT POCKLINGTON, 1988. "Granada árabe: las tres alcazabas y la madina. (Fuentes: El plano de Granada árabe de L. Seco de Lucena Escalada, con modificaciones indicadas por L. Seco de Lucena Paredes en diversos estudios)."

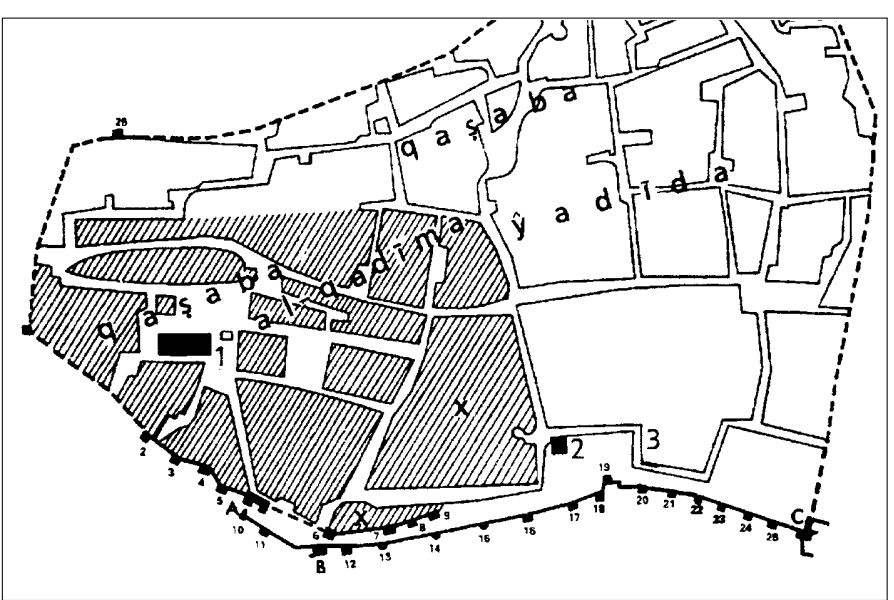




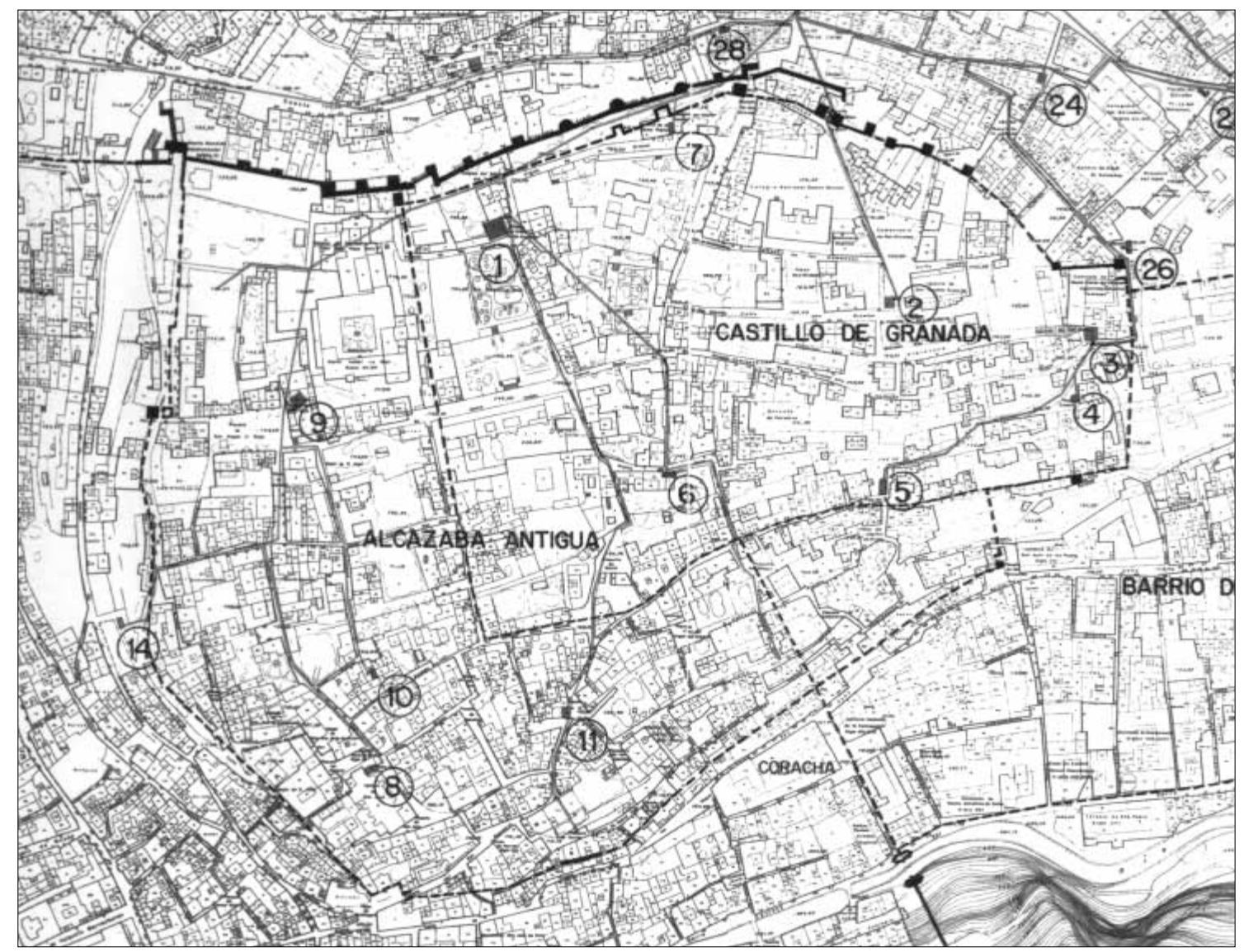

26. Castillo de Granada. Según ORIHUELA; VILCHEZ, 1990.

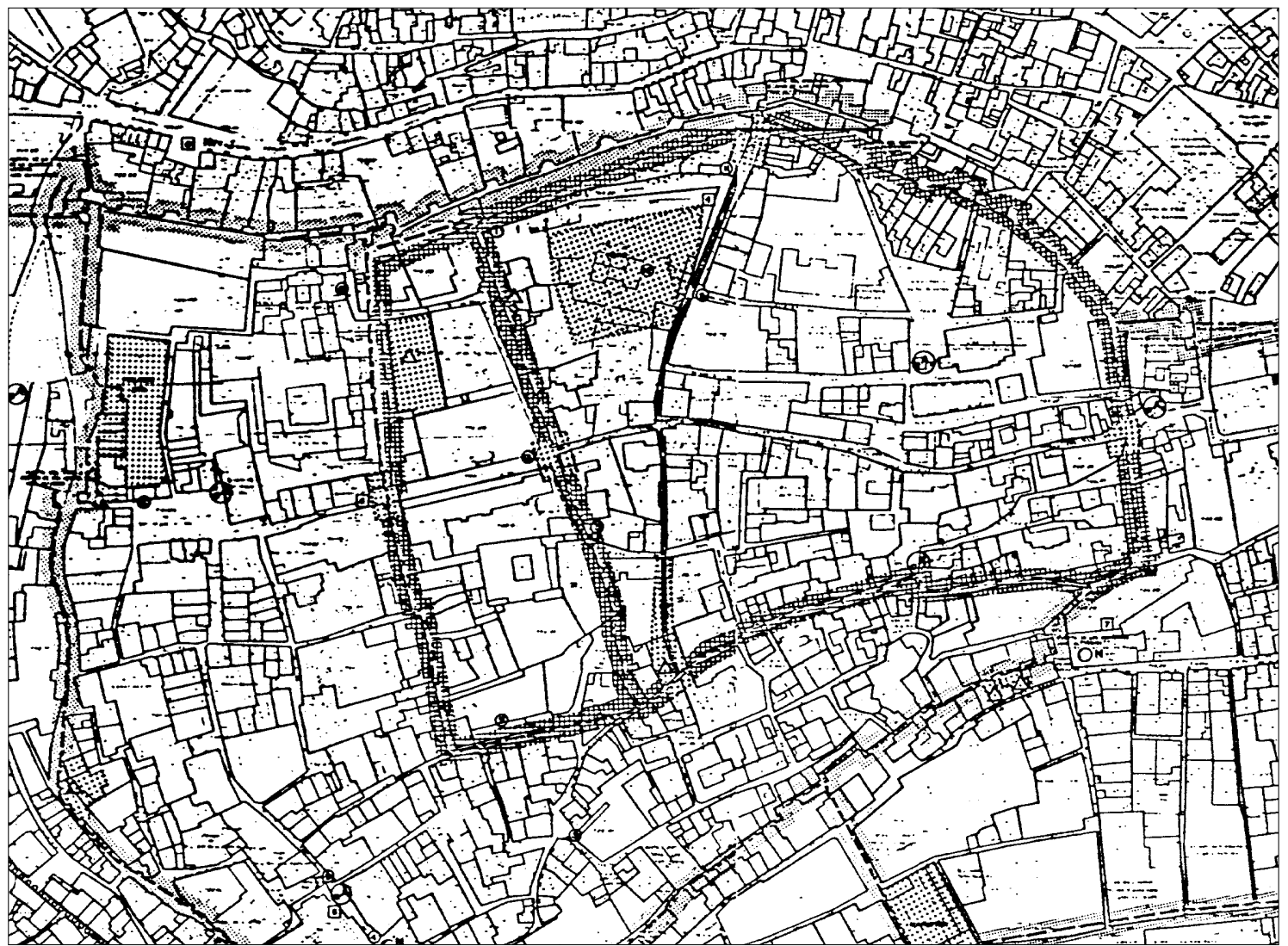

27. El supuesto recinto romano según el Plan Especial de Reforma Interior del Albaicín. 
28. Proceso de configuración urbana de Granada según Seco de Lucena Paredes.

a. Estructura del poblamiento en el territorio urbano granadino antes del siglo XI.

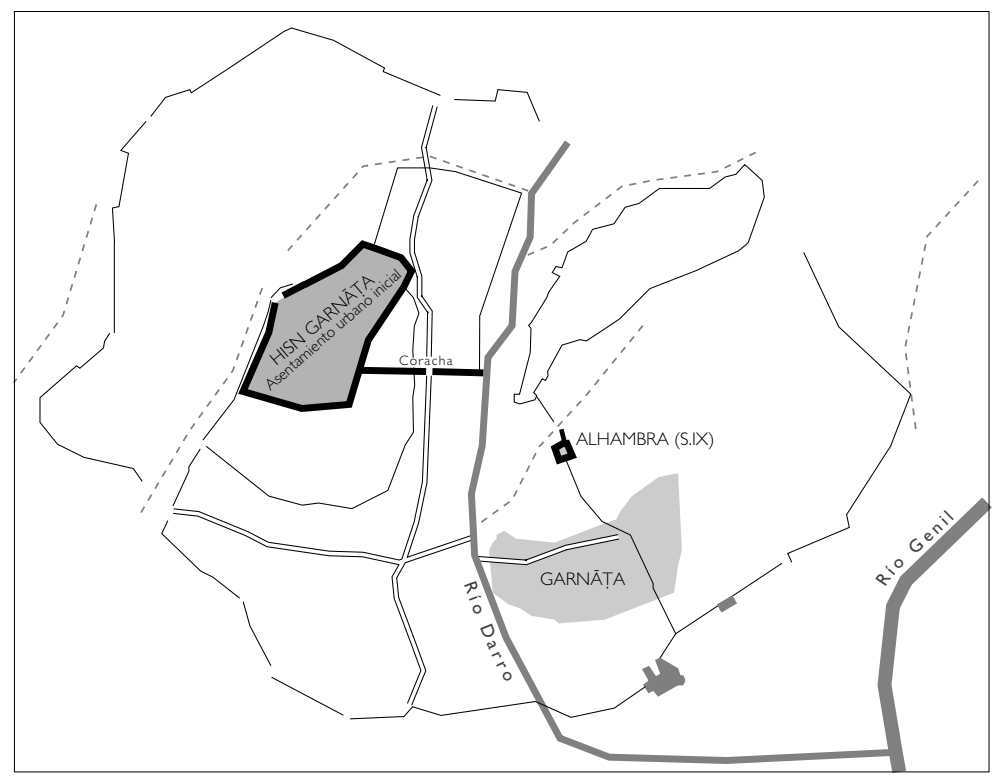

b. Estructura tras el asentamiento

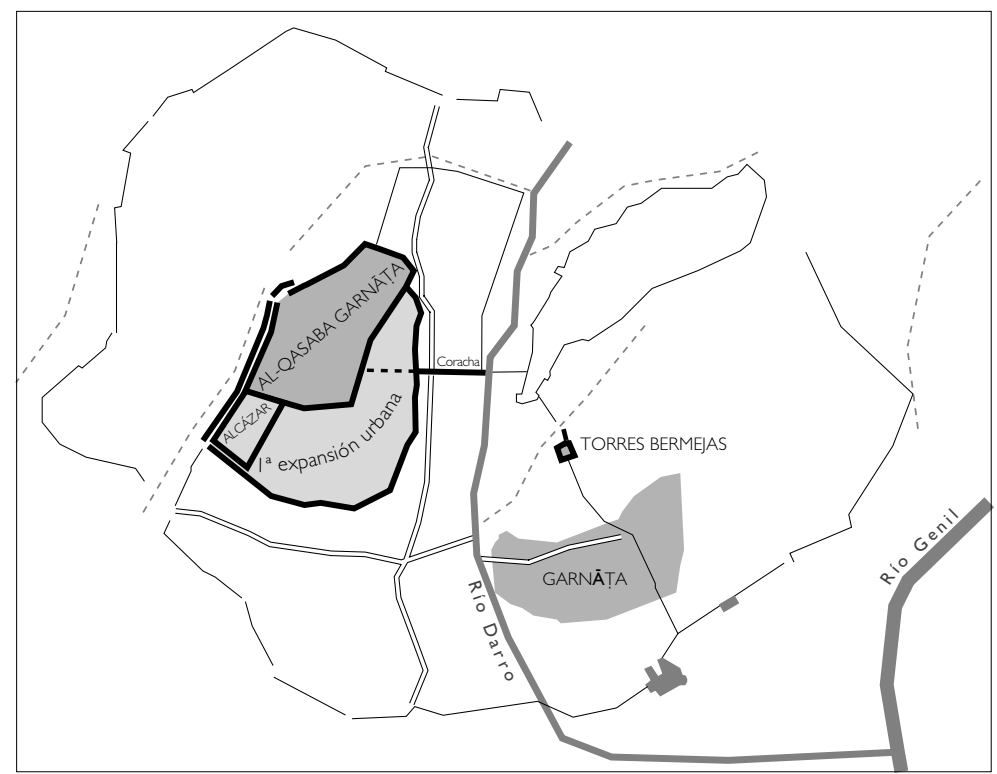
y primera expansión zirí.

c. Estructura al final del periodo zirí.

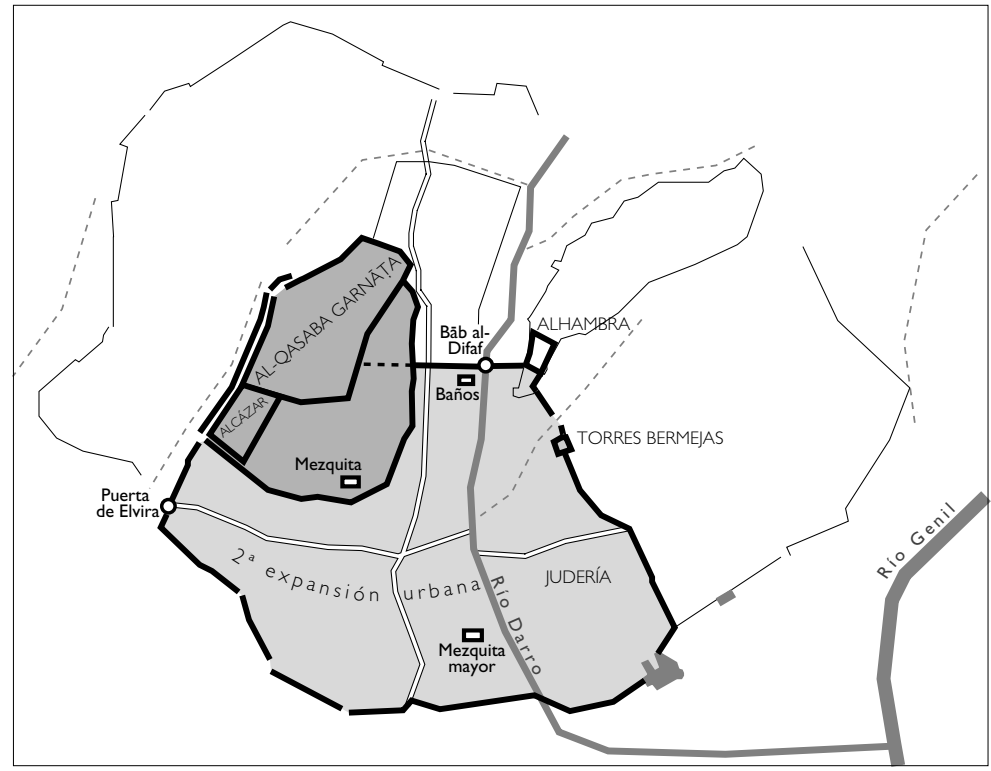

